\title{
STUDIES ON THE FRESH PROPERTIES AND DURABILITY OF UNSHRINKABLE FILL CONTAINING RECYCLED CONCRETE AGGREGATE OR NATURAL AGGREGATES OF MARGINAL QUALITY
}

By

\section{Maryam Kolahdoozan, B.Eng.}

\author{
Ryerson University \\ Toronto, Ontario, Canada 2011
}

\begin{abstract}
A Thesis Presented To Ryerson University
In Partial Fulfillment of the Requirements for the Degree of

Master of Applied Science
\end{abstract}

In The Program of Civil Engineering

Toronto, Ontario, Canada 2013

(C) Maryam Kolahdoozan, 2013 


\section{Declaration}

I hereby declare that I am the sole author of this thesis. This is a true copy of the thesis, including any required final revisions, as accepted by my examiners.

I authorize Ryerson University to lend this thesis to other institutions or individuals for the purpose of scholarly research.

I further authorize Ryerson University to reproduce this thesis by photocopying or by other means, in total or in part, at the request of other institutions or individuals for the purpose of scholarly research.

I understand that my thesis may be made electronically available to the public. 


\title{
STUDIES ON THE FRESH PROPERTIES AND DURABILITY OF UNSHRINKABLE FILL CONTAINING RECYCLED CONCRETE AGGREGATE OR NATURAL AGGREGATES OF MARGINAL QUALITY
}

\author{
Maryam Kolahdoozan \\ Master of Applied Science, Civil Engineering \\ Ryerson University, Toronto, Ontario, Canada, 2013
}

The intention of this research is to explore the feasibility of incorporating aggregates of low or marginal quality, such as Recycled Concrete Aggregate (RCA) and aggregate with high sulphate content, in U-fill mixtures. It has been determined that where RCA is used, water dissipation may be hindered due to the increase in fines caused by abrasion, hence causing an increase in hardening time. To reduce this effect, addition of natural aggregates may be necessary. Moreover, through a series of investigation it has been found that high percentages of sulphate may cause severe damage due to Ettringite and Thaumasite formation; however by incorporation of supplementary materials such as slag the deleterious effects of internal sulphate attack can be reduced. The effects of using $\mathrm{Na}_{2} \mathrm{SO}_{4}$ and gypsum in the presence of slag have also been investigated. Results indicated that due to the lower available calcium content within bars containing $\mathrm{Na}_{2} \mathrm{SO}_{4}$ expansion rate is low. 


\section{Acknowledgments}

I would like acknowledge the support of my mentor, Dr. Shehata for his dedication in helping me throughout the process of this research project. I would have not been able to reach this point of my life without his guidance. Being his student was nothing but a blessing and I am forever in debt for his infinite compassion.

I would also like to extend my appreciation and gratitude towards Dr. Lachemi, my cosupervisor for his support throughout the past two years.

This project would not have been possible without the support of Stephen Senior, Carole Anne McDonald \& Hanna Schell. I would like to express my deepest gratitude for the time that they have spent for this project and the interest that they have shown in advising me on further steps.

I would also like to thank all my hard working, intelligent and amazing friends, Bradley Maguire, Anto Sucic, Bassili Guirguis, Jonathan Andal, Jimmy Xu, Matthew Piersanti, Gregory Richard, Guilherme Ebani and Abbas Farhat for their support, and the great memories we all have created together.

My sincere appreciation goes to Philip Zacarias and Bill Gong for investing their time and providing me and my research team with the opportunity of having several field trials.

Special thanks go to the technicians of the Civil Engineering laboratories, Min Yao, Domenic Valle \& Nidal Jalouk for kindly assisting me during the process of my research.

Above all, I am greatly thankful to my dear parents and brother, for their kindness and support. Their sincere love and words of encouragement has always motivated me towards achieving my lifetime goals. 


\section{To My Dearest Grandmother}




\section{Table of Contents}

Declaration

Acknowledgments.. iii

Dedication iv

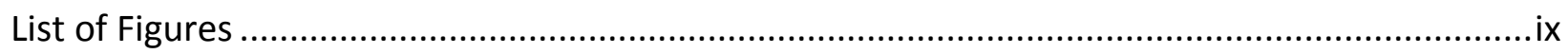

List of Tables xiii

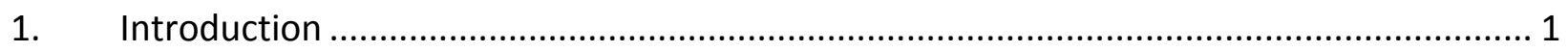

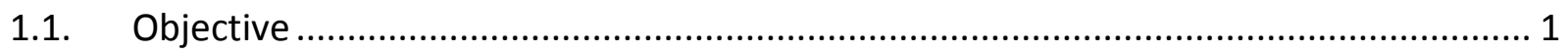

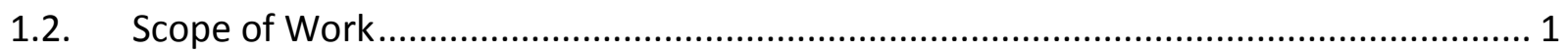

1.2.1. Determination of Physical Properties of U-fill Containing Aggregates That do not Meet All Requirements of Concrete Aggregate.............................................................. 2

1.2.2. Determination of Durability of U-fill Containing Aggregates of High Sulphate

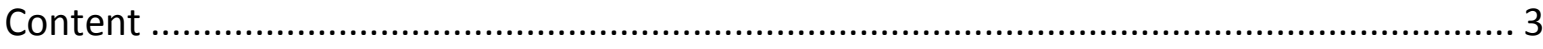

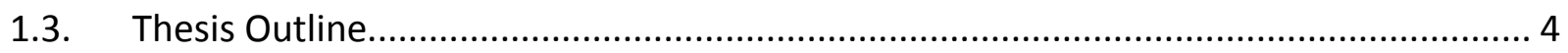

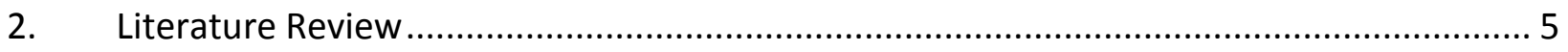

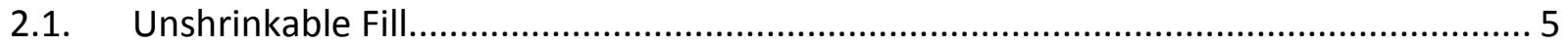

2.1.1. Characteristics of Unshrinkable Fill (U-fill) ....................................................... 5

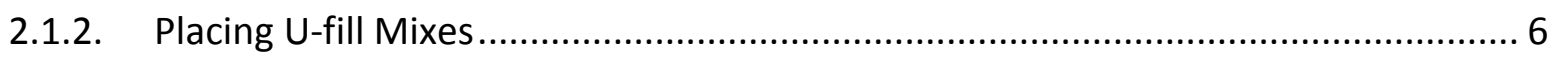

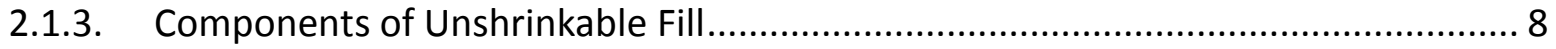

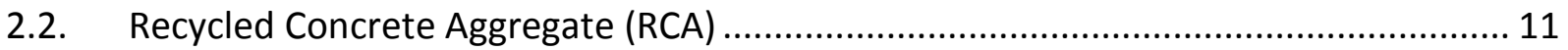

2.2.1. Production Procedure ............................................................................. 11

2.2.2. Current Use of Recycled Concrete Aggregate (RCA) ........................................ 14

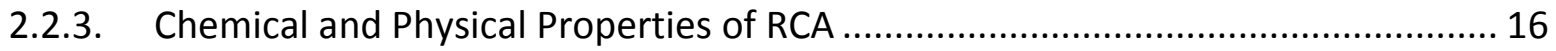

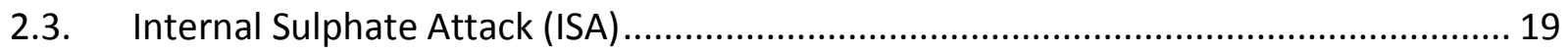


2.3.1. Cement Hydration Process ..................................................................... 19

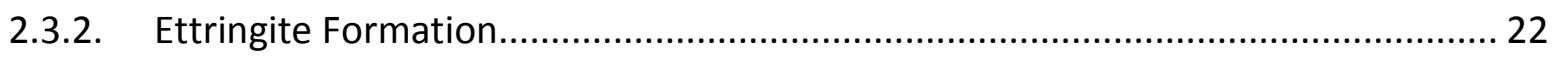

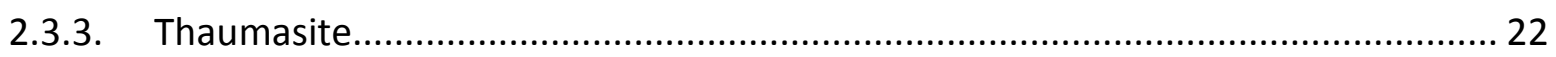

2.3.3.1. Required Conditions for Thaumasite Formation ......................................... 24

2.3.3.2. Role of Ettringite on Thaumasite Formation........................................... 26

2.3.3.3. Effects of Calcium to Silicon Ratio on Thaumasite Attack ............................. 28

2.3.3.4. Effects of Water to Cement Ratio on Thaumasite Formation....................... 29

2.3.3.5. Use of Mineral Admixtures to Prevent TSA ............................................... 29

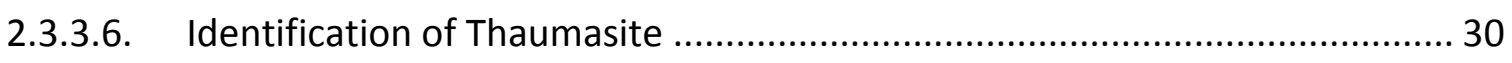

2.3.4. Cases of Structures Affected by Thaumasite Attack........................................ 31

2.3.4.1. Thaumasite Formation in Yongan Dam-China............................................ 31

2.3.4.2. Thaumasite Formation in Bapanxia Dam-China...................................... 31

2.3.4.3. Thaumasite Formation in Historic Structures- Netherlands ......................... 33

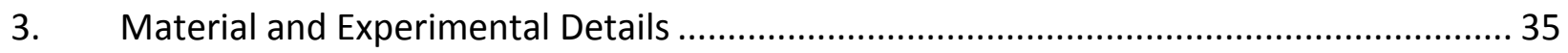

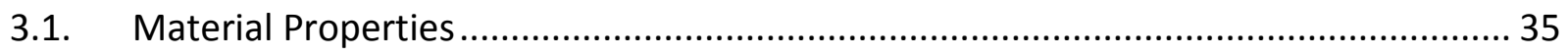

3.1.1. Physical and Chemical Properties of Aggregates......................................... 35

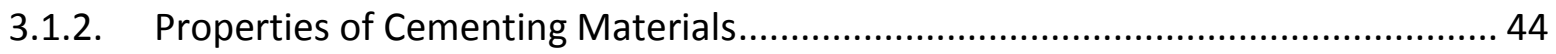

3.2. Sample Preparation and Testing Procedures ................................................. 45

3.2.1. Testing Laboratory U-fill Mixes .......................................................... 45

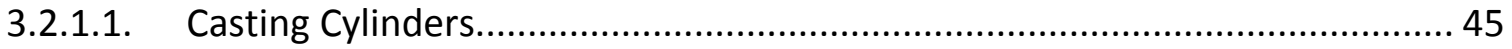

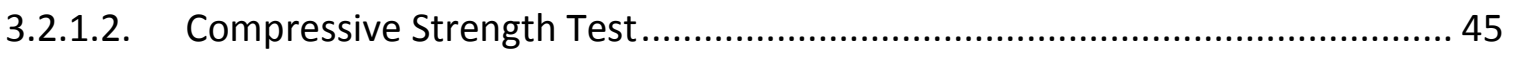

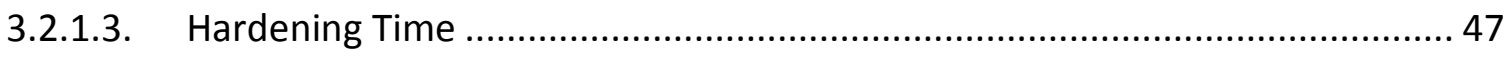

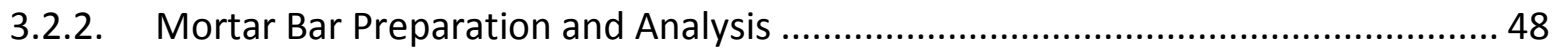

3.2.2.1. Mortar Bar Casting and Demoulding Procedure ..................................... 48 
3.2.2.2. Mortar Bar Expansion Measurement 50

3.2.2.3. Analyzing Deterioration Mechanism Using Scanning Electron Microscopy (SEM) 50

3.3. Summary of Experimental Program and Significance ............................................ 53

3.3.1. Expansion Due to Internal Sulphate Attack ................................................... 53

3.3.1.1. Phase I: Determining the Effects of High Sulphate Contents on Durability of U-

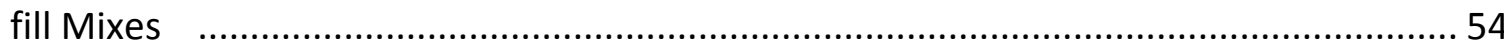

3.3.1.2. Phase II: Determination of Maximum Limit of Sulphate Content ................... 55

3.3.1.3. Phase III: Confirming Limit Using RCA as Aggregate .................................. 55

3.3.1.4. Phase IV: Reduction of Expansion Using Supplementary Cementing Material

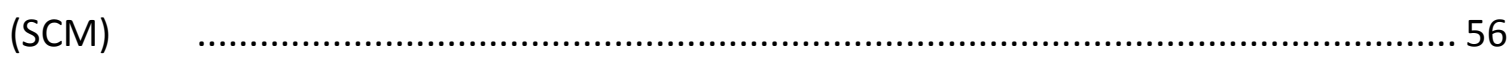

3.3.1.5. Phase V: Using $\mathrm{Na}_{2} \mathrm{SO}_{4}$ as an Alternative Source of Sulphate in Mortar Bars. 56 3.3.1.6. Simulation of Field Conditions By Means of Alternative Moulds.................... 57

3.3.2. Preparation of Laboratory and Field Trial U-fill Mixes ................................... 59

3.3.2.1. Phase I: Mixes containing Out-of-Specification Granular Aggregate .............. 60

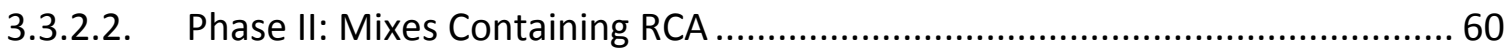

3.3.2.3. Phase III: Incorporating Gravel into RCA Mixes as a Method to Reduce

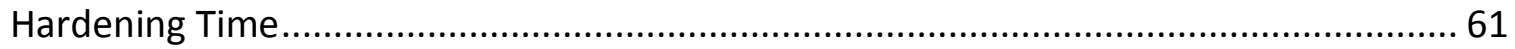

3.3.2.4. Phase IV: Mixes Containing Coarse RCA Aggregate of Low MDA Loss............ 63

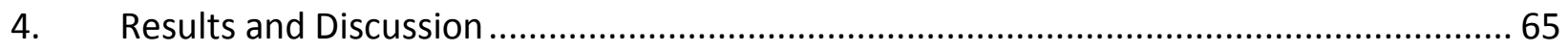

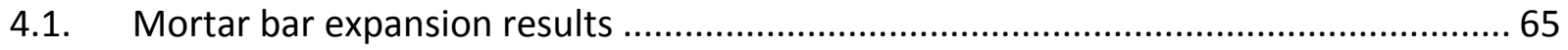

4.1.1. Phase I Results: Expansion of Mortar Bars Containing Aggregates of High Sulphate

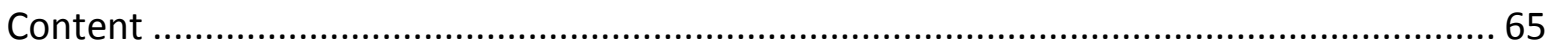

4.1.2. Phase II Results: Determination of Expansion Rate at Various Percentages of Sulphate...... 69 
4.1.3. Phase III Results: Expansion of Mortar Bars Containing RCA

4.1.4. Phase IV Results: Reduction of Expansion Due To Internal Sulphate Attack Using Supplementary Cementing Materials

4.1.5. Phase V Results: Comparison of Expansion of Bars Containing $\mathrm{Na}_{2} \mathrm{SO}_{4}$ and Gypsum 79

4.2. Expansion of U-fill Mixtures Containing Aggregate of High Sulphate Content ............ 85

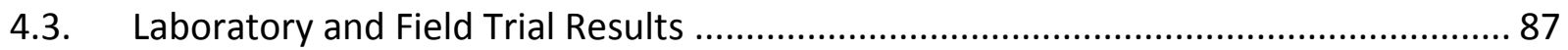

4.3.1. Phase I Results: Mixes Containing Out-of-Specification Granular Aggregate ........ 87

4.3.2. Phase II Results: U-fill Containing RCA of Low Quality .................................... 90

4.3.3. Phase III Results: Mixes Containing Gravel, Sand and RCA............................... 93

4.3.4. Phase IV Results: U-fill Mixtures Containing RCA of Low MDA Loss .................... 98

4.3.5. Effects of Unhydrated Cement Paste of RCA ................................................ 105

5. Conclusions and Recommendations for Further Studies ...................................... 107

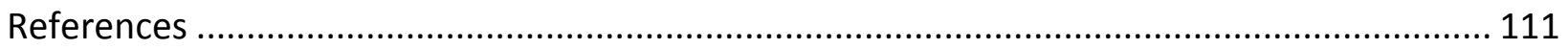




\section{List of Figures}

Figure 2.1. Pouring of $\mathrm{U}$-fill mixture into trench...................................................................... 7

Figure 2.2: Left: Tire chips (24tons Inc., 2013)-Right: Crumb rubber (CalRecycle, 2013) ............. 9

Figure 2.3: Demolished concrete stockpiled for recycling ................................................. 11

Figure 2.4: Concrete rubble being placed into crusher ....................................................... 12

Figure 2.5: Crushed aggregate being sent to stockpile by conveyor belt ............................... 12

Figure 2.6: Concrete reclaiming process (BETON Innovative services, 2013) ........................... 13

Figure 2.7: Average annual aggregate consumption in Ontario (million tonnes) (Ontario ministry

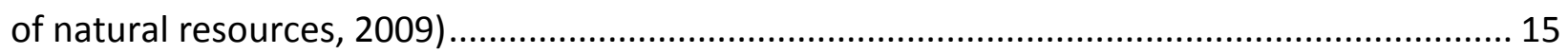

Figure 2.8: Percentage of sand and gravel consumption in Ontario in the year 2006 (Ontario

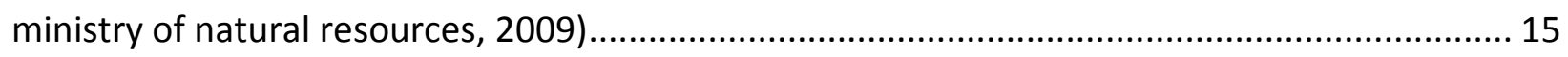

Figure 2.9: Lighter areas show hardened cement paste ................................................... 16

Figure 2.10: Rate of hydration vs. Time (Jennings \& Thomas, 2008) ..................................... 20

Figure 2.11: Rate of Thaumasite formation vs. Ettringite formation in mixes containing gypsum

(left) and $\mathrm{Na}_{2} \mathrm{SO}_{4}$ (right) as source of sulphate (Kohler et al. 2006) ..................................... 27

Figure 2.12: Cross section of tunnel passing through Bapanxia dam indicating areas of

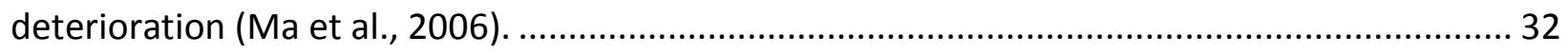

Figure 2.13: Deterioration found in drainage of tunnel in Bapanxia (Ma et al., 2006) ............... 32

Figure 2.14: SEM analysis displaying Thaumasite crystals (van Hees et al. ,2003) .................... 33

Figure 2.15: Cracks induced in exterior bricks of church tower (van Hees et al. ,2003) ............. 34

Figure 3.1: Grain size distribution of aggregate from Vinemount and Bayview Quarry ............. 38

Figure 3.2: 0.45 power gradation curves of aggregates from the Bayview and Vinemount quarry

Figure 3.3: Sieve analysis of RCA before and after mixing ............................................. 41

Figure 3.4: Grain size distribution of RCA, Sand and Gravel................................................ 42

Figure 3.5: Gradation of phase III RCA aggregate ............................................................ 43

Figure 3.6: residues of broken cylinder attached to capping jig ........................................... 46

Figure 3.7: Alternative capping method (left), Cylinder capped using alternative method (right) 
Figure 3.8: Ball drop apparatus for measuring hardening time (ASTM C6024) ...................... 47

Figure 3.9: Ball drop apparatus (left) indentation left by the ball drop apparatus (right) .......... 48

Figure 3.10: Side view of mortar bars with broken surface caused by bleeding ...................... 49

Figure 3.11: Mortar bar measurement using length comparator ............................................ 50

Figure 3.12: Mounted sample placed into SEM chamber .................................................... 51

Figure 3.13: Experimental program for investigating causes and mitigation methods for internal

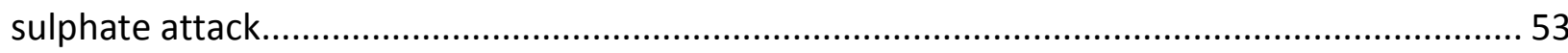

Figure 3.14: Alternative moulds produced for the simulation of field conditions ..................... 58

Figure 3.15: Experimental program for investigating the feasibility of using aggregates of

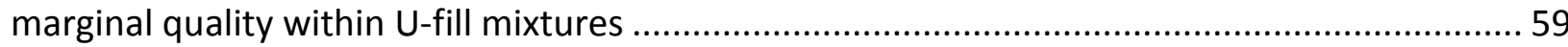

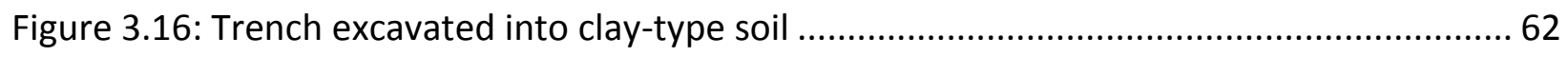

Figure 3.17: Phase IV trench excavated into porous soil..................................................... 64

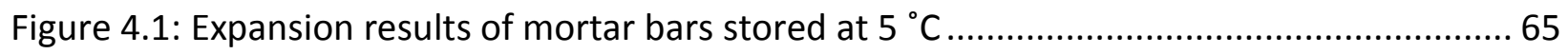

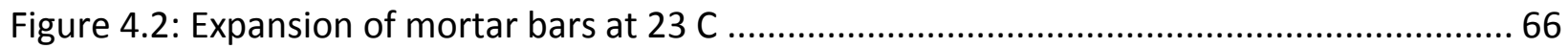

Figure 4.3: Comparison of expansion rate of mortar bars containing 3.23\% SO4 at 23 and $5^{\circ} \mathrm{C} .66$

Figure 4.4: Loss of bond between aggregate \& paste due to internal sulphate attack .............. 67

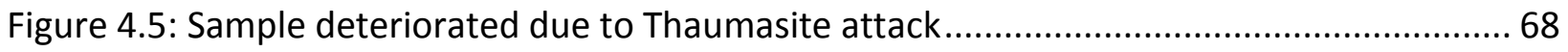

Figure 4.6: Sample deteriorated into a mud-like paste.......................................................... 68

Figure 4.7: Expansion of mortar bars containing various percentages of $\mathrm{SO}_{4}$ stored in limewater

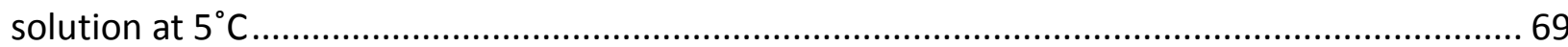

Figure 4.8: Deteriorated bars containing 3.5\% $\mathrm{SO}_{4}$ saturated in limewater solution .................. 70

Figure 4.9: Bars bent due to severe expansion ............................................................... 70

Figure 4.10: Expansion of bars containing RCA aggregate at various sulphate contents ........... 72

Figure 4.11: Cracks caused by severe expansion in bars containing $2.5 \% \mathrm{SO}_{4} \ldots \ldots \ldots \ldots \ldots \ldots \ldots . . . . . . . . . . . . .72$

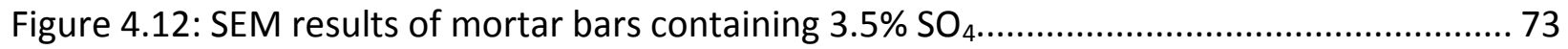

Figure 4.13: Expansion of mortar bars containing 30\% slag............................................... 74

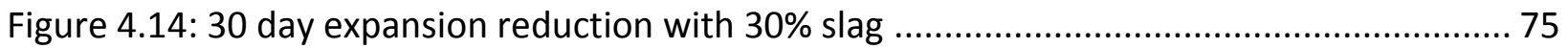

Figure 4.15: Expansion of mortar bars containing 50\% slag................................................. 75 


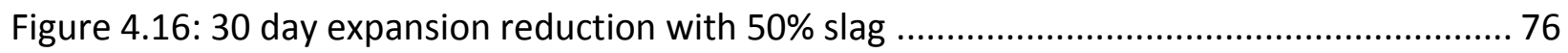

Figure 4.17: Expansion results of mortar bars containing 10\% Metakaolin............................ 77

Figure 4.18: 30 day expansion reduction with 10\% metakaolin .......................................... 77

Figure 4.19: SEM results of mortar bars containing 3.5\% SO4 and 50\% slag ........................... 78

Figure 4.20: SEM results of mortar bars containing 3.5\% $\mathrm{SO}_{4}$ and $10 \%$ Metakaolin .................. 79 Figure 4.21: Expansion of mortar bars at various sulphate contents (Sulphate added as $\mathrm{Na}_{2} \mathrm{SO}_{4}$ )

Figure 4.22: Expansion of bars containing $30 \%$ slag and $\mathrm{Na}_{2} \mathrm{SO}_{4}$ as source of sulphate ............ 81

Figure 4.23: Comparison of expansion in bars containing $30 \%$ slag and $2.5 \% \mathrm{SO}_{4} \ldots \ldots \ldots \ldots \ldots . . . . . . . . . .22$

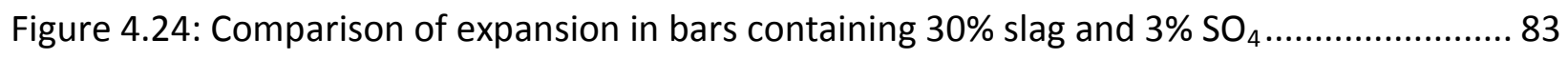

Figure 4.25: Comparison of expansion in bars containing 30\% slag and 3.5\% SO4 .................. 84

Figure 4.26: Samples containing aggregate of high sulphate content prior to saturation in

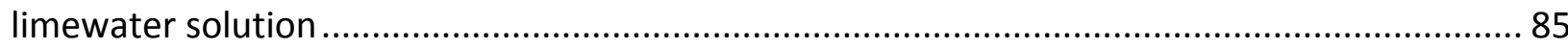

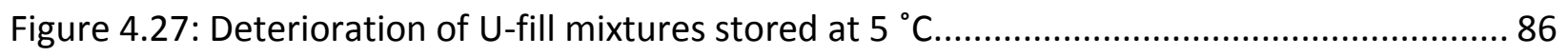

Figure 4.28: Segregation of $100 \%$ Granular 'A' at different water content ............................ 87

Figure 4.29: Samples composed of $15 \%$ sand and $85 \%$ Granular ' $A$ ' ..................................... 88

Figure 4.30: Segregation of fines within samples containing granular aggregate ..................... 88

Figure 4.31: Water content vs. hardening time................................................................. 90

Figure 4.32: Slag and RCA mix (left) cement \&RCA mix (right). Note that the excessive water in the slag mix is attributable to the presence of water in the trench prior to placement of the $U$ -

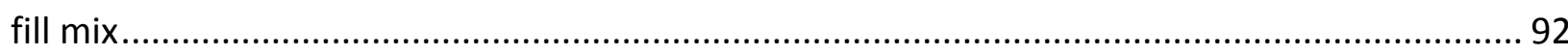

Figure 4.33: Control mixtures produced using gravel and sand ........................................... 93

Figure 4.34: Sample containing RCA and slag as the main cementing material ....................... 93

Figure 4.35: Unshrinkable fill mix containing 50\% Gravel and 50\% RCA (left)-80\%Gravel and

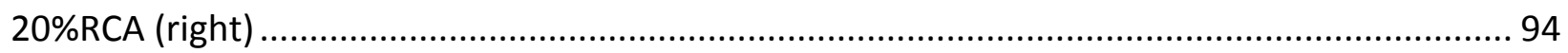

Figure 4.36: 0.45 power gradation curve of phase III mixes ................................................. 95

Figure 4.37: Hardening time of phase III laboratory mixes .................................................. 96

Figure 4.38: Field trial mix containing 50\% Gravel, 30\% RCA \& 20\% Sand (Left) \& Field trial mix containing 70\% Gravel, 30\% RCA \& 20\% Sand (Right) ..................................................... 97 
Figure 4.39: Control mix containing gravel and concrete sand

Figure 4.40: Mix 2 from phase IV containing 70\% RCA and $30 \%$ sand

Figure 4.41: Separation of coarse and fine aggregate in mix 2 containing 70\% RCA (Coarse) and

$30 \%$ concrete sand. 101

Figure 4.42: Mix 3 from phase IV containing 55\% RCA and 45\% concrete sand 102

Figure 4.43: Locations for hardening time measurements on segregated mixes 103

Figure 4.44: Agglomeration of RCA fines from a stockpile showing considerable bonding due to presence of unhydrated cement paste 105

Figure 4.45: Sample containing 55\% Gravel, $45 \%$ sand, $25 \mathrm{~kg} / \mathrm{m}^{3}$ cement and $185 \mathrm{~kg} / \mathrm{m}^{3}$ of water (left) \& sample containing RCA of high MDA loss and $185 \mathrm{~kg} / \mathrm{m}^{3}$ of water (right)..... 106 


\section{List of Tables}

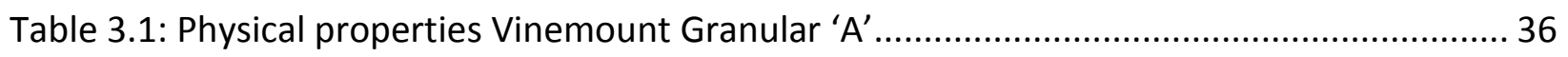

Table 3.2: Physical properties Bayview Granular 'A' ............................................................ 36

Table 3.3: Chemical Properties of Granular 'A' from Vinemount \#2 quarry .............................. 37

Table 3.4: Chemical Properties of Granular 'A' from Bayview Sutherland quarry ...................... 37

Table 3.5: Sieve analysis of aggregate from Bayview and Vinemount quarry .......................... 38

Table 3.6: MDA Loss of Phase II and III RCA (LS-618 \&619) .................................................. 40

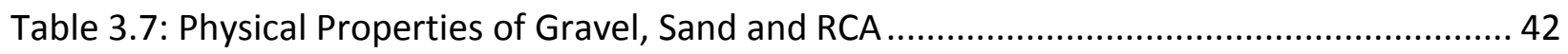

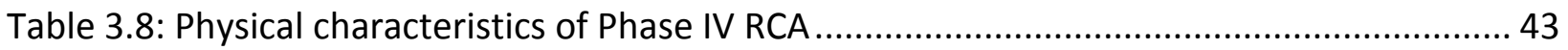

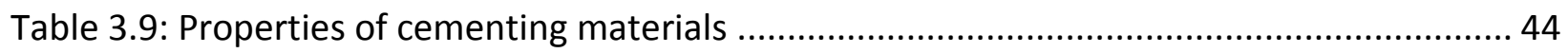

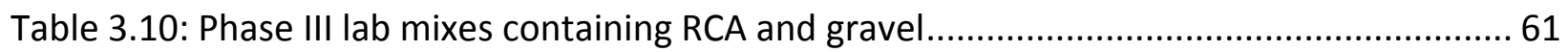

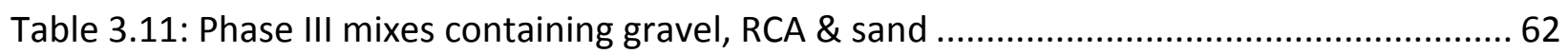

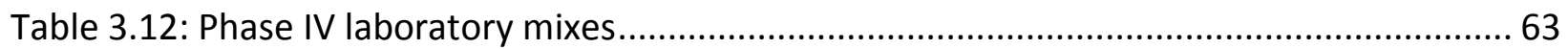

Table 4.1: Phase V expansion results for samples with 30\% slag ......................................... 81

Table 4.2: Mixes containing out-of-specification granular aggregate combined with various

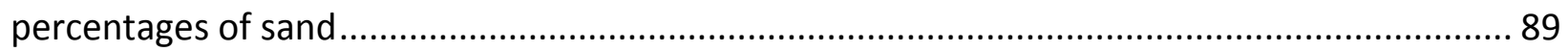

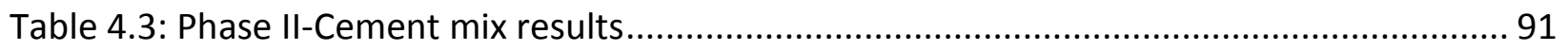

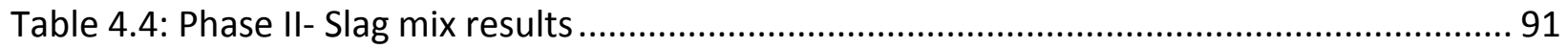

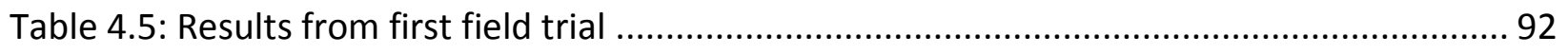

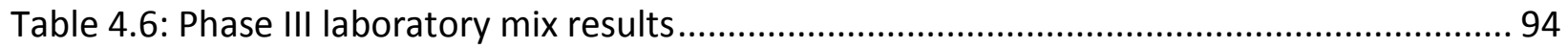

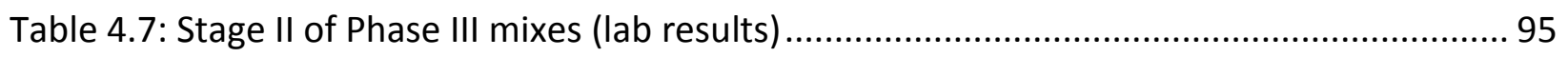

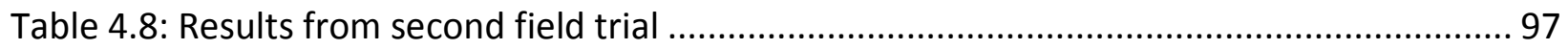

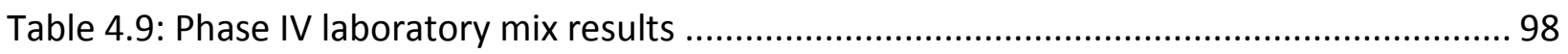

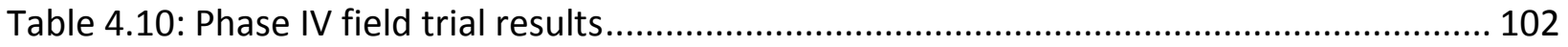

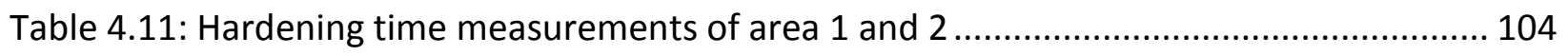




\section{Chapter 1}

\section{Introduction}

\subsection{Objective}

The purpose of this research project was to investigate the possibility of producing Unshrinkable Fill (U-fill) using alternative aggregate sources, such as Reclaimed Concrete Aggregate (RCA) and granular material containing high amounts of sulphate, while maintaining properties such as flowability, hardening time, durability and strength. Unshrinkable fill is a low strength concrete material commonly used in utility trenches or as a sub-base layer under asphalt or concrete pavements. As it currently stands, virgin aggregate is mostly used in the production of U-fill. However due to increasing cost and shortage in supplies of high quality virgin aggregate, the demands for using alternative aggregates in construction applications has been increasing and has become a more appealing option in various types of construction projects which can promote sustainability while reducing costs and energy consumption. The experimental program discussed in this paper will investigate the various chemical and physical properties of mixes produced using such aggregates.

\subsection{Scope of Work}

This research is composed of two stages:

a) Determination of physical properties of U-fill containing out-of-specification aggregate

b) Determination of durability of U-fill containing out-of-specification aggregate. Since, the virgin aggregate used here is out of specification due to high gypsum content, the resistance to internal sulphate attack will be investigated. For RCA, the sulphate resistance is determined assuming that the RCA is contaminated with sulphate. 


\subsubsection{Determination of Physical Properties of U-fill Containing Aggregates That do not Meet all Requirements of Concrete Aggregate}

In order to ensure compliance with current standards for U-fill, several mixtures were produced and tested for fresh and hardened properties such as flowability, hardening time and strength. In the initial stages, granular aggregates containing high amounts of sulphate were investigated as an alternative to virgin aggregate. The use of RCA has been also investigated as sustainable alternatives. The testing on mixes containing RCA was carried out in several stages:

Stage 1: Testing RCA with high Micro-Deval Abrasion (MDA) loss as $100 \%$ substitution of virgin aggregate

Stage 2: Inclusion of supplementary aggregates to enhance mix properties

Stage 3: Use of RCA with lower MDA loss as coarse aggregate along with concrete sand

Stage 1 was carried out by first optimizing mixtures through several trials. Once optimized mixtures were achieved, a field trial was carried out to determine the in-situ performance of the mixes. Field trial observations of optimized mixes have shown that using $100 \%$ RCA in U-fill mixes could extend the hardening time or time-to-loading extensively. Therefore gravel and sand were used along with RCA in order to provide for faster dissipation of mixing water, enabling the mix to carry load after a relatively short period of time (stage 2). It is usually recommended that hardening time of $U$-fill mixes is kept to a minimum in order to allow for subsequent construction practices or traffic operations to resume as early as possible. Through two field trials carried out using the mentioned RCA, it has been found that there is a considerable amount of increase in fines due to abrasion of RCA aggregate while mixing. To mitigate this problem, in stage 3, RCA with lower Micro-Deval abrasion loss (MDA loss) was used as coarse aggregate. To lower absorption and in order to provide for a more cohesive mix, concrete sand was also added to the mixtures. 


\subsubsection{Determination of Durability of U-fill Containing Aggregates of High Sulphate Content}

To ensure durability of U-fill mixes, the chemical properties of both aggregate types, RCA and high sulphate out-of-specification granular aggregate has been investigated in this paper. From expansion tests done on aggregate containing high sulphate contents it has been observed that deterioration can occur due to internal sulphate attack caused by Ettringite and Thaumasite formation. In order to determine a limit for sulphate content, mortar bars were produced with sulphate contents ranging from 0.5 to $3.5 \% \mathrm{SO}_{4}$ (increasing in increments of 0.5 ) by mass of aggregate. Periodic measurements indicated high rates of expansion in mortars containing 2.5, 3.0 and $3.5 \% \mathrm{SO}_{4}$. These bars were then analyzed using scanning electron microscopy (SEM).

The effects of supplementary cementing material on reduction of expansion caused by Thaumasite and Ettringite formation are also investigated in this research program. The amount of reduction in expansion of bars containing metakaolin and slag were compared to bars containing no SCM's and percentages of reduction in expansion were calculated.

As a last step the chemical testing program, the effects of two types of sulphate sources, Gypsum and $\mathrm{Na}_{2} \mathrm{SO}_{4}$, on the overall expansion of mortar bars were investigated. These two forms of sulphate can exist naturally in aggregates. However, it has been hypothesized that the effects will not be the same in terms of expansion due to internal sulphate attack. To determine the effects of $\mathrm{Na}_{2} \mathrm{SO}_{4}$ on the rate of expansion, a series of bars were produced with and without the addition of $30 \%$ slag and at various sulphate contents. 


\subsection{Thesis Outline}

The following paragraphs outline the contents of this report:

Chapter 1: Outlines the objective and the specific stages of the physical and chemical experiments done in investigating properties of U-fill containing RCA or sulphate bearing aggregate.

Chapter 2: Is a thorough review of topics related to the research program. The body of this chapter contains an overview of:

- The characteristics and properties of Unshrinkable fill

- a review of various aspects related to RCA such as production, consumption rate and its properties and characteristics

- A discussion on internal sulphate attack, factors enhancing sulphate attack, and lastly mitigation and identification procedures

Chapter 3: Summarizes the properties of materials used in this research program and the experimental methodology carried out at various phases.

Chapter 4: Provides an in depth analysis and discussion on the results obtained from the chemical and physical experimentations carried out in each stage.

Chapter 5: Presents conclusions based on the results obtained from each phase of the research program and also provide recommendation for further study. 


\section{Chapter 2}

\section{Literature Review}

\subsection{Unshrinkable Fill}

\subsubsection{Characteristics of Unshrinkable Fill (U-fill)}

Unshrinkable fill is cementing slurry consisting of an assortment of aggregates or filler, water, and cementing materials. This self-compacting low strength material is used as an economical fill or backfill material in places such as sewer trenches, foundation sub-base, utility trenches, conduit bedding, bridge abutments and pavement bases as a substitute to compacted granular fill. Since this material is self-consolidating, manual compaction is not needed and therefore the size of excavation is considerably reduced. Unlike soil, U-Fill does not settle once it is hardened. As a result, it is a great substitute for filling remote areas (NRMCA, 2000). Materials used in UFill are usually the same as those used in conventional concrete, however the mix proportions are very different as the strength desired is much less than most conventional concrete mixtures. A big advantage of U-Fill is that its mix can incorporate many materials which are of no use in many construction processes and otherwise end up in landfills. Sustainable development is encouraged by protecting the environment through utilization of these materials.

According to OPSS 1359, unshrinkable fill mixes should have the following characteristics:

- Contain a maximum of $25 \mathrm{~kg} / \mathrm{m}^{3}$ of cement

- Have a minimum slump of $150 \mathrm{~mm}$

- U-fill mixes must be self-compacting and flowable with the capability of filling trenches without the need of exerting any external energy 
- Maximum strength should be limited to $0.7 \mathrm{MPa}$

- Where needed, supplementary cementing material may be used

As mentioned previously unlike conventional concrete mixes, U-fill is designed for weakness in order to allow for ease of excavation in the future. These mixes are usually designed with very high water to cement ratio (compared to conventional concrete). High flowability and selfcompacting capabilities of $U$-fill cause it to be an appealing product to be used in hard to reach areas where compacting and vibration is not possible. An example of such applications is utility fill. By using U-fill, the pipes or any utilities are contoured completely without causing any voids. Pipes are usually anchored to the surrounding soil so floating of the pipes is prevented. Although not very common, flowability of u-fill mixes can be increased by using air entrainers or other supplementary products.

Current provincial standards do not specify limits for hardening time. However, most U-fill providers tend to design mixes with a hardening time of one hour or less. This is done in order to allow traffic to resume as fast as possible without causing any risks for public safety. Hardening time of U-fill mixes is largely dependent on the characteristics of the surrounding soil. Where U-fill mixes are being placed in areas with clay type soil, hardening time should be expected to be high. Therefore it is recommended that in such cases water content of the U-fill mixtures are kept to a minimum. On the other hand, the hardening time of the $U$-fill mixes are largely dependent on the dissipation of bleed water and the ambient temperature. If water exists prior to the placing of the mix, it is usually removed by pumps. Although not recommended, steel plates can be used on top of partially hardened U-fill mixtures order to allow for resumption of traffic.

\subsubsection{Placing U-fill Mixes}

U-fill mixes are placed and poured into trenches using either chutes or lifts. Ready mix trucks 
can easily pour U-fill mixtures into trenches with little to no effort. The ease of placement is mostly due to the flowability characteristics of U-fill. Once poured, U-fill mixes will fill up all existing voids and flow into hard to reach areas. A characteristic of a desirable U-fill mix is that it will contour all edges of a trench immediately once poured (Figure 2.1), eliminating the need for compaction, vibration or troweling.

Where U-fill is being placed as a sub-base for pavements, it is usually poured and leveled flush with the surrounding ground. Where traffic density is low, U-fill surface can be exposed while hardened until the top asphalt or concrete layer is constructed. In order to allow sufficient depth for placement of the pavement, U-fill sub-bases can be excavated to a depth of a few inches in order to accommodate the new asphalt or concrete layer.

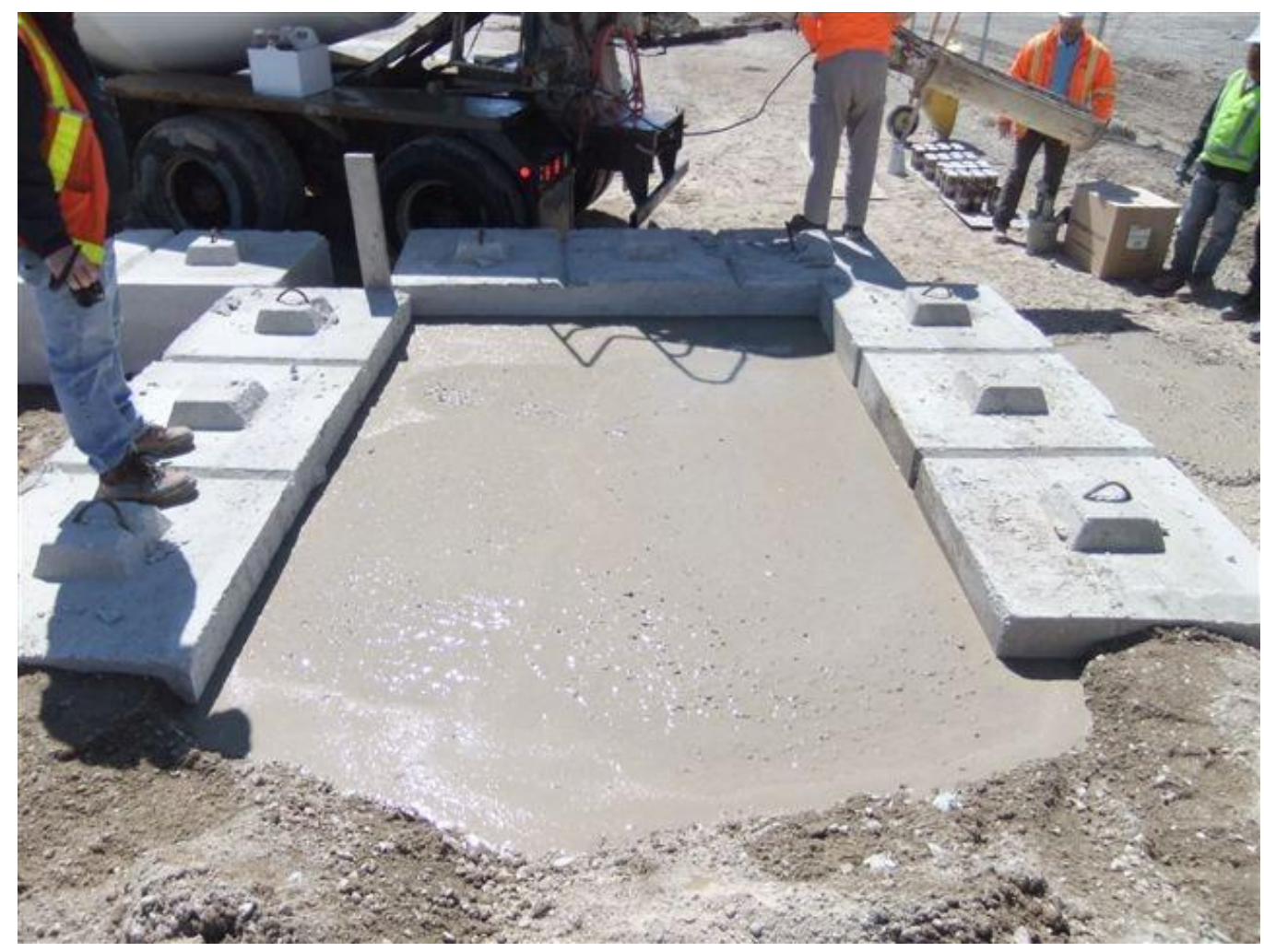

Figure 2.1. Pouring of U-fill mixture into trench 


\subsubsection{Components of Unshrinkable Fill}

The main materials used in U-fill are Portland cement, water, coarse and fine aggregate and where needed, supplementary materials. The production of $U$-fill is not limited to these materials, therefore where needed, alternative materials may be used whilst maintaining desirable fresh and hardened properties.

Fly ash is used in some U-fill application. Due to high LOI percentages (Loss On Ignition) of some fly ash material it is disposed of and sent to landfills. High LOI percentages of these out-ofspecification fly ashes cause an increase in the required amount of admixtures and total water content in conventional concrete. However, it has been found that most fly ash that does not meet the requirements for conventional concrete can be successfully used in U-fill and improve much of its fresh properties such as flowability and segregation (Siddique, 2009).

The use of Cement Kiln Dust (CKD) in U-fill has also been investigated by previous researchers. Cement kiln dust is produced during the manufacturing of cement. Fine CKD particles tend to exhibit high amounts of sulphates and alkalis while coarser CKD particles containing traces of free lime. However, generally the composition of CKD is dependent on the cement production method, the type and amount of raw materials used in the production process and the dust collection process used in the cement manufacturing plant. In an investigation done by Lachemi et al. (2008) the effects of CKD's derived from various sources on the fresh and mechanical properties of CLSM mixtures were determined. It was found that where CKD's have lower Loss On ignition (LOI) and higher $\mathrm{CaO}$ content, the compressive strength of mixes were increased while setting time of mixtures were decreased. It was found that generally where CKD contents within mixes are high, water demand and setting time tend to increase. However due to the fineness of CKD particles, bleeding is reduced. Also, at higher CKD contents an increase in drying shrinkage and a decrease in freeze-thaw resistance was observed (Lachemi et al., 2008).

The use of slag in combination with CKD has also been found to produce acceptable mixtures. Do to the pozzolanic reaction of slag; there is an increase in strength gain at late ages. Therefore in order to allow for future excavation and to limit strength gain, slag content should 
be kept to a minimum (Lachemi et al., 2010). Moreover, the use of CKD in conjunction with fly ash has been reported by Siddique (2009). It was observed that high amount of CKD can reduce flowability of U-fill mixtures when used in conjunction with fly ash (CKD:FA=1:1). However where CKD to fly ash ratios of 1:6 or 1:12 where used, flowability was improved (Siddique, 2009).

In terms of aggregate, it has been common practice to use high quality natural stones in U-fill. However, in recent years more interest has been driven towards the use of more sustainable and economical substitutes, such as crushed glass (Ohlheiser, 1998), scrap tires (Pierce and Blackwell, 2003) and RCA. Crushed glass has been found to be comparable to concrete sand and when used in U-fill mixtures, exhibits similar characteristics to mixtures produced using natural aggregate.

The use of scrap tire on the other hand has been investigated by Pierce and Blackwell (2003). Scrap tire can be used in one of two ways, either as tire chips or crumb rubber (Figure 2.2). Tire chips are shredded to sizes ranging from one to twelve inches while crumb rubber is produced by grinding scrap tires to sand size fraction. Due to its light weight and density, high compressibility, permeability and thermal insulation, tire chips are ideal material to be used as a drainage layer under pavements.

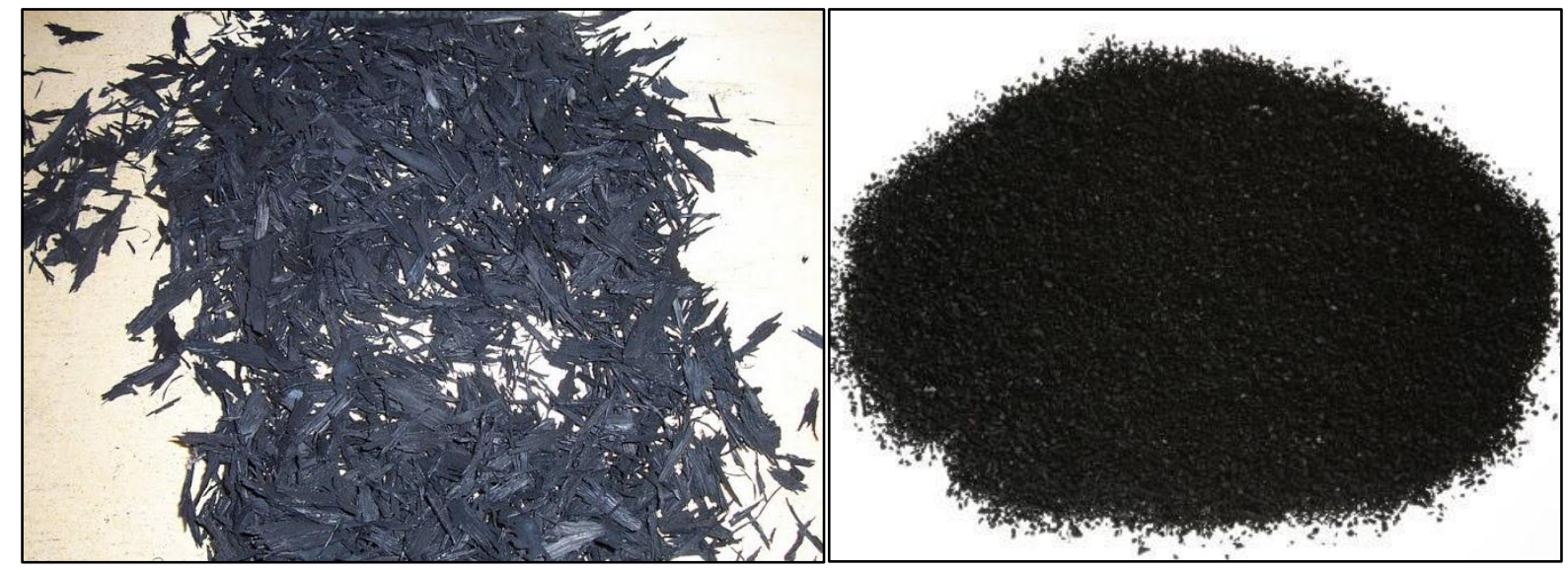

Figure 2.2: Left: Tire chips (24tons Inc., 2013)-Right: Crumb rubber (CalRecycle, 2013) 
The effects of crumb rubber on cement based material have been studied by Clark and Fattuhi (1995). Their research has shown that there is a reduction in the overall density and compressive strength at increasing rubber to cement ratios in conventional concrete mixtures. Yet due to this fact, mixes produced with crumb rubber can be an ideal material to be used as trench fill or pipe bedding (Clark \& Fattuhi, 1996).

Another alternative source of aggregate that has been gaining more attention in recent years is recycled concrete aggregate (RCA). The characteristics of concrete produced using RCA have been extensively investigated by many researchers. The following section will provide an overview of RCA and its effect on fresh and hardened properties of concrete mixes. 


\subsection{Recycled Concrete Aggregate (RCA)}

\subsubsection{Production Procedure}

Once concrete structures reach the end of their useful lifespan, they are demolished and sent to landfills. However, in recent years the use of the concrete retrieved from demolished structures in the form of aggregate has been gaining more attention. Instead of sending the old concrete to landfills, it is crushed into smaller sizes in order to be used in concrete mixtures. Concrete rubbles are stockpiled (Figure 2.3) then crushed to desirable sizes using aggregate crushers (Figure 2.4). Steel reinforcements and other non-concrete materials are then removed and the aggregates are then sieved and stockpiled for later use (Figure 2.5).

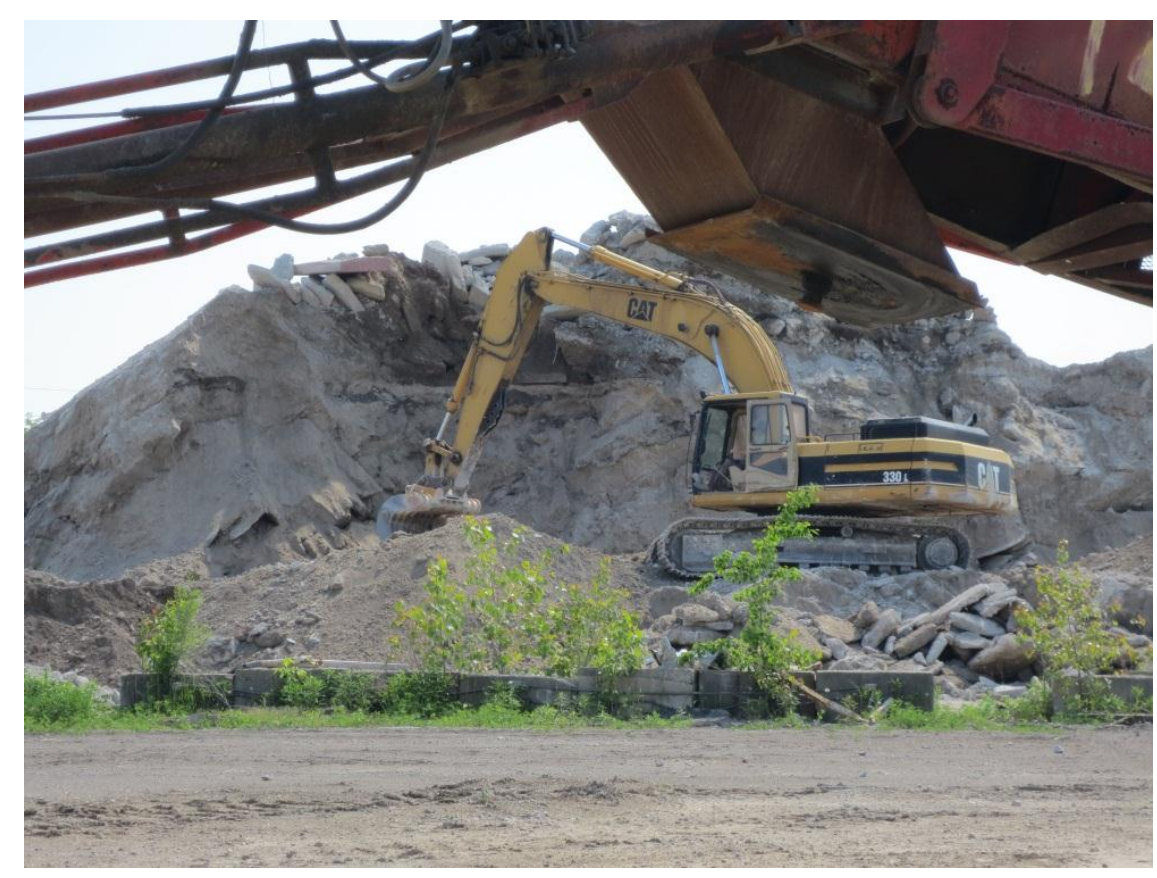

Figure 2.3: Demolished concrete stockpiled for recycling 


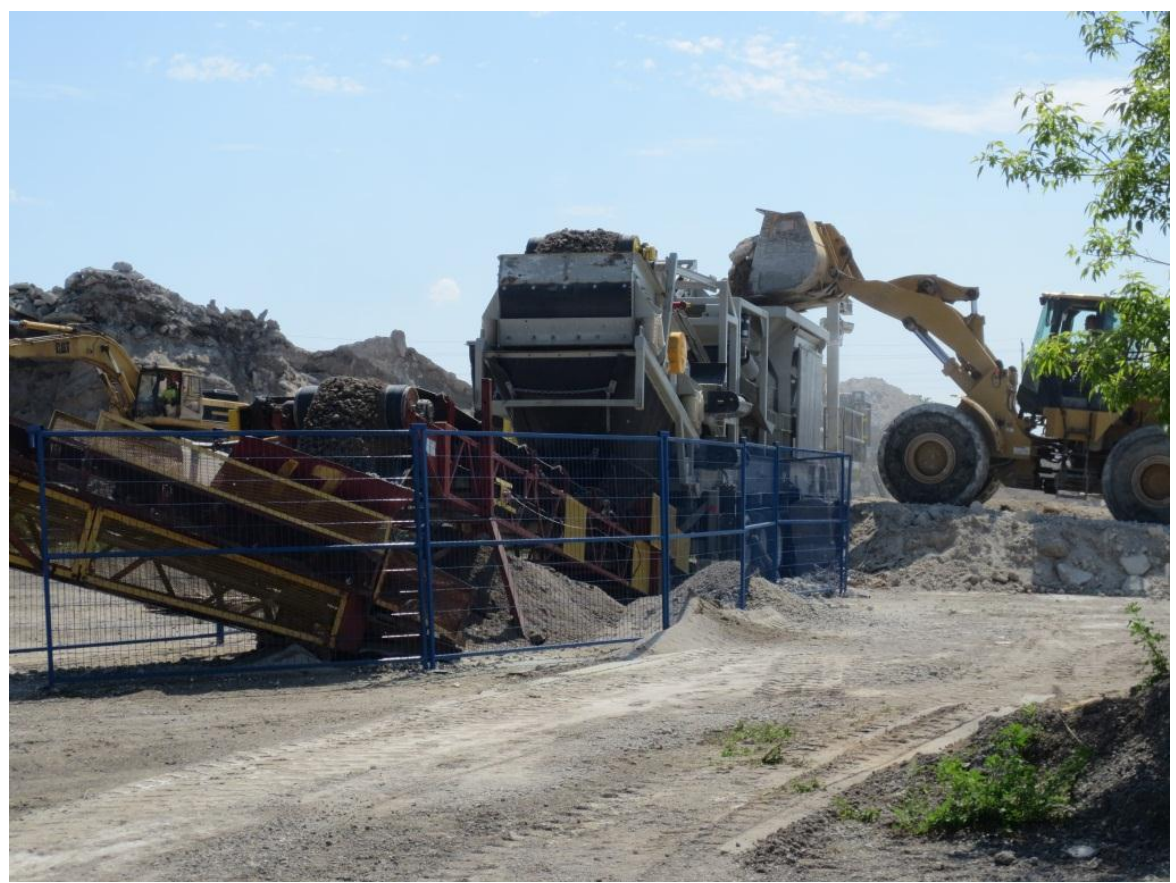

Figure 2.4: Concrete rubble being placed into crusher

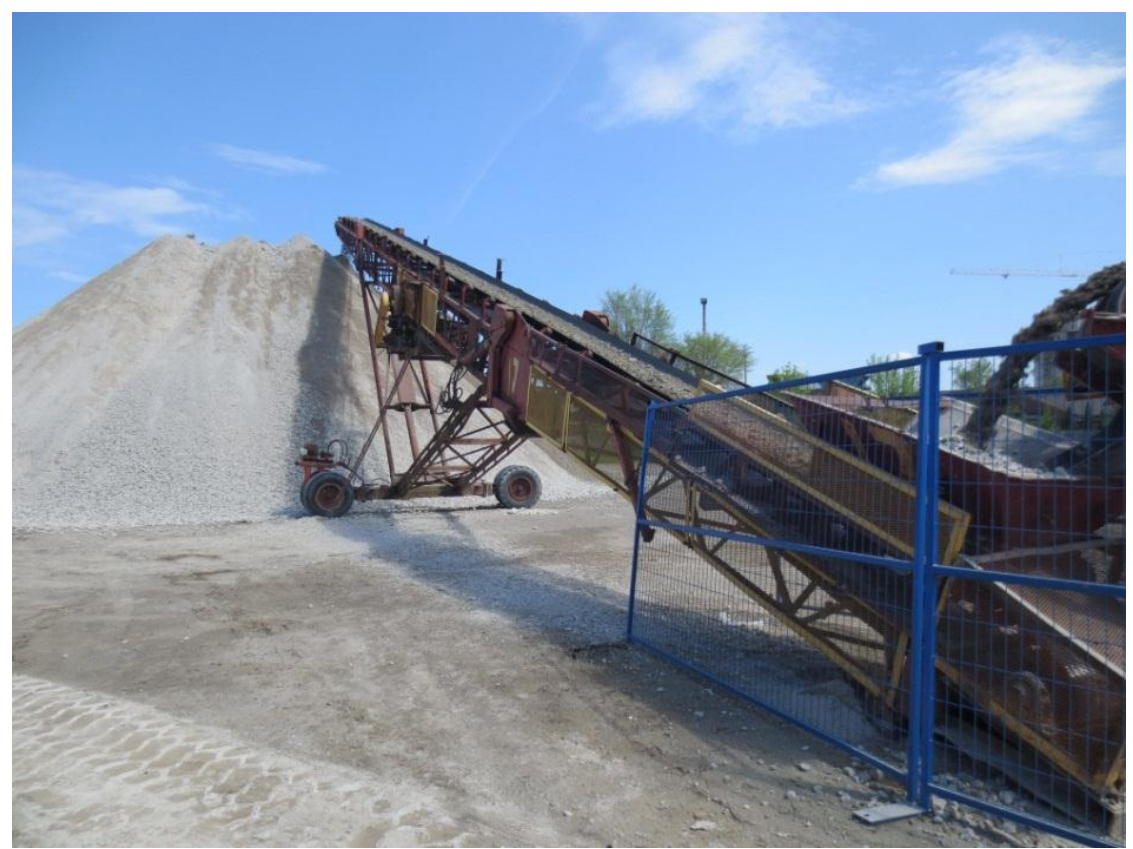

Figure 2.5: Crushed aggregate being sent to stockpile by conveyor belt

Concrete recycling may take other forms as well. Where there is a surplus in order from 
concrete plant or where concrete mixes have been rejected, fresh concrete mixes are returned to the mixing plants. The fresh mixes then can be decided to either be washed in order to dispose of the cement and admixtures in the slurry, or can be left in the concrete plant to be hardened and crushed. In the first case, the aggregate retrieved from washing the surplus or rejected concrete will be defined as "reclaimed" concrete aggregate while if it is crushed, it is considered as recycled aggregate. Concrete reclaimers (Figure 2.6) are used for the washing process of the returned-to-plant aggregate. The concrete mixtures are washed out of the mixing trucks and discharged into hoppers where coarse aggregates are separated from the cement and find particle slurry also called "grey water" by means of a screen. The excess water remaining from the washing process initially poured into mixing truck can then be reused again by allowing suspending cement particles to settle and be removed. Using the aggregate as reclaimed rather than recycled has the added advantage of being able to use natural aggregate with high freeze-thaw and wetting and drying resistance and lower abrasion loss due to the absence of cement paste surrounding the aggregate particles.

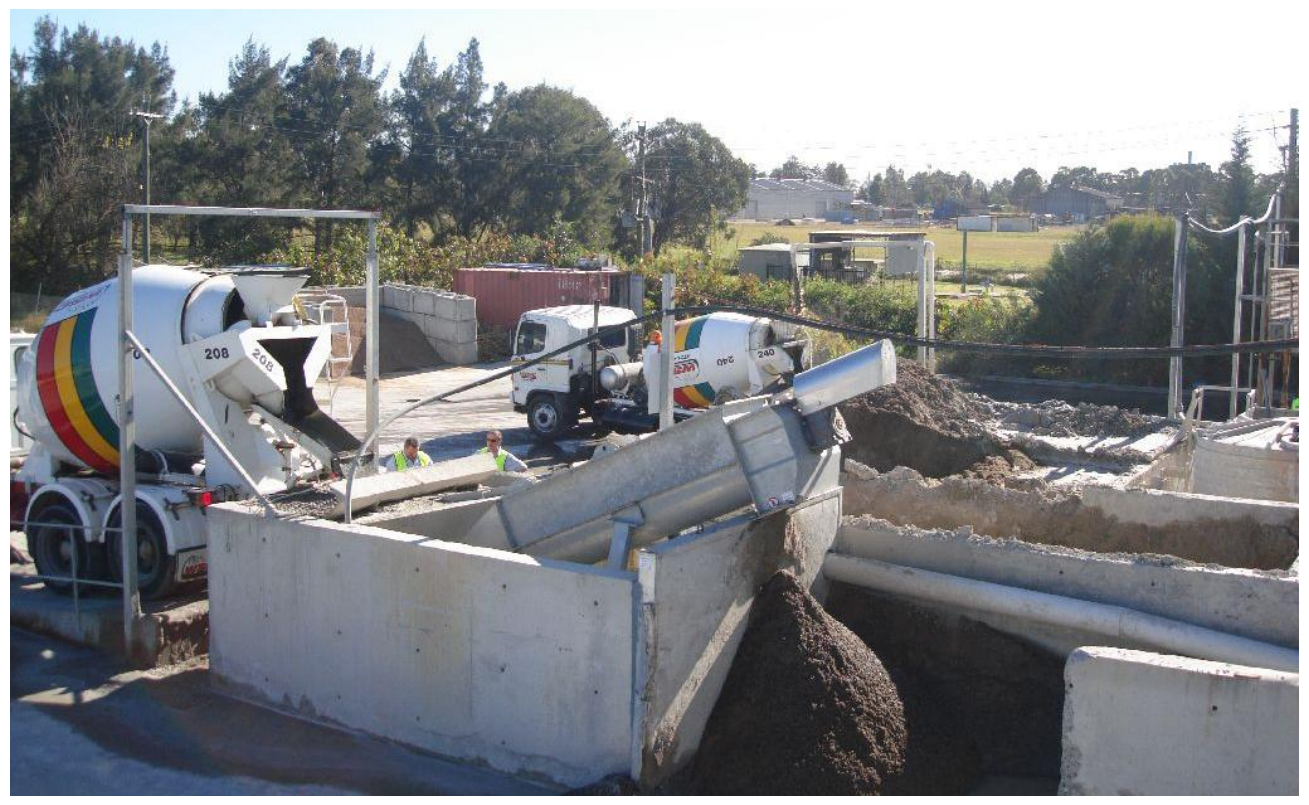

Figure 2.6: Concrete reclaiming process (BETON Innovative services, 2013) 


\subsubsection{Current Use of Recycled Concrete Aggregate (RCA)}

Every year, many demolition and rehabilitation projects are being undertaken across Canada. Most byproducts of these demolition activities are disposed of and sent to landfills. These waste materials are usually twenty to thirty times more than waste produced during construction (Recycling Council of Ontario, 2005). However, in recent years more interest has been raised about the ability to use these concrete wastes in everyday construction practices. Recycled Concrete Aggregate (RCA) has been receiving extensive attention due to its economic and ecological benefits. The use of RCA as fill material was first introduced in the United States in the late 1970's (Buck, 1977).

Concrete recycling has significantly increased in Ontario within the past few decades. Currently, $42 \%$ of concrete waste produced is being used as recycled aggregate (Recycling Council of Ontario, 2005). In 2004, redevelopment projects done on terminal one of Pearson international airport used nearly $95 \%$ of the construction waste acquired from the demolition of the existing structures in the construction of new structures. Over 200,000 tonnes of the concrete waste from demolished structures were used on-site as RCA. Using RCA produced on-site provided savings of $\$ 9 /$ tonne which resulted in a net saving of $\$ 1,845,000$ in the concrete production alone (Recycling Council of Ontario, 2005).

According to a report by the Ontario ministry of natural resources (2009), more than 3 billion tonnes of aggregate have been used in Ontario in the past 20 years, about 164 tonnes each year from which a third is used in GTA alone. Due to the use of secondary sources of aggregate such as RCA, there has been a steady decline in natural aggregate consumption in Ontario. The use of RCA has been predicted to increase in the next few decades. Figure 2.7 below shows the average annual consumption in various years. 


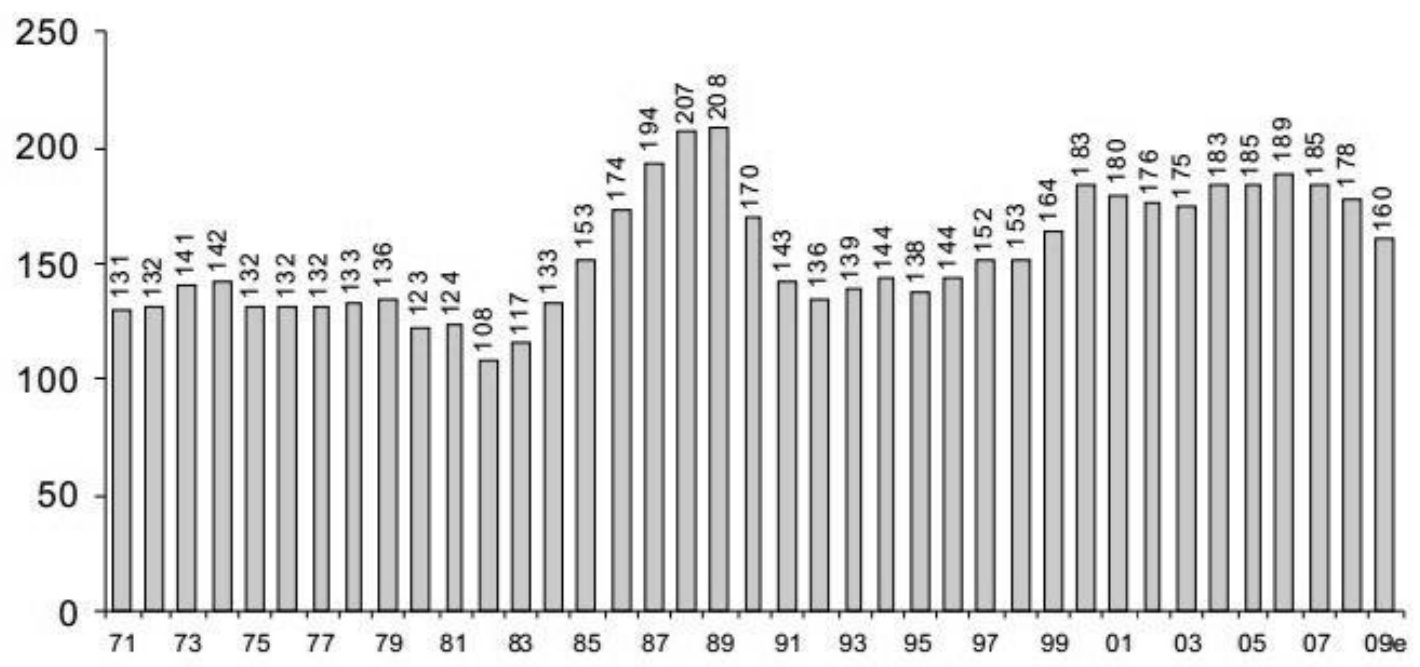

Figure 2.7: Average annual aggregate consumption in Ontario (million tonnes) (Ontario ministry of natural resources, 2009)

Road construction consumes the largest amount of aggregate annually in Ontario. The figure below shows the total percentages of aggregate used in 2006 in various construction projects. As shown, $30 \%$ of total sand and gravel is consumed in the construction of road beds and surfaces. On the other hand, $6.6 \%$ of the aggregate is used in filler material, higher than asphalt aggregate (3.9\%).

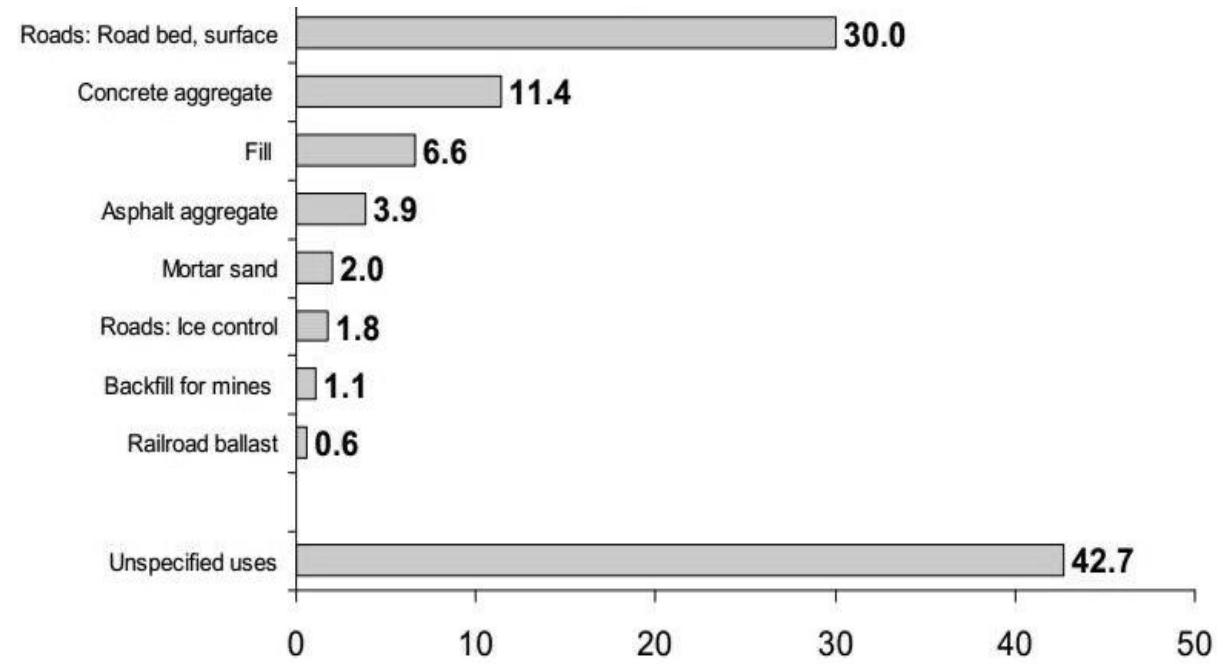

Figure 2.8: Percentage of sand and gravel consumption in Ontario in the year 2006 (Ontario ministry of natural resources, 2009) 
From the statistics shown in Figure 2.8 it can be determined a significant leap can be made towards sustainability if road construction projects were to be carried out using alternative and environmentally beneficial aggregate sources instead of the commonly used natural aggregate.

\subsubsection{Chemical and Physical Properties of RCA}

Due to the existence of hardened cement paste in RCA (Figure 2.9), RCA tends to have higher absorption compared to natural aggregate; which in turn would increase water consumption or specifically the water needed to achieve the same workability and slump as compared to conventional concrete mixtures. As seen in Figure 2.9, RCA aggregate are similar in shape and size to natural crushed aggregate.

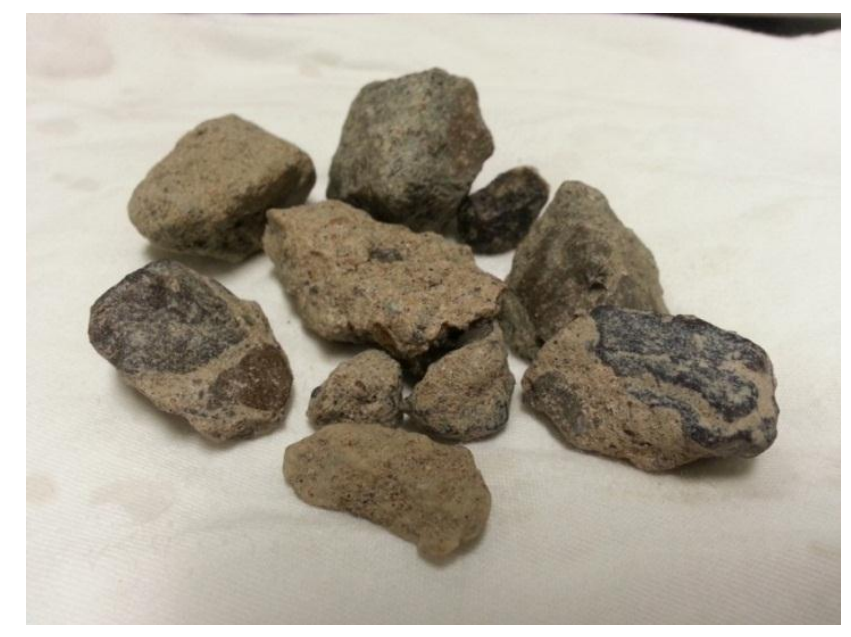

Figure 2.9: Lighter areas show hardened cement paste

Although using RCA in construction projects is a seemingly great alternative to using natural stones due to both economic and ecological benefits, it also has certain downfalls. Depending on the source which the RCA is retrieved from, chemical and physical durability of the concrete produced from these aggregate may be significantly affected. Resistance to various forms of chemical attacks, strength, corrosion and elasticity of concrete are some factors which should be carefully considered when using recycled concrete aggregate. 
Due to the large variation of properties amongst RCA, it is recommended that these aggregates are thoroughly examined for their chemical and physical properties prior to being used in any concrete mixture. The large amount of paste in RCA may cause concrete structures to be prone to deterioration due to various environmental conditions and exposure to de-icer salt or other chemicals such as sulphates.

It has been argued by Abbas et al. (2009) that conventional mix design procedures should not be applied where RCA aggregates are being used. This is mainly due to the fact that since RCA is not composed of aggregate alone, but rather contains both aggregate and mortar. Therefore the total mortar of a concrete mix should be calculated as the sum of the fresh paste and the residual mortar surrounding the RCA aggregate (Abbas et al., 2009). To overcome this issue it was proposed that the Equivalent Mortar Volume method (EMV) should be used where through this method the total amount of mortar and total aggregate volume in mixtures containing RCA would be comparable to mixes containing natural aggregate, hence displaying similar or even more enhanced properties. The results of extensive research done by Abbas et al. (2009) on properties of mixtures produced using this method as compared to mixtures produced using the conventional mix design techniques has shown that using the EMV method will result in mixtures with enhanced hardened properties. Due to the lower amount of overall mortar, mixes produced using the EMV method showed a higher compressive strength and freeze-thaw resistance compared to mixes which were produced using conventional mix design methods.

Since unshrinkable fill mixtures are not designed for optimum hardened properties such as high compressive strength or flexibility, using RCA will not have a significant impact on these characteristics. As it will be discussed in section 4.3, since the overall compressive strength of U-fill should be limited to a 28 day strength of $0.7 \mathrm{MPa}$ (according to OPSS 1359), the amount of reduction or variation in strength of $\mathrm{U}$-fill mixtures containing RCA as compared to those containing natural aggregate is negligible. However, using RCA can have significant consequences on chemical properties and resistance to various chemical attacks. The main 
mode of deterioration studied in the paper has been internal sulphate attack caused by Thaumasite and Ettringite formation. The following section will provide an overview of the required conditions, mechanisms and effects of internal sulphate attack on durability of concrete structures. 


\subsection{Internal Sulphate Attack (ISA)}

Internal sulphate attack is known to occur when concentrations of sulphates are high within the concrete. The sources of sulphate are usually either provided by cement or aggregates with high sulphate contents. Damages related to internal sulphate attack have only been discovered since the mid 80's in pre-stressed concrete railway ties (Collepardi, 2003). Internal Sulphate Attack (ISA) can take various forms and severity of damages caused by internal sulphate attack can vary depending on the reaction products produced. Some examples of ISA include Thaumasite attack, Ettringite formation, gypsum formation and magnesium sulphate attack. The modes of ISA investigated in this research program were mainly Thaumasite and Ettringite formation; therefore the following sections provide a review of the mechanisms, causes, mitigation, and the consequences of both types of ISA. Since internal sulphate attack is closely related to hydration products of cement, it is helpful first to understand its hydration process. The following section provides a brief overview of the different components of cement and the chemical process that occurs during hydration.

\subsubsection{Cement Hydration Process}

Cement formation involves a series of chemical processes. When Portland cement is being produced, clay, limestone and shale are mixed inside rotary kilns at very high temperatures, resulting in the production of clinker. The clinker is then mixed with gypsum to control setting time. The produced clinker consists of calcium aluminates and calcium silicates (Taylor, 2007). When Portland cement is mixed with water, heat is liberated. This heat is called the heat of hydration which is a result of an exothermic chemical reaction between water and cement. Overall, the hydration of cement can be thought of as a two-step process. In the initial step which is called dissolution, the cement is dissolved in water and thus releasing ions. The water containing the ions is usually referred to as the pore solution (Jennings \& Thomas, 2008).

The cement minerals Gypsum, $\mathrm{C}_{3} \mathrm{~S}$ and $\mathrm{C}_{3} \mathrm{~A}$ are very soluble and dissolve at a fast rate compared to the other existing ions. The concentration of these ions increases quickly once the cement 
and water are combined. Once the pore solution reaches a supersaturated stage the ions combine into new solid phases called hydration products. At this point the second stage is reached which is referred to as precipitation.

As the hydration products are produced from the oversaturated pore solution, it makes way for more cement minerals to seep into the solution and consequently more hydration products being produced. Therefore the pore solution can be thought of as a transition zone between the un-hydrated cement particles and the hydration product (Jennings \& Thomas, 2008). The solid hydration products that precipitate out of the pore solution are stable and have reached a state of equilibrium. The stability of these phases is determined by the amount free energy. This parameter shows the amount of chemical and thermal energy which is contained in the phase. If the free energy is low, the phase is considered to be stable (Taylor, 2007).

Cement minerals are usually produced at temperatures of $1400 \mathrm{C}$ or higher because they have the lowest free energy at this temeperature. Therefore, during cement hydration where the temperature is much lower, the cement minerals are unstable (have high free energy) and therfore readily desolve in water. The figure below shows the rate of cement hydration over time.

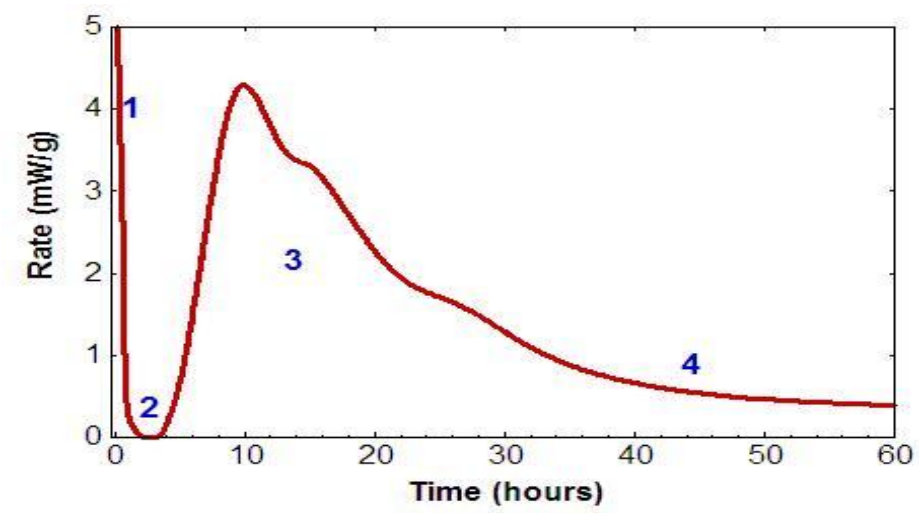

Figure 2.10: Rate of hydration vs. Time (Jennings \& Thomas, 2008)

As seen from Figure 2.10, stage 1 is very brief; this is due to the fact that an amorphous layer is initially produced which coats the cement particles and separates them from the pore solution and prevents further dissolution. During this stage, $\mathrm{C}_{3} \mathrm{~S}$ and water react together rapidly and 
release heat which is a result of the dissolution of $\mathrm{C}_{3} \mathrm{~S}$ shown as:

$$
\mathrm{C}_{3} \mathrm{~S}+3 \mathrm{H}_{2} \mathrm{O} \rightarrow 3 \mathrm{Ca}^{2+}+\mathrm{H}_{2} \mathrm{SiO}_{4}{ }^{2-}+4 \mathrm{OH}^{-}
$$

$\mathrm{C}_{3} \mathrm{~S}$ continues to dissolve into the solution until equilibrium has been reached between the calcium and silicate concentrations. Some have argued that the deceleration at stage 1 is due to the existence of a thin metastable layer of $\mathrm{C}-\mathrm{S}-\mathrm{H}$ that reduces the reaction of the existing alite with water.

In the second stage, which is called the induction period, the rate of reaction is much lower compared to the first stage. However once stage three is reached the reaction rate increases rapidly and reaches its maximum point in less than 24 hours after mixing. This is mostly due to the hydration of $\mathrm{C}_{3} \mathrm{~S}$. By the time stage 3 has ended, $30 \%$ of the cement has hydrated. In this stage the hydration products, namely $\mathrm{C}-\mathrm{S}-\mathrm{H}$ and $\mathrm{CH}$, deposit rapidly into the pores which had been originally occupied by the mix water. Consequently, there will be a large decrease in the total pore volume and as a result, strength is increased. From this stage onward, in order for more hydration to occur the ions either has to move into the capillary pores or water has to move inwards to reach the cement core which has not yet reacted (Jennings \& Thomas, 2008). As the hydration layer becomes thicker the reaction becomes much slower, this stage is called the diffusion limited reaction period (Stage 4).

The C-S-H gel occupies about 50\% of the paste volume (Jennings and Thomas, 2008). This gel forms a layers that binds the cement particles together therefore is responsible for most of the physical properties of the cement paste. As it will be discussed in the following sections, the failure of a concrete structure due to Thaumasite attack is mostly due to the decomposition of the $\mathrm{C}-\mathrm{S}-\mathrm{H}$ paste which results in a significant loss of strength. Other hydration products however do not have the strong binding capability that the $\mathrm{C}-\mathrm{S}-\mathrm{H}$ gel has. As $\mathrm{C}-\mathrm{S}-\mathrm{H}$ gel expands it develops very small pores called gel pores that are much smaller than the capillary pores. These pores do contain some water; however since they are not interconnected, they cannot react with the cement minerals. As the $\mathrm{C}-\mathrm{S}-\mathrm{H}$ gel expands it connects with other surrounding gel 
resulting in a continuous phase. This will result in the hardening of the cement paste.

\subsubsection{Ettringite Formation}

As mentioned previously, gypsum is added to the cement clinker in order to regulate setting time. Without the addition of gypsum to the cement clinker, $\mathrm{C}_{3} \mathrm{~A}$ will react rapidly with water thus causing a reduction in setting time and workability. Through the reaction of gypsum and $\mathrm{C}_{3} \mathrm{~A}$ however, a thin layer of Ettringite surrounds $\mathrm{C}_{3} \mathrm{~A}$ particles, thus prohibiting its reaction with water. The amount of gypsum added to Portland cement is usually $5 \%$ however this amount may vary depending on various manufacturing processes and total $C_{3} A$ content of the cement. Where gypsum is not proportioned properly compared to the total $C_{3} A$ content, sulphate attack may occur. The Ettringite initially formed by the reaction of $C_{3} A$ and gypsum will not cause expansion since it forms at initial stages of hydration where concrete is still fluid and elastic. Once Ettringite is formed, if there are any unreacted $C_{3} A$ remaining within the chemical system, it may react with Ettringite to form monosulphate. Once this occurs, for monosulphate to reach a state of equilibrium, it will react with sulphates present within the system. Once monosulphate reacts with the sulphates, Ettringite is formed once more. However at this stage, the effects of expansion are much more severe and may cause cracks and scaling within the concrete structure. The Ettringite produced at later stages may crystalize in pores or cracks of hardened concrete and exerts a force onto the surrounding mortar, causing expansion.

\subsubsection{Thaumasite}

Thaumasite $\left(\mathrm{CaSiO}_{3} \cdot \mathrm{CaCO}_{3} \cdot \mathrm{CaSO}_{4} \cdot 15 \mathrm{H}_{2} \mathrm{O}\right)$ is a form of sulphate attack that occurs when calcium silicate hydrates (C-S-H) in Portland cement are targeted. Erlin and Stark (1965) were amongst the first to report the optical characteristics of Thaumasite formed in concrete. Thaumasite can either form naturally, or if favoring conditions are present, can form in concrete structures as a result of several chemical processes. Natural Thaumasite is commonly observed as a mass of colorless or white crystals (Sibbic et al. 2003) however it can vary in appearance depending on 
the water and carbonate content of the Thaumasite crystals. When comparing the crystalline structure of naturally occurring Thaumasite to Thaumasite formed in concrete due to TSA, Sibbick et al. (2003) found that the birefringence refraction indices of the two forms of Thaumasite are rather similar and no significant differences were detectable.

Thaumasite forms where there is a supply of $\mathrm{CO}_{3}{ }^{2-}, \mathrm{Ca}^{2+}$, Silicates and sulphates. The formation of Thaumasite is also usually favored at low temperatures. According to Sibbic et al. (2003), concrete subjected to TSA will undergo four stages of degradation and the identification of degradation mechanism can be described as follows:

- Identification of Thaumasite attack is not visually possible however crystal forms of either Thaumasite, Ettringite or both are present in cracks or around aggregate.

- Thaumasite formation can be visually observed in cracks existing on the surface of concrete as white masses. Precipitation of $\mathrm{CaCO}_{3}$ can be found in these cracks and small amounts of portlandite can be observed in the cement paste matrix.

- There is an increase in the amount of paste attacked by Thaumasite. Cracks containing white masses of Thaumasite become more visually apparent and are spread abundantly over the concrete surface. A white contour of Thaumasite can be seen around coarse and fine aggregate. As stage 2, calcium carbonate precipitates can occasionally be found within cracks and a slight amount of portlandite can be found in the paste.

- Cement paste matrix completely loses cohesion and bonding strength between cement paste and aggregate is significantly reduced. All paste transforms into Thaumasite, and aggregates are found to be embedded inside a white mud-like paste.

The extent of deterioration and expansion caused by Thaumasite attack are largely dependent on the orientation of the crystalline structure of Thaumasite. Since Thaumasite tends to form in voids or cracks, with a randomly oriented crystalline structure, there is more force imposed on 
the surface of cracks rather than if it were to be uniformly oriented and parallel to the void or crack surface. A school of thought exists however that in concrete experiencing TSA, expansion is not caused by the forces caused by Thaumasite crystal itself, but rather by the absorption of water by Thaumasite formed within the concrete (Shi et al. 2012). A commonality in all theories about the effects of Thaumasite is that it has the ability to significantly reduce bonding strength, both within concrete components itself, or concrete and other materials such as reinforcement steel in structures. Gorst and Clark (2003) have compared the bonding strength of concrete and reinforcement steel before and after Thaumasite attack. Through their research it was observed that on average there is a $15 \%$ reduction in bond strength between concrete and reinforcement bars due to TSA. However, the amount of reduction in strength is highly dependent on the extent of Thaumasite attack in concrete.

Thaumasite is structurally similar to Ettringite and in most cases it is very hard to distinguish between the two:

\section{Thaumasite: $\mathrm{CaSiO}_{3} \cdot \mathrm{CaCO}_{3} \cdot \mathrm{CaSO}_{4} \cdot 15 \mathrm{H}_{2} \mathrm{O}$ \\ Ettringite: $\quad 3 \mathrm{CaO} \cdot \mathrm{Al}_{2} \mathrm{O} .3 \mathrm{CaSO}_{4} \cdot 31 \mathrm{H}_{2} \mathrm{O}$}

During Ettringite formation, calcium aluminate hydrates are consumed and cause expansion. As a result cracks occur in the hardened concrete structure. However, TSA (Thaumasite Sulphate Attack) targets $\mathrm{C}-\mathrm{S}-\mathrm{H}$ in the cement paste, which is the main bonding component of concrete. Once the $\mathrm{C}-\mathrm{S}-\mathrm{H}$ is attacked there is a severe reduction in strength and durability within the concrete. TSA is known to be more deleterious than any other form of sulphate attack because of the fact that the calcium silicate hydrates are affected rather than only the portlandite and calcium aluminate phases which lead to complete deterioration of the concrete.

\subsubsection{Required Conditions for Thaumasite Formation}

Factors favoring Thaumasite formation are as follows: 
1. Low temperature

2. Presence of carbonate (Source should preferably be from the aggregate)

3. Sources of sulphate

4. High $\mathrm{pH}$ value

\section{Low temperature}

In order for TSA to occur, temperatures usually below $15{ }^{\circ} \mathrm{C}$ is needed. As temperature decreases the rate of formation of Thaumasite increases, however Thaumasite can still occur at ambient temperatures. Severe deterioration has been found in mortars stored at temperatures as high as $23^{\circ} \mathrm{C}$ (Collepardi, 1999). Overall, it has been found that Thaumasite is stable up to temperatures as high as $40^{\circ} \mathrm{C}$. However, beyond this temperature and at low relative humidity Thaumasite will decompose. The rate of Thaumasite formation at higher temperatures might be slower, but could accelerate if other factors favoring Thaumasite formation are present (Bensted, 2003). In a research done by Kohler et al. (2005), it was found that Thaumasite crystals were more easily detected in samples stored at $5^{\circ} \mathrm{C}$ compared to those stored at $10^{\circ} \mathrm{C}$ which could be an indication of higher rates of Thaumasite formation at lower temperatures.

\section{Presence of carbonate}

Some have argued that the presence of carbonate is an essential requirement for TSA to occur (Sims and Huntley, 2004). Carbonate can be sourced from various admixtures, cement or aggregate. Where limestone is present within the cement, chances of Thaumasite formation are much higher. De-dolomization of dolomite aggregates may be another source of carbonate (Thomas et al. 2003). Carbonate can also be supplied by the carbon present in the atmosphere or ground, surface, marine or sea water (Torres et al. 2004). However, some studies have shown that Thaumasite attack could occur where there is no source of carbonate (Sims \& Huntley, 2004).

\section{Source of sulphate}

As mentioned previously, sulphates can either be supplied from internal or external sulphates 
and consequently causing internal or external sulphate attack. The internal sources of sulphate are mainly aggregate or in some cases may be supplied from sulphate based cements. In external sulphate attack however, sulphates are supplied by groundwater carrying various forms of sulphates such as sodium, magnesium or calcium sulphates (Shi et al., 2012). Some building materials could also act as the source of sulphate such as plaster, brick and/or other clay based material.

\section{High pH}

According to Shi et al. (2012), TSA formation is usually favored at pH values of 10.5 or above. Gaze and Crammond (2000) have confirmed that there is a higher chance of TSA formation where $\mathrm{pH}$ is high. However, at very advanced stage of TSA at which all calcium is depleted from the system, the $\mathrm{pH}$ of the concrete may drop to neutral. Some have argued that TSA may still occur where $\mathrm{pH}$ is below 10.5 (Sibbick and Crammond, 2001). Overall, Thaumasite is much more stable where the concrete is basic.

\subsubsection{Role of Ettringite on Thaumasite Formation}

It has been recently come to attention that in most cases where Thaumasite crystals are present, Ettringite is present as well and coexist within the concrete matrix alongside Thaumasite. As it will be discussed in section 4.1, in order to study Thaumasite formation, SEM investigations were carried out on several mortar bars containing various percentages of sulphate. The SEM results on mortar bars deteriorated due to internal sulphate attack revealed the presence of solid phases of both Thaumasite and Ettringite. A study done by Kohler et al. (2006) shows that where aluminate was not present in the concrete matrix, Thaumasite was not formed and that there is an increase in Thaumasite formation when aluminate contents are increased. Since Aluminate is a requirement for Ettringite formation, it is assumed that Thaumasite cannot be formed if requirements for Ettringite form of sulphate attack are not present. It was found that in mixtures containing the highest amounts of $\mathrm{Al}_{2} \mathrm{O}_{3}$, Thaumasite was formed after only 14 days. When mixtures were produced with all conditions necessary for 
Thaumasite formation and in the absence of any aluminates, no Thaumasite formation was detected. Similarly, Blanco-Valera et al. (2006) found that where $C_{3} A$ was low, only Thaumasite crystals were found. However where concrete contained higher amounts of $C_{3} A$, solid phases of both Thaumasite and Ettringite were present (Shi et al. 2012).

In their experiment, Kohler et al. (2006) also found that where $\mathrm{Na}_{2} \mathrm{SO}_{4}$ was used as source of sulphate in mixtures alongside fly ash, Thaumasite was not detectable. However, traces of Thaumasite were found where gypsum was used as the source of sulphate. Adding gypsum to the mixtures allowed for complete reaction with aluminates to form Ettringite, whereas in mixes containing $\mathrm{Na}_{2} \mathrm{SO}_{4}$, this did not occur. Where more gypsum was added to their mixes, due to the higher amounts of Ettringite produced, Thaumasite formation was enhanced as well. As it can be seen in Figure 2.11, Kohler et al. (2006) found a continuous increase in Thaumasite formation in samples containing gypsum whereas in samples containing $\mathrm{Na}_{2} \mathrm{SO}_{4}$ this was not observable.
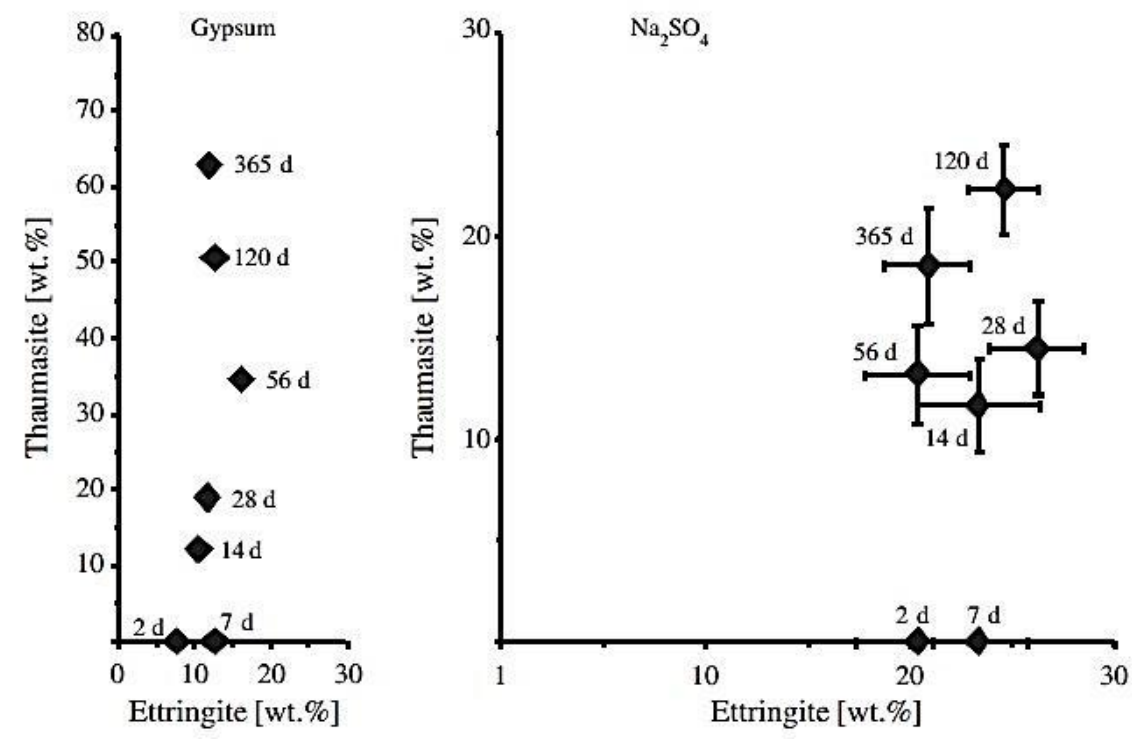

Figure 2.11: Rate of Thaumasite formation vs. Ettringite formation in mixes containing gypsum (left) and $\mathrm{Na}_{2} \mathrm{SO}_{4}$ (right) as source of sulphate (Kohler et al. 2006)

One theory presented to explain these occurrences has been given by Shi et al. (2012). They have hypothesized that Thaumasite is forms where $\mathrm{Al}$ and $\left[3 \mathrm{SO}_{4}{ }^{2-}+2 \mathrm{H}_{2} \mathrm{O}\right]$ in Ettringite is 
replaced by $\mathrm{Si}$ and $\left[2 \mathrm{CO}_{3}{ }^{2-}+2 \mathrm{SO}_{4}{ }^{2-}\right]$. Once this process occurs some aluminates are liberated into the pore solution and consequently result in the production of more Ettringite, which would explain the reason why frequently Thaumasite and Ettringite are observed together.

Another theory present in explaining this phenomena is named the "dissolution-precipitation mechanism". This theory suggests that if sufficient amounts of sulphate are present in the pore solution, Ettringite formation will occur until all aluminates are consumed. If more sulphates are present, gypsum will form through the reaction of the remaining sulphates and $\mathrm{Ca}(\mathrm{OH})_{2}$ (portlandite) and will cause the $\mathrm{pH}$ to drop. Lastly, if carbonates are present in the system, Thaumasite will form while $\mathrm{C}-\mathrm{S}-\mathrm{H}$ is dissolved which in turn will cause deterioration of the concrete paste (Crammond, 2003).

\subsubsection{Effects of Calcium to Silicon Ratio on Thaumasite Attack}

In their experiment, Bellmann and Stark (2007) investigated the effects of silicon rich C-S-H phases and calcium rich C-S-H phases on resistance to sulphate attack. They indicated that C-S$\mathrm{H}$ phases with a calcium/silicon ratio of 1.7 that forms in the presence of portlandite can result in the formation of Thaumasite at very low sulphate concentrations (Bellmann \& Stark, 2007). However, if the calcium to silicon ratio in the C-S-H phases are reduced to 1.1, by adding pozzolanic or hydraulic admixtures, higher sulphate contents can be resisted by these phases while preventing the formation of Thaumasite. Bellmann and stark carried out their experiment by producing mortar bars containing different cement and mineral admixtures. These mortar bars were exposed to sulphate contents of $1500 \mathrm{mg} / \mathrm{l}$ at $8{ }^{\circ} \mathrm{C}$. The samples which had insufficient amount of mineral admixtures were found to be badly corroded. This was due to the fact that the inadequate amount of these minerals resulted in the inability to convert portlandite into C-S-H phases and to lower calcium silicon ratio of the C-S-H phases. However, once coal fly ash or blast furnace slag was added to lower the calcium/silicon ratio of the C-S-H phase to 1.1, no signs of TSA were found. As a result of these experiments it was proposed that $\mathrm{C}-\mathrm{S}-\mathrm{H}$ phases with low calcium/silicon ratios could reduce the potential risk of TSA occurrence provided that pozzolanic or hydraulic admixtures are added to ensure that portlandite is 
consumed to reduce the calcium/silicon ratio (Bellmann \& Stark, 2007).

\subsubsection{Effects of Water to Cement Ratio on Thaumasite Formation}

In an experiment done by Bruckner et.al. (2002), it was established that a factor controlling TSA was the water to cement ratio. They have suggested that a w/c of 0.35 is needed for most aggressive environments and 0.55 for slightly aggressive environments in order to resist TSA (Brueckner, Williamson \& Clark, 2002). Their experimental results showed that high rates of TSA are possible in conventional concrete designs with $\mathrm{w} / \mathrm{c}$ of 0.55 and $320 \mathrm{~kg} / \mathrm{m}^{3}$ cement. Therefore, the rate of deterioration was found to be dependent on the mix design. However, results obtained from the experiments showed that the rate of TSA is decreased in concrete with higher strengths and therefore should not be a concern where the concrete has a compressive strength of $70 \mathrm{~N} / \mathrm{mm}^{2}$ or higher (Brueckner, Williamson \& Clark, 2002). Although high strength concrete cannot completely prevent deterioration due to TSA, it can decrease the amount and depth of Thaumasite formation on the outer layers of concrete, if the sources of sulphates are external. However, where internal sulphate attack is dominating form of deterioration, this principle cannot be applied. Regardless of strength, when sulphate bearing aggregates are used in concrete, severe deterioration can occur, which is significantly more deleterious compared to where sulphate sources are external.

\subsubsection{Use of Mineral Admixtures to Prevent TSA}

In order for Thaumasite to form within concrete structure ions such as $\mathrm{SO}_{4}{ }^{2-}, \mathrm{Ca}^{2+}$ and $\mathrm{CO}_{3}{ }^{2-}$ and sufficient amount of moisture need to be transported through the hardened cement paste. Some admixtures that reduce the permeability and refine the pore structure therefore might help in reducing TSA.

In a study done by Tsivilis et.al. (2013) found that by incorporating metakaolin and ground granulated blast furnace slag, the resistance to sulphate attack can be significantly improved. 
Slow reacting pozzolans however are unable to provide enough resistant against sulphate attack if the concrete is exposed to sulphates before the reaction of pozzolans begin (Tsivilis et al., 2013). A study done by Higgins and Crammond (2003) has shown that where $70 \%$ Ground Granulated Blast Furnace Slag (GGBFS) was used alongside carbonate aggregate of normal quality, Thaumasite was not formed. However, this was not the case where lower quality carbonate aggregates were used.

The use of fly ash in reducing Thaumasite formation has been investigated by Mulenga et al.(2003). Fly ash is known to reduce Thaumasite formation through the consumption of calcium hydroxide. In their experiment, Mulenga et al.(2003) found that where $50 \%$ fly ash was mixed with limestone cement, no Thaumasite was formed. However, where $50 \%$ fly ash was used alongside sulphate-resisting cement, concrete deterioration was accelerated. Therefore the effect of fly ash on the amount of reduction of Thaumasite is largely dependent on the type of cement being used.

\subsubsection{Identification of Thaumasite}

Identifying Thaumasite using XRD and optical microscopy is very difficult due to its crystallographic similarities with Ettringite. However, using Scanning Electron Microscopy (SEM) and energy dispersive spectroscopy is suitable for identifying the elements of both Thaumasite and Ettringite in concrete structure. Ettringite has three distinctive peaks of Aluminum, Sulfur and calcium while Thaumasite has the peaks of Silicon, sulfur and calcium. Another method for identifying Thaumasite is Raman spectroscopy (Sahu, Exline \& Nelson, 2002). The advantage of using Raman spectroscopy is that it can identify Thaumasite as it has a characteristic peak of $658 \mathrm{~cm}-1$ corresponding to silicon. The Raman chemical imaging combines molecular analysis with visual imaging and thus can provide a more accurate identification for Thaumasite (Sahu, Exline \& Nelson, 2002). 


\subsubsection{Cases of Structures Affected by Thaumasite Attack}

Most cases presented to date on Thaumasite attack have been related to deterioration caused by external sources of sulphate. However since the mechanism and effects of Thaumasite formed through the presence of both external and internal sources of sulphate are rather similar, these cases will be further discussed in the following section.

\subsubsection{Thaumasite Formation in Yongan Dam-China}

There have been several records of concrete structures deteriorated due to Thaumasite attack. An example of such occurrence has been found in the Yongan dam in china and discussed by Fumei et al. (2006). The construction of Yongan dam was completed in 2003. Less than a year after completion, the dam was found to be severely deteriorated where the concrete had been in contact with groundwater. EDX analysis done on samples retrieved from the dam showed obvious traces of Thaumasite, but not Ettringite. Through the analysis of the components of the concrete structure it was found that all conditions necessary for Thaumasite attack were present. Carbonate necessary for the formation of Thaumasite was present through the coarse and fine carbonate aggregate used in the concrete and the powdered limestone within the cement. Sulphates were supplied by the groundwater which was found to carry noticeably high amounts of sulphate, the ambient temperature of the area was relatively low, which all together, the presence of these conditions favored the formation of Thaumasite.

\subsubsection{Thaumasite Formation in Bapanxia Dam-China}

Severe deterioration due to Thaumasite formation was also found in a tunnel passing through Bapanxia dam located in northwest of china. This dam was constructed between 1969 and 1975. The groundwater of the area surrounding the Bapanxia dam, similar to the Yongam dam, was also found to contain a large amount of sulphates (Ma et al., 2006). Sulphate rich 
groundwater was found to intrude into the tunnel through cracks and ducts, which consequently caused severe deterioration. Deterioration was also found in drainage channels on the sides of the tunnel where water had been collected. The figure below shows the areas where severe deterioration was found within the tunnel.

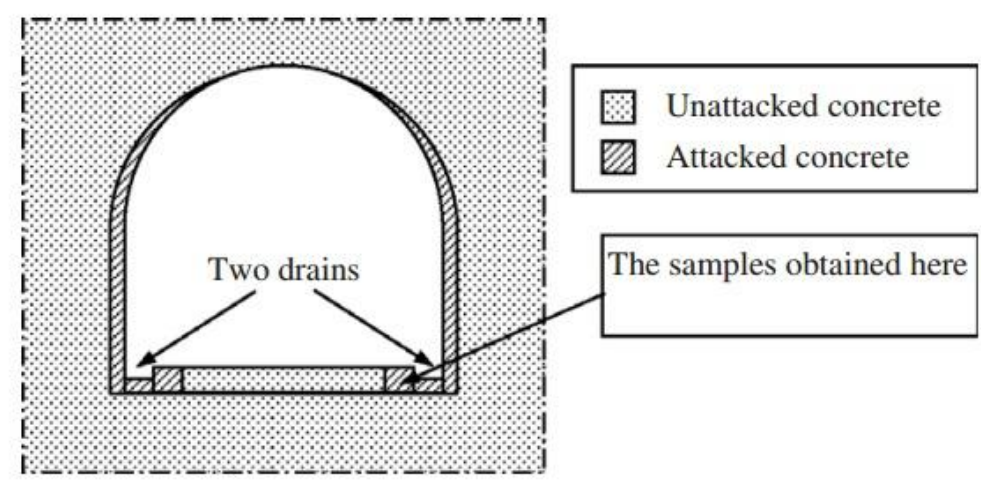

Figure 2.12: Cross section of tunnel passing through Bapanxia dam indicating areas of deterioration (Ma et al., 2006).

Drainage areas on both sides of the tunnel were found to be severely decomposed and displayed characteristics of deterioration due to Thaumasite (Figure 2.13). Several analyses were done on sample retrieved from the deteriorated concrete and was examined using Scanning Electron Microscopy (SEM), X-ray diffraction, Fourier transform infrared (FTIR), Raman spectroscopy and Energy dispersive X-ray spectroscopy. The results of all analysis indicated the presence of both Thaumasite and Ettringite.

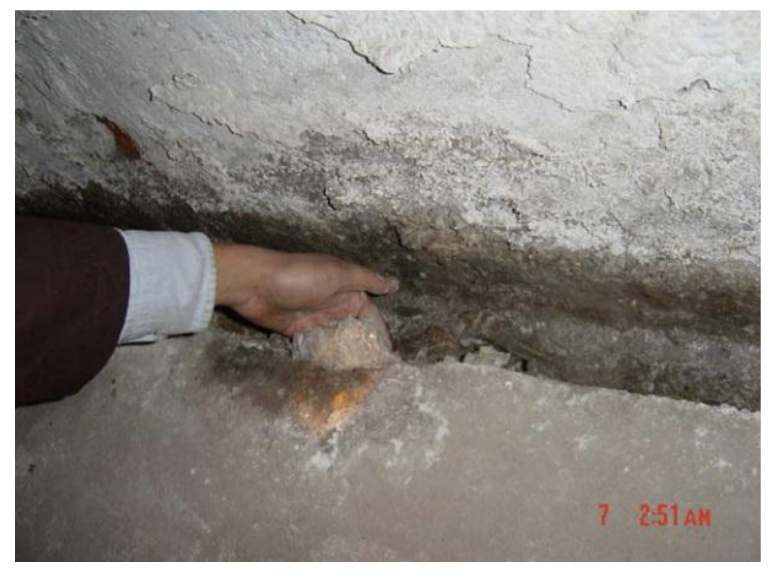

Figure 2.13: Deterioration found in drainage of tunnel in Bapanxia (Ma et al., 2006) 
It was speculated that due to concrete carbonation, most deterioration occurs on the surface, even if sulphate bearing water penetrated through the unexposed concrete surface (Ma et al., 2006).

\subsubsection{Thaumasite Formation in Historic Structures- Netherlands}

Thaumasite has also been detected in few of Netherlands historic landmarks. In a report done by van Hees et al. (2003), the mechanism of Thaumasite formation in a historic bridge built in 1728 and a church tower built in 1926 were investigated. The bridge exterior was found to be constructed by a high quality clay brick while the interior contained bricks rich in sulphates embedded into a hydraulic mortar. Most deterioration was observed in the vaults where bricks were found to be cracked and the mortar in between were pushed outwards. Through SEM (Figure 2.14) and EDAX analysis of the bedding mortar, it was found that Thaumasite and also monochloride formation were the main causes of deterioration. The main reason of Thaumasite formation was determined to be due to: 1) The hydraulic bedding mortar, 2) sulphate supplied from the interior bricks and 3) the exhaust from boats which were rich in sulfur oxide.

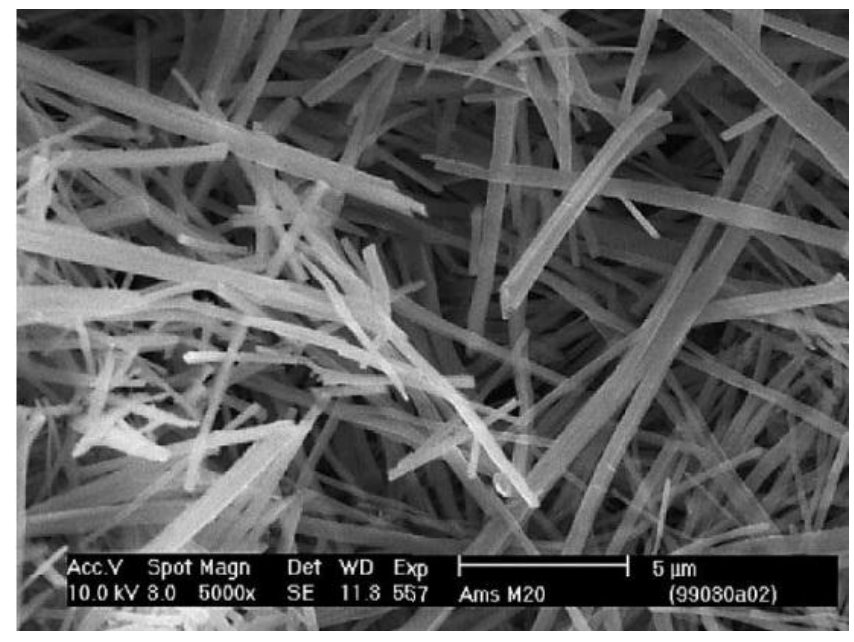

Figure 2.14: SEM analysis displaying Thaumasite crystals (van Hees et al. ,2003) 
Similar to the bridge, high quality brick exterior and a low quality brick interior rich in sulphates were used in the construction of the historic church. Horizontal and vertical cracks were observed in the exterior brick layer. Studies on the bedding mortar of the interior brick indicated the presence of Thaumasite and Ettringite. Through the migration of water inwards from the exterior cracks, sulphates in the interior bricks were dissolved and reacted with the lime-cement bedding mortar thus causing Thaumasite and Ettringite formation. As a result of the forces exerted from the bedding mortar and the interior bricks, cracks were induced into the exterior bricks (Figure 2.15).

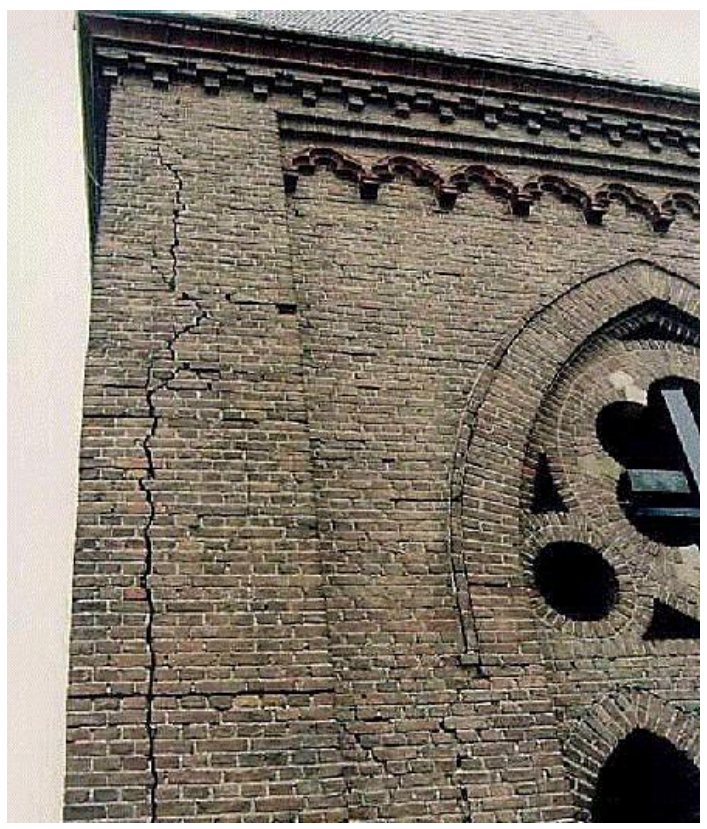

Figure 2.15: Cracks induced in exterior bricks of church tower (van Hees et al. ,2003) 


\section{Chapter 3}

\section{Material and Experimental Details}

\subsection{Material Properties}

\subsubsection{Physical and Chemical Properties of Aggregates}

At the preliminary stages of this research project, two types of out-of-specification granular aggregate were used to produce laboratory U-fill mixes, one being from Vinemount \#2 Quarry (waterfold Sand and Gravel Ltd.) and another from the Bayview Quarry (Sutherland H. Construction). The chemical and physical properties of both mentioned aggregates are summarized in the tables below. As seen Table 3.1 and Table 3.2, micro-deval abrasion loss percentages for both Vinemount and Bayview aggregate are relatively high. Based on OPSS 1002 standards maximum Micro-Deval abrasion loss for coarse and fine concrete aggregate must not exceed $17 \%$ and $20 \%$ respectively. Also, freeze-thaw resistance for concrete aggregate is limited to $6 \%$, clearly both Vinemount and Bayview aggregate do not meet these requirements, however, the performance of $\mathrm{U}$-fill mixes are not dependant on high strength or freeze-thaw resistance as it is mainly used as a sub-base layer. As mentioned previously, according to OPSS 1359 strength of U-fill mixes must not exceed 0.7 MPa. Due to this fact, there is more leeway for using aggregates of lower quality in the production of $\mathrm{U}$-fill mixes. 
Table 3.1: Physical properties Vinemount Granular ' $A$ '

\begin{tabular}{|c|c|c|}
\hline Aggregate Type & $\begin{array}{c}\text { Vinemount Granular 'A' } \\
\text { Coarse }\end{array}$ & $\begin{array}{c}\text { Vinemount Granular ' } A \text { ' } \\
\text { Fine }\end{array}$ \\
\hline Density (OD) $\left(\mathrm{kg} / \mathrm{m}^{3}\right)$ & 2651.5 & 2694.8 \\
\hline Density (SSD) $\left(\mathrm{kg} / \mathrm{m}^{3}\right)$ & 2704.8 & 2724.9 \\
\hline Density (Apparent)(kg/m³) & 2857.6 & 2778.7 \\
\hline Absorption (\%) & 2.01 & 1.12 \\
\hline MDA Loss (\%) & 21.8 & 25.13 \\
\hline Freeze-Thaw Loss (\%) & 11.3 & --- \\
\hline
\end{tabular}

Table 3.2: Physical properties Bayview Granular ' $A$ '

\begin{tabular}{|c|c|c|}
\hline Aggregate Type & $\begin{array}{c}\text { Bayview Granular 'A' } \\
\text { Coarse }\end{array}$ & $\begin{array}{c}\text { Bayview Granular ' } A \text { ' } \\
\text { Fine }\end{array}$ \\
\hline Density (OD) $\left(\mathrm{kg} / \mathrm{m}^{3}\right)$ & 2611.5 & 2601.9 \\
\hline Density (SSD) $\left(\mathrm{kg} / \mathrm{m}^{3}\right)$ & 2670.8 & 2671.2 \\
\hline Density (Apparent) $\left(\mathrm{kg} / \mathrm{m}^{3}\right)$ & 2775.3 & 2795.2 \\
\hline Absorption (\%) & 2.27 & 2.669 \\
\hline MDA Loss (\%) & 16.8 & 18.85 \\
\hline Freeze-Thaw Loss (\%) & 29.81 & --- \\
\hline
\end{tabular}

The chemical properties of both granular aggregate are summarized in Table 3.3 and Table 3.4. As it will be discussed in the following sections, the effects of high sulphate content in both of the mentioned out-of-specification granular aggregate had to be determined in order to be able to accurately predict the performance of the final U-fill product produced using these aggregates. From chemical analysis, it was noticed that both granular aggregate contained traces of sulphate, with vinemount granular ' $A$ ' having the highest sulphate content. In Table 3.3 and Table 3.4 "fines" refers to the as-sieved fine portion $(<4.75 \mathrm{~mm}$ ) of the aggregate while 
the term "crushed coarse" is used to refer to the crushed coarse portion of the aggregate (>4.75 mm). As In Table 3.3 and Table 3.4, sulphate content in the uncrushed aggregates (fine/ as-sieved aggregate) is much higher than the crushed-coarse portion.

Table 3.3: Chemical Properties of Granular 'A' from Vinemount \#2 quarry

\begin{tabular}{|c|c|c|}
\hline Aggregate Type & $\begin{array}{c}\text { Vinemount Granular 'A' } \\
\text { (Fines) }\end{array}$ & $\begin{array}{c}\text { Vinemount Granular 'A' } \\
\text { (Crushed coarse) }\end{array}$ \\
\hline Total Sulphur content & 1.69 & 0.75 \\
\hline $\mathrm{SO}_{4}(\%)$ & 3.23 & 0.94 \\
\hline
\end{tabular}

Table 3.4: Chemical Properties of Granular 'A' from Bayview Sutherland quarry

\begin{tabular}{|c|c|c|}
\hline Aggregate Type & $\begin{array}{c}\text { Bayview Granular 'A' } \\
\text { (Fines) }\end{array}$ & $\begin{array}{c}\text { Bayview Granular 'A' } \\
\text { (Crushed) }\end{array}$ \\
\hline Total Sulphur content (\%) & 0.29 & 0.35 \\
\hline SO $_{4}(\%)$ & 0.53 & 0.23 \\
\hline
\end{tabular}

Table 3.5 and Figure 3.1 show the gradation of both granular aggregate. The aggregate from the Bayview Quarry (Sutherland H. Construction) was determined to be less uniform in gradation as compared to the Vinemount aggregate. 
Table 3.5: Sieve analysis of aggregate from Bayview and Vinemount quarry

\begin{tabular}{|c|c|c|}
\hline & Vinemount aggregate & Bayview aggregate \\
\hline Sieve size $(\mathrm{mm})$ & \%Passing & \%Passing \\
\hline 22.4 & 100 & 100 \\
\hline 19 & 96.88 & 95.91 \\
\hline 16 & 90.76 & 84.51 \\
\hline 13.2 & 83.34 & 72.67 \\
\hline 9.5 & 69.16 & 53.69 \\
\hline 6.7 & 57.23 & 41.69 \\
\hline 4.75 & 48.09 & 34.4 \\
\hline 2.38 & 34.43 & 21.86 \\
\hline 1.18 & 24.29 & 14.94 \\
\hline 0.6 & 17.61 & 11.09 \\
\hline 0.3 & 13.86 & 8.93 \\
\hline 0.15 & 11.68 & 7.55 \\
\hline 0.075 & 9.89 & 6.62 \\
\hline
\end{tabular}

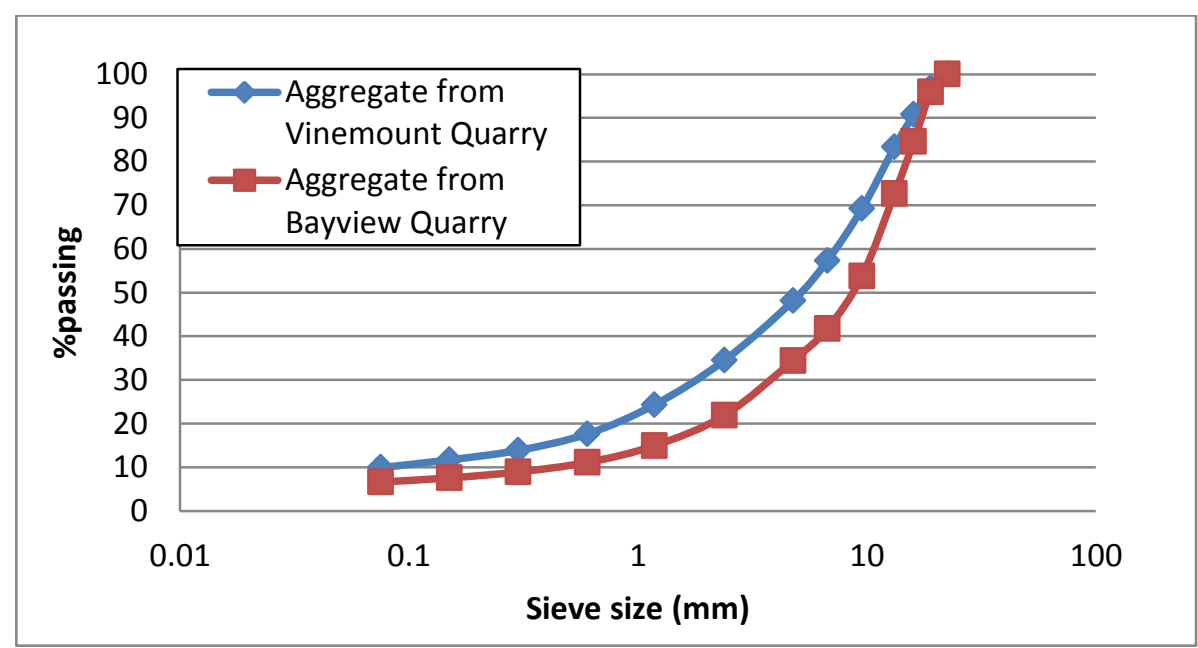

Figure 3.1: Grain size distribution of aggregate from Vinemount and Bayview Quarry 
The 0.45 gradation curves of both granular aggregates are displayed in Figure 3.2. In comparison to the maximum density line, it can be seen that the Vinemount granular aggregate is much more densely graded as compared to the Bayview granular aggregate. As it will be discussed in the following sections, mixes produced using aggregate from the Bayview quarry alone displayed a significant amount of segregation. Cement alone is not a significant provider of strength in U-fill mixtures. Particle to particle contact is of great importance in terms of bearing external forces therefore decisions on type and amount of aggregate to be used in U-fill mixes should be made based on the location of the aggregate gradation curves in relation to the maximum density line of the aggregates under study.

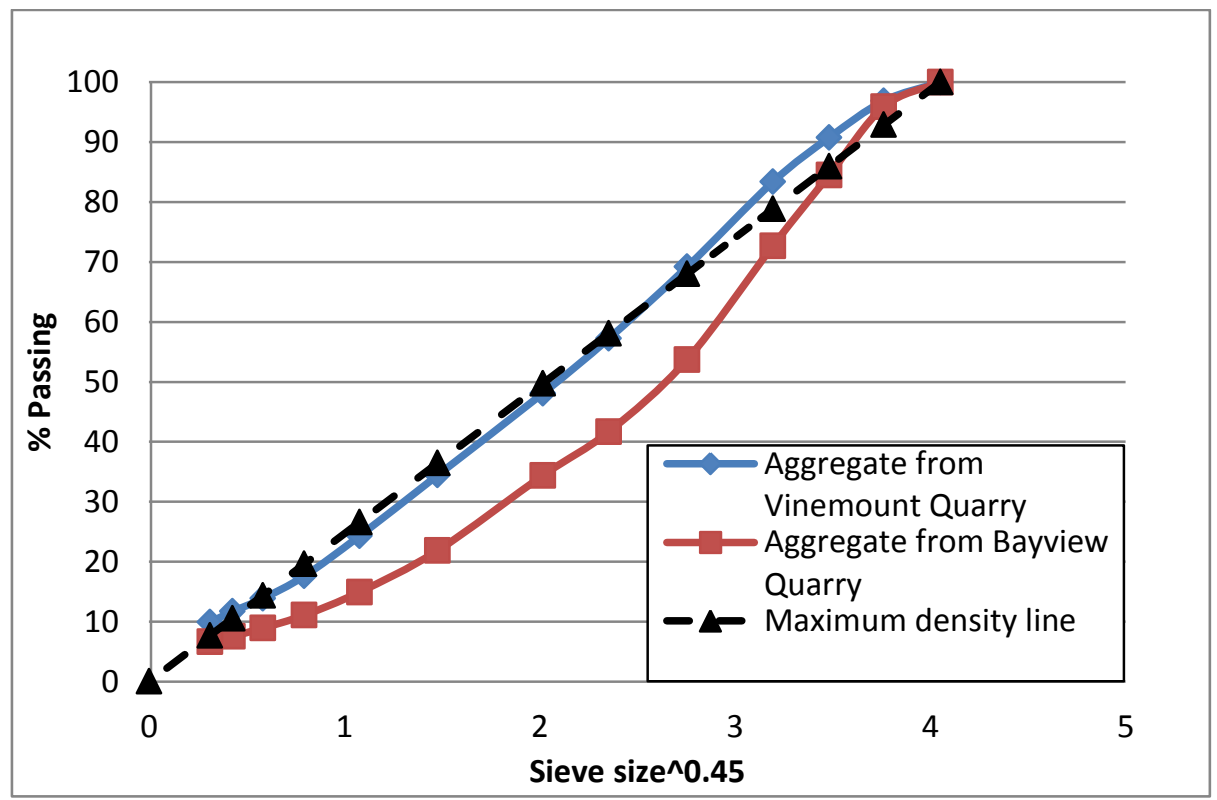

Figure 3.2: 0.45 power gradation curves of aggregates from the Bayview and Vinemount quarry

As another alternative source of aggregate, the use of RCA was also investigated in this research program. As RCA aggregate contain a considerable amount of residual paste, it was imperative to determine the amount of increase in fines due to abrasion during mixing in order to be able to accurately predict the performance of the Unshrinkable fill product produced 
using RCA. Bleeding, segregation, drainage and hardening time are highly dependent on the amount of sand-sized fraction in the mix. In order to determine the abrasion resistance, coarse and fine (passing $4.75 \mathrm{~mm}$ sieve) portions of the RCA aggregate were tested using the MicroDeval abrasion test (MDA). The results are listed in Table 3.6. These values provide an indication of the relative amounts of fines that are likely to be produced during mixing. Higher loss indicates that higher levels of fines are produced during an extended mixing time. The maximum allowable MDA loss specified for granular base coarse aggregates in Ontario (Granular A) are 25\% for coarse aggregate and 30\% for fine aggregate (OPSS 1010). For concrete aggregate however, the limits are $17 \%$ and $20 \%$, for coarse and fine aggregate respectively. In Ontario, the current specification for $U$-fill requires the use of concrete aggregate in U-fill (OPSS 1002).

Table 3.6: MDA Loss of Phase II and III RCA (LS-618 \&619)

\begin{tabular}{|c|c|c|c|c|c|c|}
\hline & \multicolumn{3}{|c|}{ RCA (Coarse) } & \multicolumn{3}{|c|}{ RCA (Fine) } \\
\hline Trial \# & $\begin{array}{l}\text { Initial } \\
\text { (g) }\end{array}$ & Final (g) & $\begin{array}{c}\text { Percent Loss } \\
\text { (\%) }\end{array}$ & Initial (g) & Final (g) & $\begin{array}{c}\text { Percent Loss } \\
\text { (\%) }\end{array}$ \\
\hline Trial \#1 & 1474 & 1119 & 24.1 & 500 & 353 & 29.4 \\
\hline Trial \#2 & 1484 & 1110 & 25.2 & 501 & 347 & 30.7 \\
\hline Trial \#3 & 1494 & 1108 & 25.8 & 502 & 330 & 34.3 \\
\hline \multicolumn{3}{|r|}{ Average $=$} & $25.03 \%$ & & Average $=$ & $31.46 \%$ \\
\hline
\end{tabular}

Other than testing for MDA test, the amount of increase in fine fraction was also investigated through mixing. To do so, sieve analysis was done on three samples of the same RCA as mentioned above. Each sample of aggregate was set into and mixer along with water to simulate abrasion which would possibly occur in a concrete mixer truck. All three samples were mixed for approximately 15 minutes. The RCA along with mixing water were poured carefully into a large size pan and set into an oven to completely dry for 24 hours. After drying the 
aggregate were sieved once more. The results of this sieve analysis are summarized in Figure 3.3.

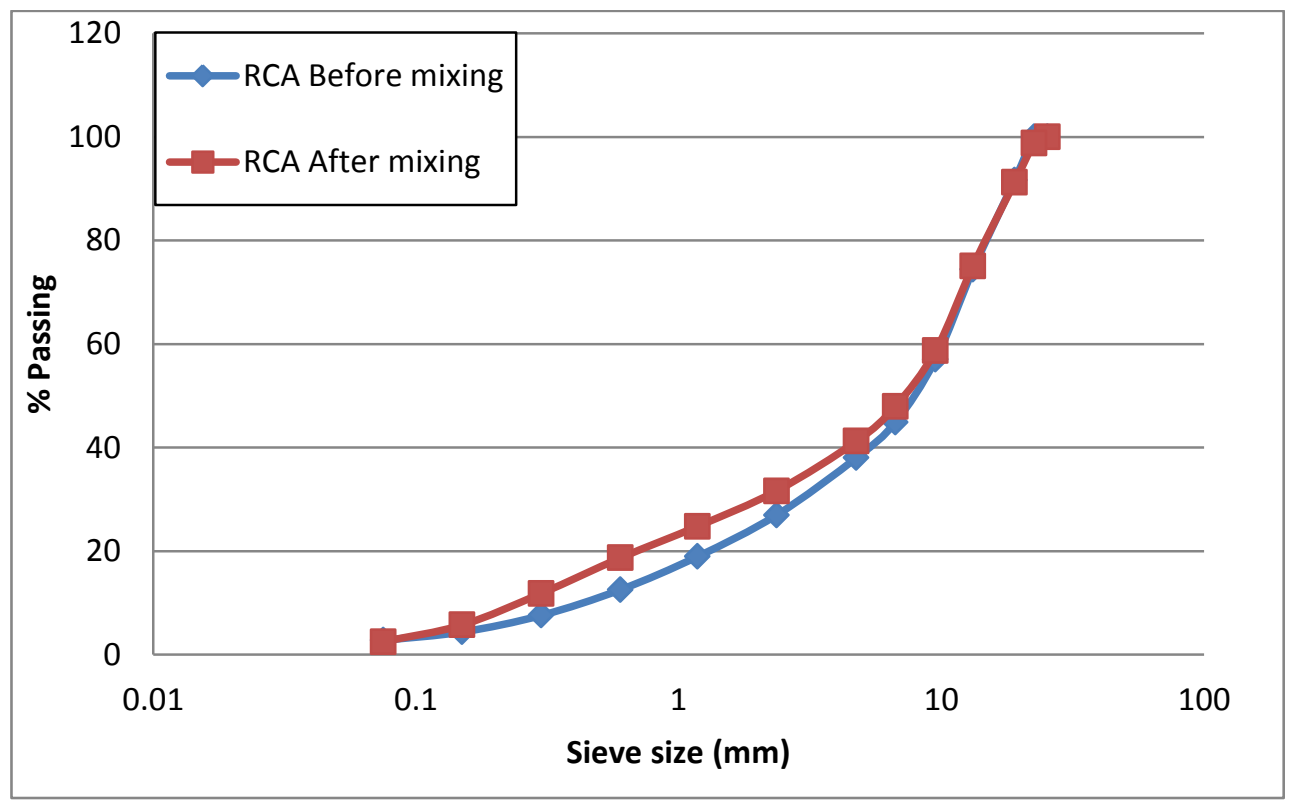

Figure 3.3: Sieve analysis of RCA before and after mixing

As it can be determined from Figure 3.3, there is a definite increase in fines caused by abrasion due to mixing. However, the amount of increase in fines $(<4.75 \mathrm{~mm})$ would be much higher if it were to be mixed with coarse aggregate such as gravel. It should also be noted that since the RCA aggregate was mixed in a laboratory mixer, much less force was exerted onto the RCA aggregate compared to if it were to be mixed in a concrete mixer truck.

Preliminary mix results showed that using 100\% RCA aggregate in the mixes resulted in segregation of fines and an increase in hardening time. Therefore to obtain more desirable fresh and hardened properties, gravel and sand were incorporated into U-fill mixes. The gradations for each aggregate type are shown in Figure 3.4 and physical properties are summarized in Table 3.7. It should be noted that RCA contains both coarse and fine fractions. 
Table 3.7: Physical Properties of Gravel, Sand and RCA

\begin{tabular}{|c|c|c|c|}
\hline & Gravel & Sand & RCA \\
\hline Bulk Specific Gravity $\left(\mathrm{kg} / \mathrm{m}^{3}\right)$ & 2658 & 2719 & 2254 \\
\hline Bulk Specific Gravity, SSD $\left(\mathrm{kg} / \mathrm{m}^{3}\right)$ & 2688 & 2749 & 2423 \\
\hline Apparent Specific Gravity $\left(\mathrm{kg} / \mathrm{m}^{3}\right)$ & 2711 & 2805 & 2711.5 \\
\hline Absorption (\%) & 1.08 & 1.12 & 7.58 \\
\hline
\end{tabular}

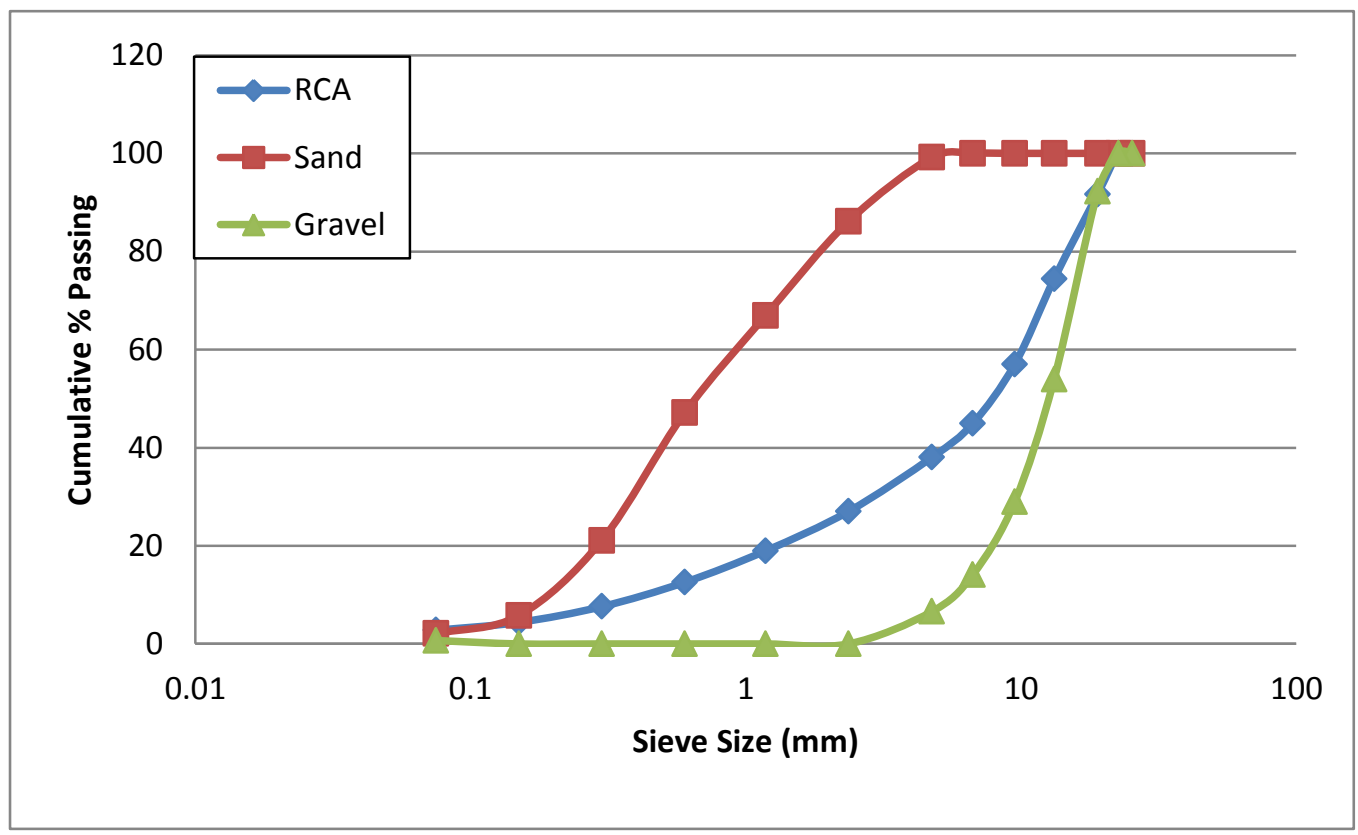

Figure 3.4: Grain size distribution of RCA, Sand and Gravel

As an alternative, the use of RCA with higher quality (meeting requirements of OPSS 1002) was also investigated. Table 3.8 below summarizes the physical properties of this aggregate. 
Table 3.8: Physical characteristics of Phase IV RCA

\begin{tabular}{|c|c|c|c|}
\hline RCA \# & $\mathbf{1}$ & $\mathbf{2}$ & $\mathbf{3}$ \\
\hline \%MDA loss (Trial 1) & 19.2 & 17.3 & 20.2 \\
\hline \%MDA loss (Trial 2) & 19.4 & 17.2 & 18.8 \\
\hline \%MDA loss (Average) & 19.3 & 17.25 & 19.5 \\
\hline Relative Density (kg/m ${ }^{3}$ ) & 2.32 & 2.26 & 2.36 \\
\hline Absorption (\%) & 4.45 & 4.32 & 3.76 \\
\hline
\end{tabular}

A total of three RCA's were retrieved from three different aggregate plants and were combined and used in both laboratory and field trial mixes. As it can be clearly seen from Table 3.8, MDA loss of this aggregate is significantly lower than those shown in Table 3.6. It was hypothesized that due to the lower overall abrasion loss of this type of RCA, the overall fresh properties of the U-fill mixes would be enhanced. Figure 3.5 shows the gradation of all three RCA's, RCA 2 and RCA 3 meet the upper and lower requirements of CSA A23.1-2009 while RCA 1 is partially out of the lower limit boundary, however since all three RCA's were combined the final total grain size distribution meets both upper and lower limit requirements.

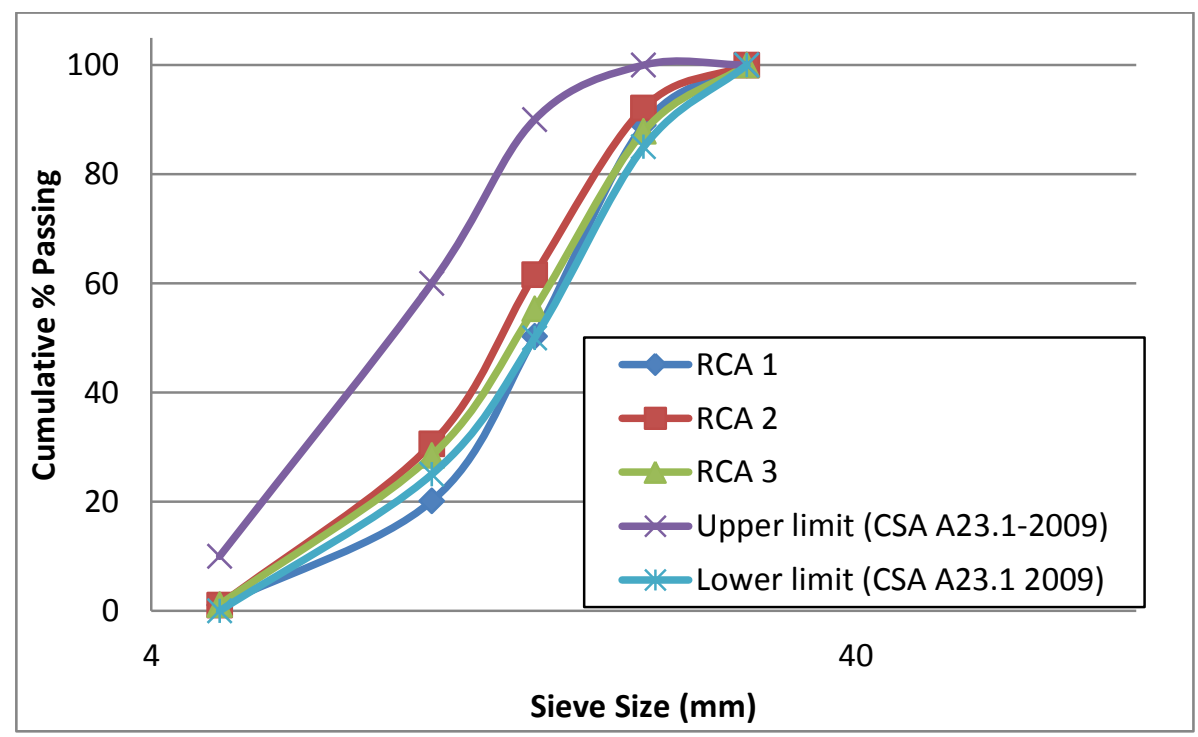

Figure 3.5: Gradation of phase III RCA aggregate 


\subsubsection{Properties of Cementing Materials}

The properties of three cementing materials used in at various stages of this experimental program are shown in Table 3.9. The main two cementing materials used in the production of U-fill mixes were type GU Portland cement and slag. Portland cement is commonly used in U-fill mixtures, however as a sustainable and economical alternative, performance of U-fill mixtures containing slag were also investigated. In the chemical analysis program, the effects of all three cementing materials on the rate and reduction of expansion has been investigated.

Table 3.9: Properties of cementing materials

\begin{tabular}{|c|c|c|c|}
\hline & $\begin{array}{c}\text { GU Portland Cement } \\
\text { (GU PC) }\end{array}$ & $\begin{array}{c}\text { Ground Granulated Blast Furnace Slag } \\
\text { (GGBFS) }\end{array}$ & Metakaolin \\
\hline $\mathrm{SiO}_{2}$ & 19.58 & 34.4 & 48.25 \\
\hline $\mathrm{Al}_{\mathbf{2}} \mathbf{O}_{\mathbf{3}}$ & 5.35 & 7.4 & 44.05 \\
\hline $\mathrm{Fe}_{\mathbf{2}} \mathbf{O}_{\mathbf{3}}$ & 2.29 & 0.94 & 0.9 \\
\hline $\mathrm{CaO}$ & 62.84 & 43.2 & 0.79 \\
\hline $\mathrm{MgO}$ & 2.43 & 9.3 & 0.62 \\
\hline $\mathbf{S O}_{\mathbf{3}}$ & 4.1 & 0.83 & - \\
\hline $\mathrm{K}_{\mathbf{2}} \mathbf{O}$ & 1.13 & 0.58 & 0.11 \\
\hline $\mathrm{Na}_{\mathbf{2}} \mathbf{O}$ & 0.21 & 0.57 & $<0.01$ \\
\hline $\mathrm{TiO}_{\mathbf{2}}$ & 0.31 & 0.44 & 1.98 \\
\hline $\mathbf{P}_{\mathbf{2}} \mathbf{O}_{\mathbf{5}}$ & 0.11 & $175 \mathrm{ppm}$ & 0.05 \\
\hline
\end{tabular}




\subsection{Sample Preparation and Testing Procedures}

\subsubsection{Testing Laboratory U-fill Mixes}

\subsubsection{Casting Cylinders}

As mentioned in section 2.1.1, the maximum allowable 28 days strength for $U$-fill must be limited to 0.7 MPa. Due the weakness of U-fill mixes, demoulding samples can prove to be a difficult process. Therefore, it is common practice to use cardboard moulds in place of plastic cylinders for ease of demoulding. Cardboard moulds can be easily and carefully peeled off while keeping the U-fill sample intact. Samples were poured into cylinders in three layers and tamped using a cylindrical rod with a diameter of $10 \mathrm{~mm}$. Samples were not placed into a curing room as this would not be representative of actual field processes for curing. Common curing methods are usually not applied to U-fill mixtures since total cement content is limited to only $25 \mathrm{~kg} / \mathrm{m}^{3}$ and water contents is much higher than most conventional concrete mixes. Therefore all casted cylinders were cured at room temperature instead and measured for compressive strength at 7 and 28 days.

\subsubsection{Compressive Strength Test}

To measure for compressive strength sample surfaces were capped using a sulphur capping compound. Capping equipment and apparatus similar to the one described in ASTM C617 was used. The common practice for capping is to pour the compound into the capping jig and place sample cylinder on top until the sulphur compound has hardened. However using this method was not practical for U-fill samples since placing and removing the samples would cause failure (Figure 3.6). To avoid this problem, a new capping method was developed.

Cylinders were placed on a level surface with either a cardboard or plastic cylinder wrapped around it. Molten sulphur compound was poured on top of the sample in 2-3 layers until a smooth surface was achieved (Figure 3.7). The caps were given a minimum of 10 minutes to 
cool down and harden, after which the surrounding cardboard or plastic mould was removed. As a more convenient alternative method however, neoprene pads can be used for capping $U$ fill samples. Due to the ease of placement and removal, using neoprene pads will cause minimum damage to U-fill cylinders.

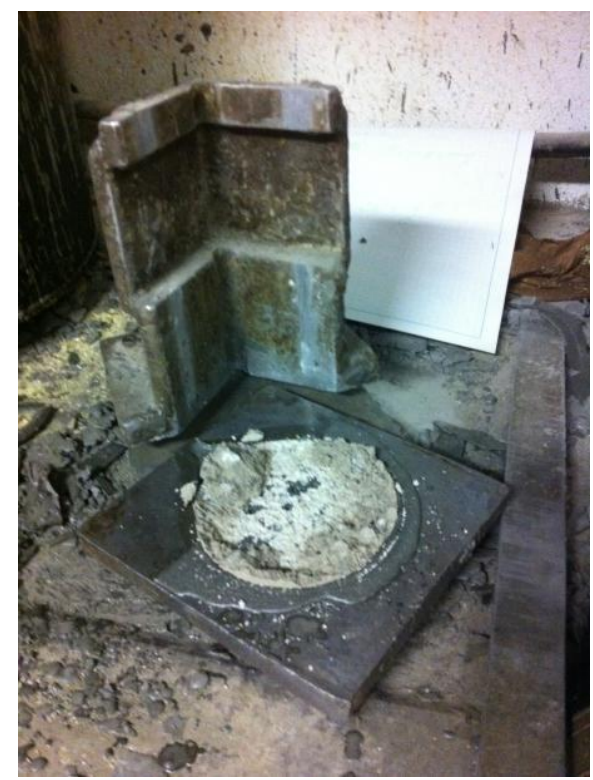

Figure 3.6: residues of broken cylinder attached to capping jig

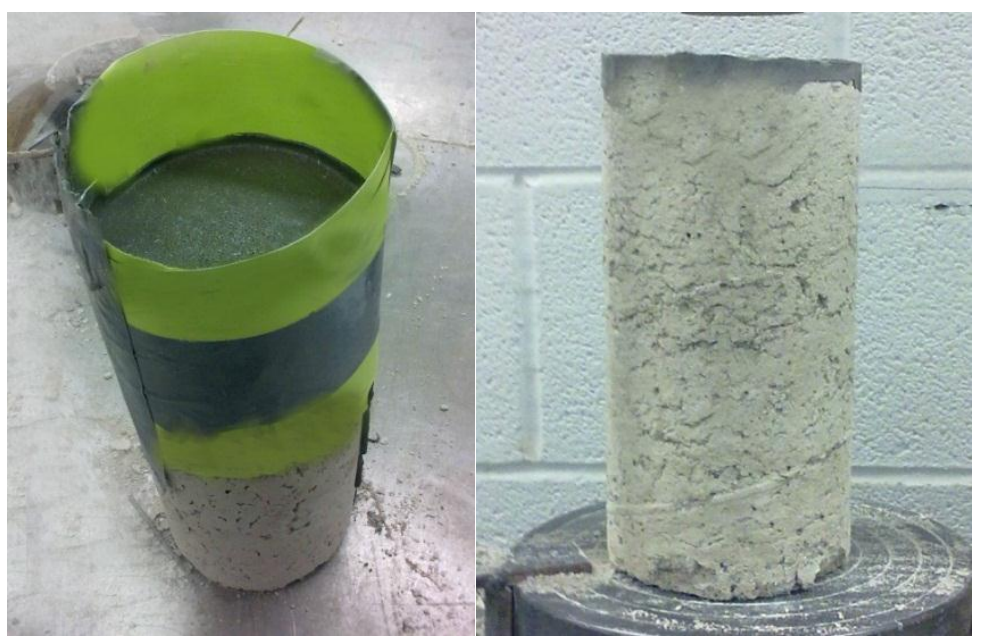

Figure 3.7: Alternative capping method (left), Cylinder capped using alternative method (right) 
After capping was completed, the samples were tested for compressive strength. The loading mechanism used was able to show a load change of 1 Newton. Once the sample began to deform significantly, or showed a sharp drop in resisting force, the test was ended. Appearance of small diagonal cracks also indicates the sample has been loaded past failure Crushing forces were recorded and converted into units of MPa using the sample effective surface area.

\subsubsection{Hardening Time}

To measure hardening time, the ball drop test as per ASTM D6024 was used. A ball drop apparatus with a weight of 14-15 kg was set upon two $9 \times 9 \times 18 \mathrm{~cm}$ wooden blocks (Figure 3.8). The mixes were considered hardened when the indentation left by the ball drop apparatus was less than $76 \mathrm{~mm}$ in diameter. For lab mixtures, the U-fill was cast and tested in wooden boxes of the dimension $70 \times 45 \times 13 \mathrm{~cm}$ (Figure 3.9). For the field trenches, the test was done on top of the U-fill mixtures within the trench after pouring. The ball drop apparatus was then used several times at various time increments until an indentation of $76 \mathrm{~mm}$ was observed. It must be noted that since the ball drop apparatus is set upon the mixtures surface, it can be used only after bleed water has dissipated outwards or evaporated.

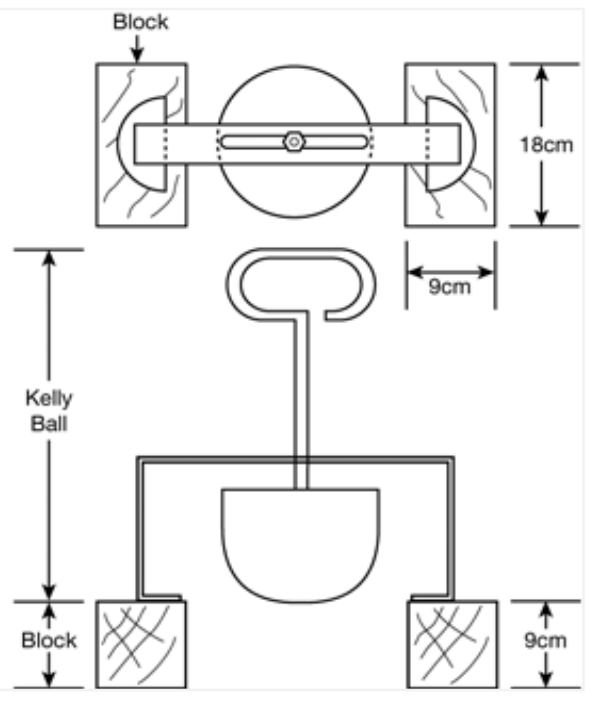

Figure 3.8: Ball drop apparatus for measuring hardening time (ASTM C6024) 


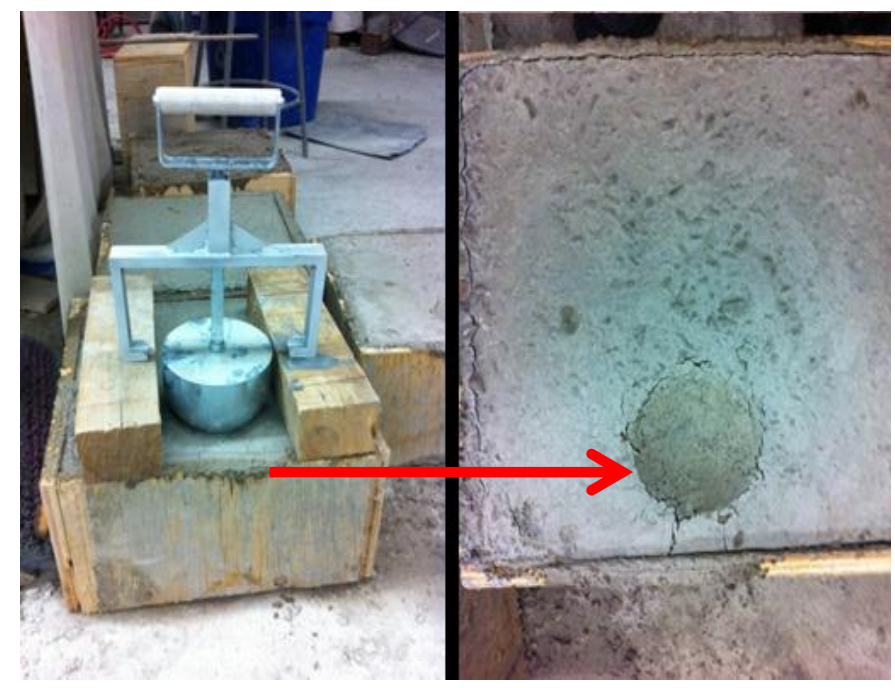

Figure 3.9: Ball drop apparatus (left) indentation left by the ball drop apparatus (right)

\subsubsection{Mortar Bar Preparation and Analysis}

\subsubsection{Mortar Bar Casting and Demoulding Procedure}

In order to measure for expansion due to internal sulphate attack, mortar bars were prepared using a modified version of ASTM C452. Since cement content in U-fill mixes is much lower than that of conventional concrete or in standard mortar bars, an aggregate to cement ratio of 11:1 and a water to cement ratio of 1.9, excluding the absorption of aggregate, was used instead of the specified 2.75:1 aggregate to cement ratio and 0.485 water to cement ratio outlined in ASTM C452. Where mortar bars were found to be too weak, these proportions were adjusted. In determining the proper water to cement ratio and aggregate to cement ratio's for the mortar bars, several trial mixes were produced. The ratios where then selected based on the mix designs with the highest water to cement and aggregate to cement ratio where bars would not break.

In order to ensure homogeneity of the mortar mixes, dry ingredients were mixed at low speed to prevent loss of fines. As a source of sulphate $\mathrm{Na}_{2} \mathrm{SO}_{4}$ and gypsum were used in the mortar bar mixtures. Due to the high binding ability of gypsum, it was ensured that it is added while all ingredients and mixing bowl are completely dry to prevent agglomeration of the fine 
aggregates. Where $\mathrm{Na}_{2} \mathrm{SO}_{4}$ was used, this compound was dissolved into the mixing water then added to the dry ingredients within the mix.

Due to the high water content within the mortar bar mixes, compaction of fresh mixes within the mortar bar moulds resulted in excessive bleeding and accumulation of water on the top surface of fresh mixes. When hardened, the top $3-4 \mathrm{~mm}$ of the exposed surfaces were easily breakable (Figure 3.10). To reduce the effects of bleeding, compaction of fresh samples within the mortar bar moulds was kept to a minimum and mixes were only slightly compacted near and around studs to ensure proper bonding.

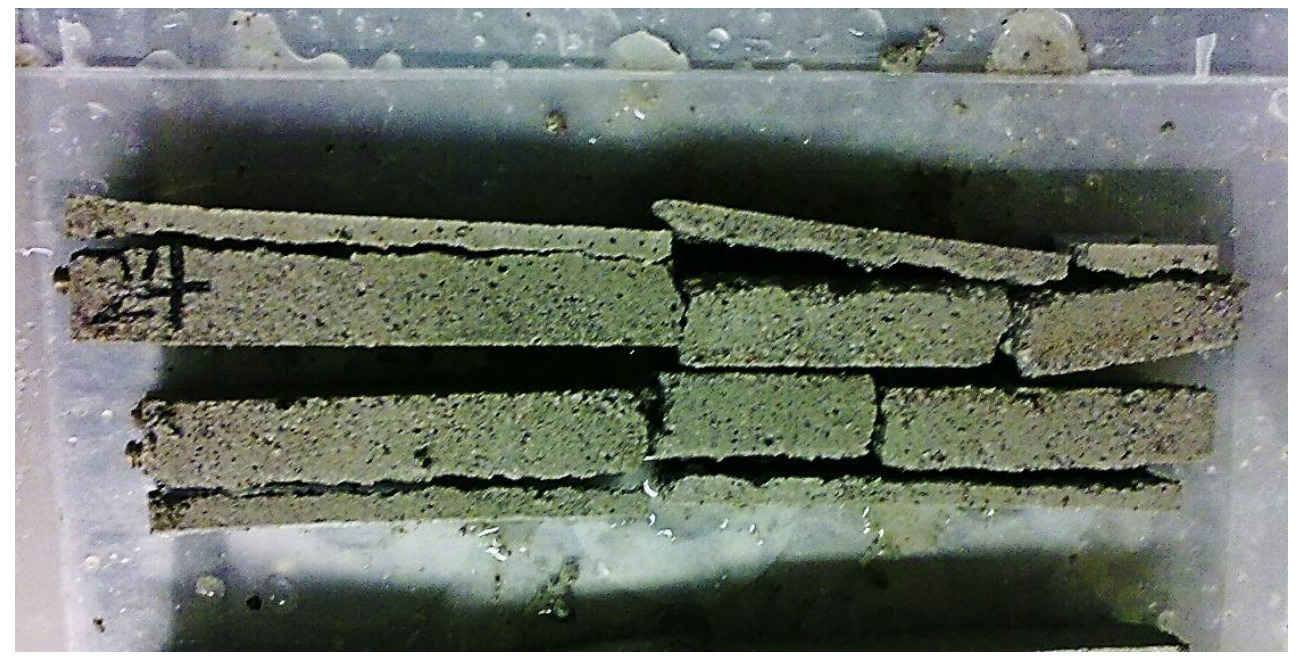

Figure 3.10: Side view of mortar bars with broken surface caused by bleeding

Prior to casting, mould were coated with a thin layer of a mould release agent. Once tamping of the fresh mixes was completed, the top surfaces of the mortars were lightly levelled using a trowel. Moulds were then cured at $40^{\circ} \mathrm{C}$ for 24 hours prior to demoulding.

To demould mortar bars, once unscrewed, all corners of the moulds were tapped with a light force to prevent cured mortar bars from breaking. Once demoulded, the bars were stored in plastic containers and saturated in a limewater solution. All samples were then stored at either $23^{\circ} \mathrm{C}$ or $5^{\circ} \mathrm{C}$ to investigate Ettringite and Thaumasite formation. 


\subsubsection{Mortar Bar Expansion Measurement}

Test bars were measured every week using a length comparator in accordance with ASTM C157 (Figure 3.11). Percent length changes were then plotted against sample age. All bars were conditioned to room temperature twenty four hours prior to measurement. To ensure that correct readings are obtained, the length comparator was calibrated after every 6 readings.

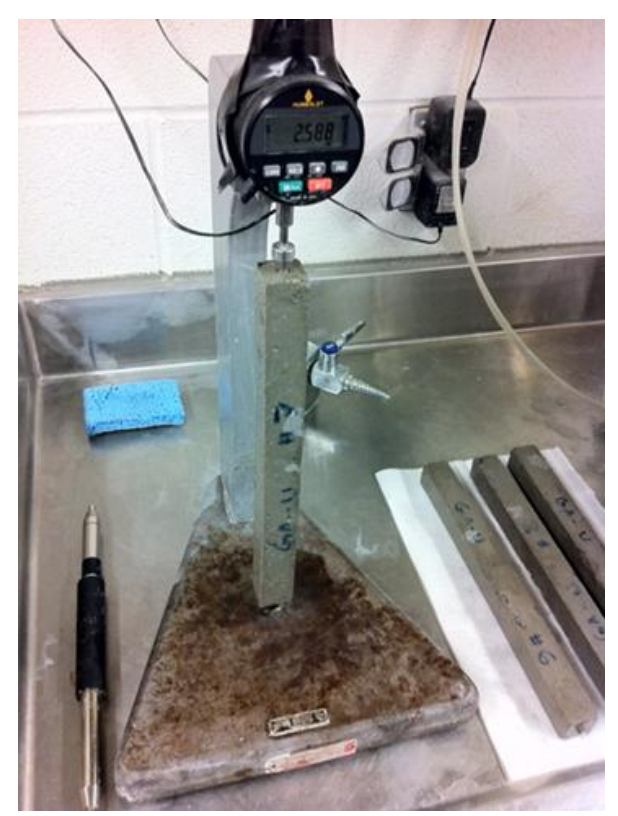

Figure 3.11: Mortar bar measurement using length comparator

\subsubsection{Analyzing Deterioration Mechanism Using Scanning Electron Microscopy (SEM)}

Scanning Electron Microscopy (SEM) was used to investigate the deterioration mechanism of mortars containing high sulphate content. Scanning Electron Microscopy (SEM) is petrography method which uses high energy electrons to produce various signals at the surface of a sample. These signals reveal information such as the orientation, location and composition of crystalline structures, and overall amount and composition of the chemical compounds existing within the 
specimen (Swapp, 2012). Once electrons are accelerated towards the surface of the specimen, it can either pass through the sample without any interaction or undergo elastic or inelastic scattering.

Data can either be collected over a selected area or on a selected point which is an ideal method to use where chemical composition and/or studying the crystalline structure are required. Samples being examined under SEM must be of size that fits within the SEM chamber (Figure 3.12).

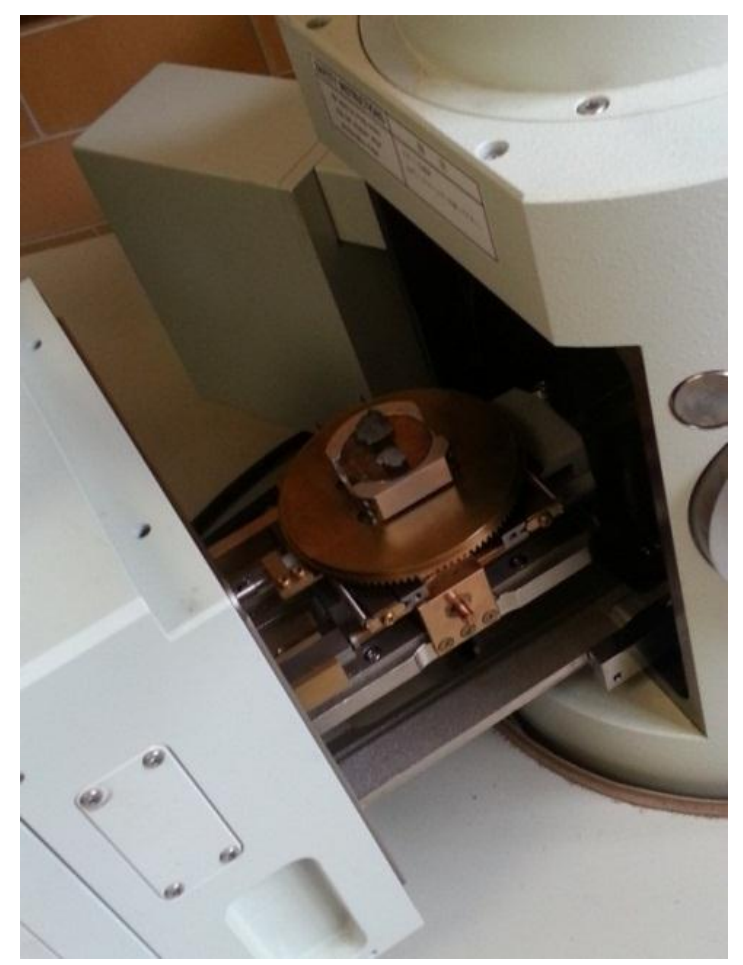

Figure 3.12: Mounted sample placed into SEM chamber

Due to the weakness of the mortar bars made in this research program, samples could not be studied as polished surfaces rather they were studied as fractured surface samples. Mortar bars were crushed and set into a vacuum chamber for a period of one weak to be dried. After this period, the samples were mounted onto a baseplate using double-sided carbon tape. The surfaces of the samples were then coated using gold coating and degassed. Since Ettringite and 
Thaumasite crystals tend to form in cracks and voids within concrete, these areas were mainly investigated. Both point and area analysis was done where crystalline structures were detected. As mentioned previously, due to the similarities between Thaumasite and Ettringite differentiating the two visually could be rather difficult; however, chemical analysis of the crystalline structure of Ettringite tends to show three distinctive peaks of Aluminum, Sulfur and calcium while Thaumasite has the peaks of Silicon, sulfur and calcium. Therefore identification of crystals was mainly accomplished through the analysis of the chemical composition of the crystalline structures. 


\subsection{Summary of Experimental Program and Significance}

\subsubsection{Expansion Due to Internal Sulphate Attack}

In this phase of the research program, a series of experiments were carried out in order to determine the causes and effects of internal sulphate attack. A summary of the tests carried out in this stage are shown below:

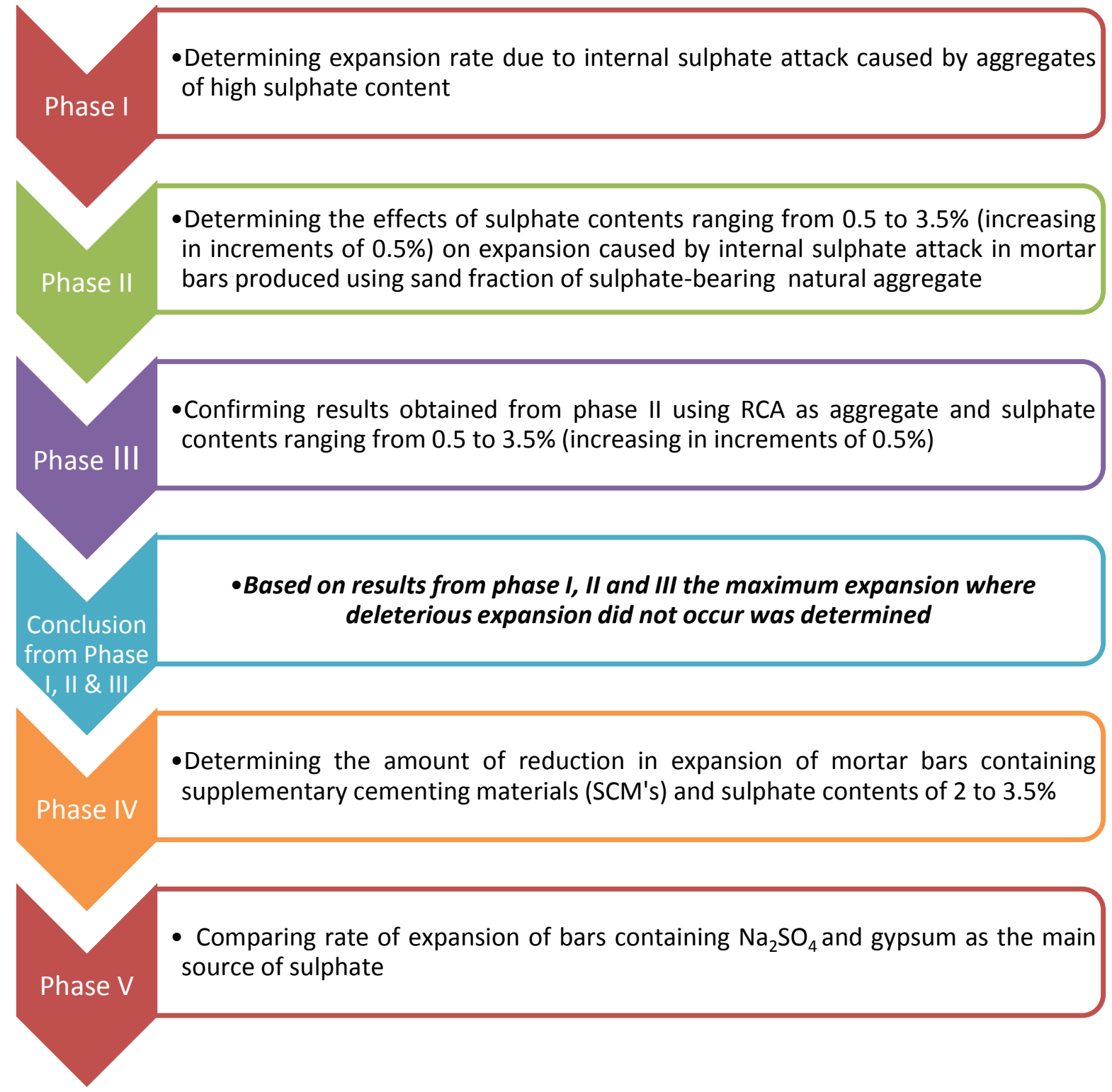

Figure 3.13: Experimental program for investigating causes and mitigation methods for internal sulphate attack 


\subsubsection{Phase I: Determining the Effects of High Sulphate Contents on Durability of U-fill Mixes}

In the preliminary stages of the sulphate testing program, mortar bars were produced using granular aggregate with high sulphate contents (vinemount aggregate). A total of three sets of bars were produced in this stage. The first batch was produced using concrete sand as a reference sample, the second and third batch were produced using the sulphate bearing aggregate in one of two ways:

- Aggregate fines: The fine portion of the sulphate bearing aggregate $(<4.75 \mathrm{~mm})$ was taken as sieved and used in producing mortar bars based a modified version of ASTM C452 where the total sulphate content in the fine portion of the aggregate was determined to be $3.23 \%$ (Table 3.3).

- Crushed coarse: The coarse portion of the aggregate $(>4.75 \mathrm{~mm})$ was crushed into fines and used to make a third batch of mortar bars. Total sulphate content in the crushed portion of the granular aggregate was $0.94 \%$ (Table 3.3).

It was predicted that due to the existence of sulphates within the aggregate, deterioration could occur as a result of internal sulphate attack, either by the formation of Ettringite or Thaumasite. As discussed in section 2.3, Ettringite is formed when sulphate react with calcium aluminate present from the cement. This reaction can cause expansion and a decrease in bond between the paste and aggregate. In addition, sulphates can react with silica from the hydration products of cement (calcium silicate hydrates) in the presence of carbonate ions, and form Thaumasite. As a result of this reaction, the concrete paste breaks down into a mud-like paste.

Since the formation of Thaumasite is favored at lower temperatures $\left(<5^{\circ} \mathrm{C}\right)$, three sets of bars containing the crushed coarse portion of the sulphate bearing aggregate, the fine portion and lastly a control sample containing concrete sand were kept in a fridge at $5^{\circ} \mathrm{C}$. Also since 
Ettringite formation is favored at higher temperatures $\left(23\right.$ to $70{ }^{\circ} \mathrm{C}$ ) an additional set of bars with identical composition as those stored at $5^{\circ} \mathrm{C}$, were made and stored at $23^{\circ} \mathrm{C}$.

\subsubsection{Phase II: Determination of Maximum Limit of Sulphate Content}

As a result of the initial findings, it was necessary to determine the maximum amount of sulphate where significant expansion and deterioration would not occur. To find a limit for maximum sulphate content, natural aggregate with a total sulphate content of $0.5 \%$ was used in producing another set of bars. To determine the limits for expansion, gypsum (plaster of Paris) was added into the mortar mixes in order to increase the overall sulphate content. Mortar bars were produced with sulphate contents of $0.5,1,1.5,2,2.5,3$ and $3.5 \%$. Since the

phase I tests exhibited higher expansion at lower temperature, bars in this stage were only stored at $5{ }^{\circ} \mathrm{C}$ and saturated in lime water solution. These bars were then measured periodically every week for one year. Mix proportions were similar to mortar bars produced in phase I.

\subsubsection{Phase III: Confirming Limit Using RCA as Aggregate}

To confirm the results obtained from phase II, and also to explore the possibility of using RCA aggregate of lower quality in unshrinkable fill mixes, RCA aggregate was used in this phase to produce mortar bars. As in phase II, in order to increase sulphate content within these bars, gypsum was introduced into the mixes. Mortar bars were produced with sulphate contents ranging from 0.5 to $3.5 \% \mathrm{SO}_{4}$, increasing in increments of 0.5 . Due the high amount of absorption of residual paste in recycled aggregate, water to cement ratio was slightly increased where flowability of mortar mixes were low, in order to better simulate actual U-fill mixtures. 


\subsubsection{Phase IV: Reduction of Expansion Using Supplementary Cementing Material (SCM)}

As a mitigation method for reducing expansion due to internal sulphate attack, Ground Granulated Blast Furnace Slag (GGBFS) and Metakaolin were incorporated into mortar bar mixes. It has been seen in in previous research that SCM's have the ability to reduce the overall expansion due to both external and internal sulphate attack. To investigate the amount of reduction caused by the addition of SCM's, three sets of bars were produced in this phase:

1. $30 \%$ GGBFS-70\% Portland cement

2. $50 \%$ GGBFS- $50 \%$ Portland cement

3. $10 \%$ Metakaolin- $90 \%$ Portland cement

All mixes were made using RCA aggregate and similar to bars in the previous stages, gypsum was incorporated into the mixes as a source of sulphate. All bars were saturated in lime water solution and stored at $5{ }^{\circ} \mathrm{C}$ and measured every week for expansion. An aggregate to cement ratio of 9:1 and water-to-cement ratio of 2.1 was used in producing these bars. Properties of the cementing material used in this phase are summarized in Table 3.9.

\subsubsection{Phase V: Using $\mathrm{Na}_{2} \mathrm{SO}_{4}$ as an Alternative Source of Sulphate in Mortar Bars}

Sulphate is known to exist within aggregates in the form of various compounds, namely gypsum or $\mathrm{Na}_{2} \mathrm{SO}_{4}$. It had been speculated that due the overall higher rate of solubility of $\mathrm{Na}_{2} \mathrm{SO}_{4}$ compared to gypsum, rate of expansion would significantly differ. Also, it was hypothesized that where gypsum is added to mixtures as the main source of sulphate, compounds necessary to form Ettringite and Thaumasite are both readily available and thus expansion would be much more pronounced rather than where sulphates are supplied through $\mathrm{Na}_{2} \mathrm{SO}_{4}$. To confirm This matter, the following two sets of mortar bars were produced in phase V: 
1) Bars containing $0.5,1,1.5,2,2.5,3$ and $3.5 \% \mathrm{SO}_{4}$, with sulphate added as $\mathrm{Na}_{2} \mathrm{SO}_{4}$ : This set was produced in order to determine the variation in expansion rate in mortar bars, where $\mathrm{Na}_{2} \mathrm{SO}_{4}$ is used as the source of sulphate rather than gypsum. Expansion results obtained from these bars were compared to results obtained in phase III from bars containing gypsum as sulphate and RCA as aggregate.

2) Bars containing 2.5, 3 and $3.5 \% \mathrm{SO}_{4}$ with sulphate added as $\mathrm{Na}_{2} \mathrm{SO}_{4}$ and $30 \%$ Slag: These bars were produced in an attempt to determine the effects of supplementary cementing materials such as slag on the amount of reduction in expansion caused by internal sulphate attack where $\mathrm{Na}_{2} \mathrm{SO}_{4}$ is used as the source of sulphate. Expansion results obtained from this set was then compared to results obtained in phase IV from bars containing gypsum as the source of sulphate, RCA as aggregate and $30 \%$ slag.

\subsubsection{Simulation of Field Conditions By Means of Alternative Moulds}

Based on initial results obtained by tests on expansion caused by over-sulphated aggregate, it was necessary to determine the overall force or displacement that expansion due to internal sulphate attack could cause on surface layers such as asphalt or concrete pavements. To do so, mixes containing Vinemount aggregate with a total sulphate content of 3.23\% were used within a U-fill mixture with a total cement content of $25 \mathrm{~kg} / \mathrm{m}^{3}$. Mixes were then poured into plastic moulds as shown in (Figure 3.14) and saturated in a limewater solution at $5^{\circ} \mathrm{C}$. Holes were drilled around the circumference and under the moulds in order to allow for complete saturation of the mixtures. A thick absorbent cloth was used to line the interior of the moulds to insure uniform saturation throughout the mixture. A surcharge with an approximate weight of $2.5 \mathrm{~kg}$ was set on top of the mixtures. Dial gauges were put into contact at three points of the surcharge and reading were taken periodically from each dial gauge and expansion was calculated. 


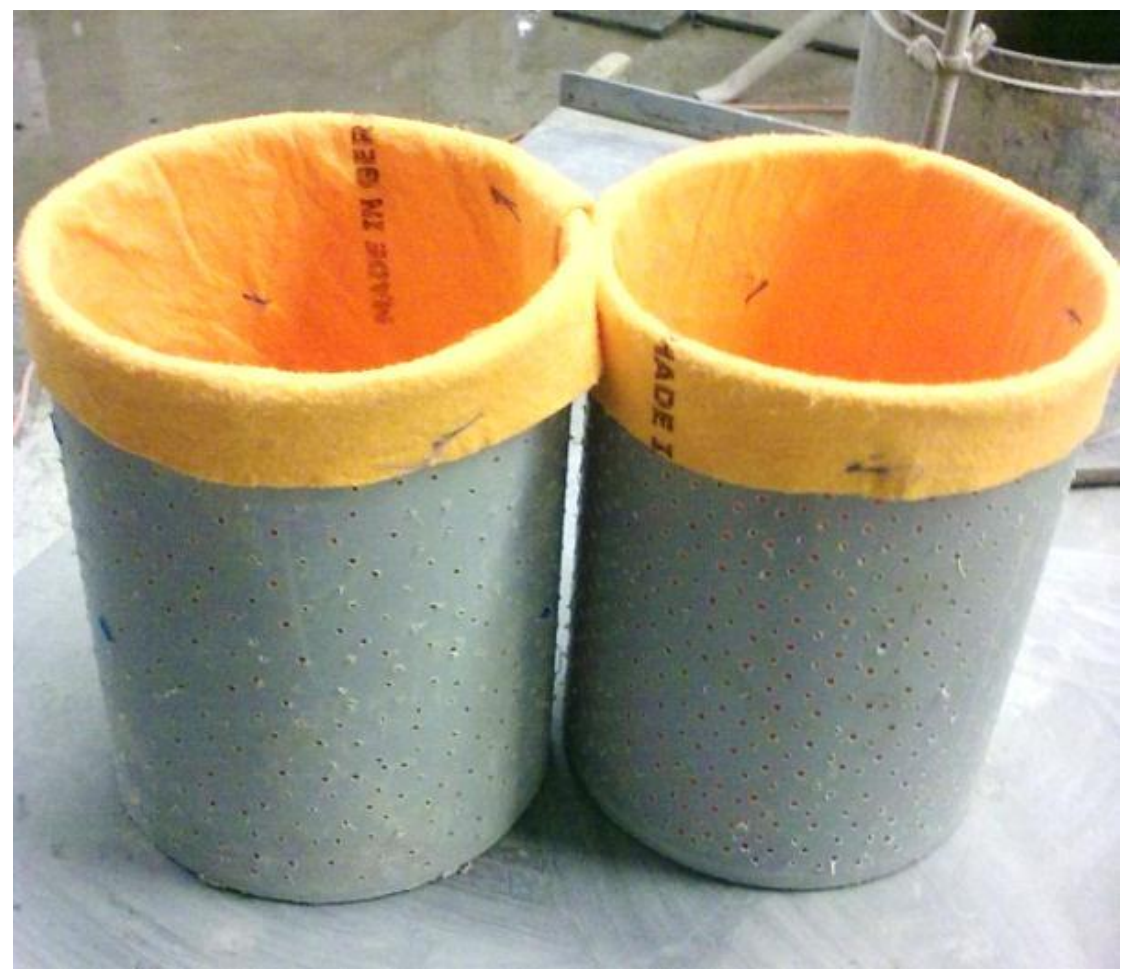

Figure 3.14: Alternative moulds produced for the simulation of field conditions 


\subsubsection{Preparation of Laboratory and Field Trial U-fill Mixes}

This phase of the research program was done in order to investigate the physical properties of U-fill mixtures containing various percentages of low or marginal quality aggregate. The following figure summarizes the steps taken in this phase of the experimental program:

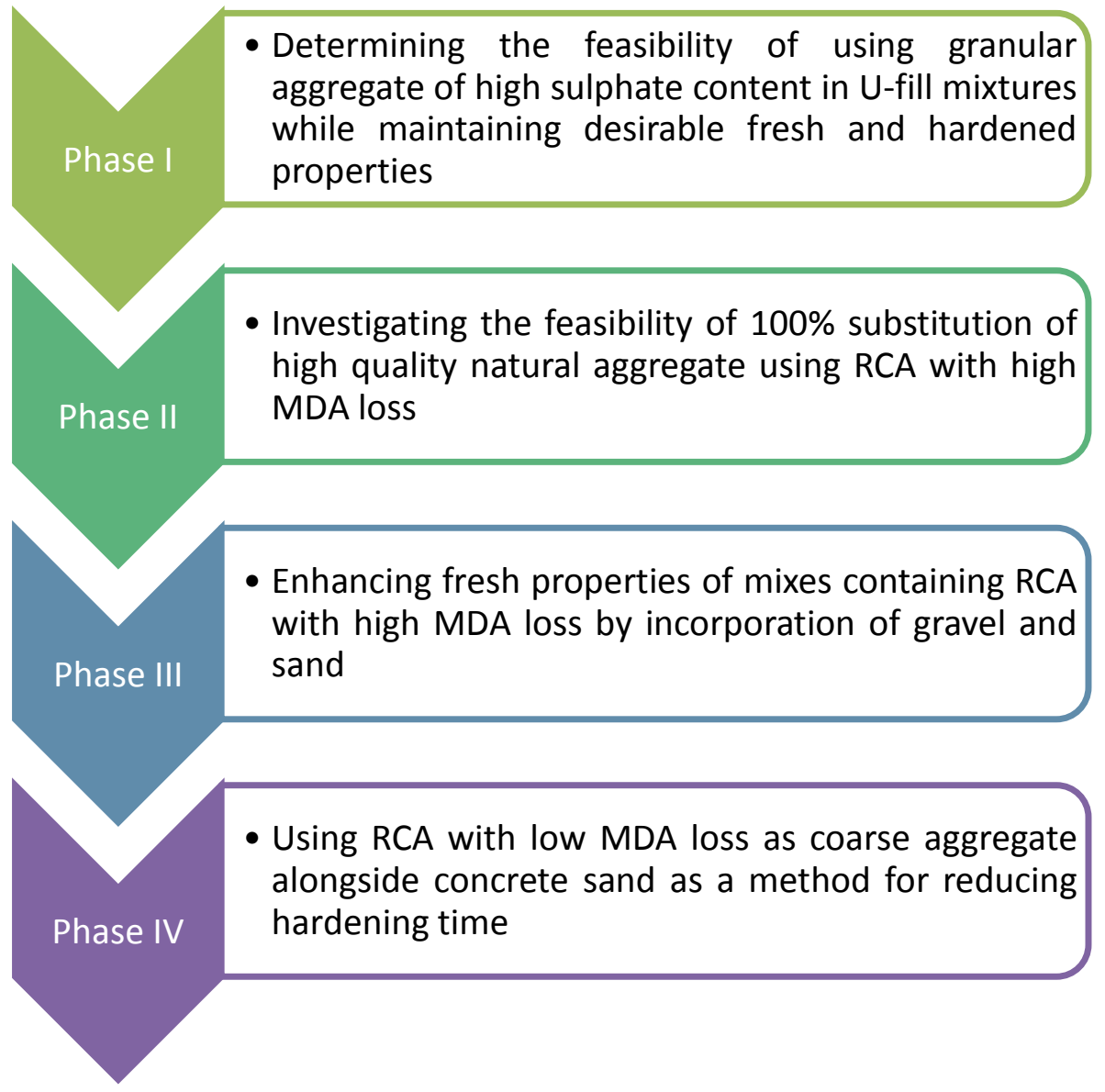

Figure 3.15: Experimental program for investigating the feasibility of using aggregates of marginal quality within U-fill mixtures 


\subsubsection{Phase I: Mixes containing Out-of-Specification Granular Aggregate}

The use of granular aggregate which did not meet requirements for concrete aggregate (OPSS 1002) has been investigated in this research program. Properties of the aggregate used in this stage are summarized in Table 3.1,Table 3.2,Table 3.5, Figure 3.1 and Figure 3.2. Mixes in this phase were produced with water contents of 160,185 , and $220 \mathrm{~kg} / \mathrm{m}^{3}$. From the preliminary tests it was observed that mixes containing solely granular aggregate experienced severe bleeding and segregation. Therefore, sand was integrated into the mixes alongside granular aggregate used initially in order to enhance the fresh and hardened properties. Mixes were produced using $15 \%$ and $25 \%$ sand and tested for hardening time. Compressive strength of each mix was also measured at 7 and 28 days to ensure compliance with OPSS 1359.

\subsubsection{Phase II: Mixes Containing RCA}

The following two sets of laboratory mixes were prepared in order to determine the feasibility of producing U-fill containing only RCA aggregate:

- $1700-1850 \mathrm{~kg} / \mathrm{m}^{3} \mathrm{RCA}, 25 \mathrm{~kg} / \mathrm{m}^{3}$ type GU Portland cement and water contents of 160 , 185 and $220 \mathrm{~kg} / \mathrm{m}^{3}$ (Mix\#1, 2 \& 3).

- $1700-1830 \mathrm{~kg} / \mathrm{m}^{3} \mathrm{RCA}, 25 \mathrm{~kg} / \mathrm{m}^{3}$ of Ground granulated blast furnace slag (no Portland cement), and water contents of 160, 185 and $220 \mathrm{~kg} / \mathrm{m}^{3}$ (Mix \#4, 5 and 6). Ground granulated blast furnace slag (GGBFS) was investigated as a sustainable and economical alternative for Portland cement.

To further evaluate the performance of each mix, field tests were done using optimized mixes from each set and evaluated for their fresh and hardened properties. A total of three trenches were excavated into stiff, clay soil, locally known as the Halton Till, a thick over consolidated glacial deposit characterized by poor drainage. Each trench had an approximate size of $2.5 \mathrm{~m}^{3}$. 
Batches were poured in after approximately 10 minutes of mixing time. Where needed, water content of the field trial mixes was adjusted to enhance flowability.

\subsubsection{Phase III: Incorporating Gravel into RCA Mixes as a Method to Reduce Hardening Time}

In order to enhance the fresh and hardened properties, particularly in terms of achieving shorter hardening time, mixes from phase II were modified using various percentages of gravel, sand and RCA. Mixes in this phase were made with the aim of achieving a quicker hardening time while maintaining minimal segregation and high flowability. The first five mixes were produced using RCA and gravel only. The mix proportions were as follows:

Table 3.10: Phase III lab mixes containing RCA and gravel

\begin{tabular}{|c|c|c|c|}
\hline Mix \# & RCA & Gravel & Water $\left(\mathbf{k g} / \mathbf{m}^{\mathbf{3}}\right)$ \\
\hline 7 & $70 \%$ & $30 \%$ & 180 \\
\hline 8 & $70 \%$ & $30 \%$ & 220 \\
\hline 9 & $50 \%$ & $50 \%$ & 220 \\
\hline 10 & $80 \%$ & $20 \%$ & 185 \\
\hline 11 & $80 \%$ & $20 \%$ & 220 \\
\hline
\end{tabular}

For all the above mixtures, the Portland cement content was $25 \mathrm{~kg} / \mathrm{m}^{3}$.RCA and gravel are expressed as \% of total aggregate content. It was observed from these mixes that more fine aggregate is required to further reduce segregation. Therefore sand was also incorporated into three mixes with the proportions indicated in table 3.11 . 
Table 3.11: Phase III mixes containing gravel, RCA \& sand

\begin{tabular}{|c|c|c|c|c|}
\hline Mix \# & Gravel & RCA & Sand & Water $\left(\mathbf{k g} / \mathbf{m}^{\mathbf{3}}\right)$ \\
\hline 12 & $50 \%$ & $30 \%$ & $20 \%$ & 220 \\
\hline 13 & $40 \%$ & $30 \%$ & $30 \%$ & 220 \\
\hline 14 & $30 \%$ & $40 \%$ & $30 \%$ & 220 \\
\hline
\end{tabular}

Portland cement was kept at $25 \mathrm{~kg} / \mathrm{m}^{3}$ and water was adjusted to obtain the required workability (a minimum of $150 \mathrm{~mm}$ slump). The hardening time and flowability of each mix was evaluated.

Optimized mixes produced from the combination of the three aggregates were then tested in a field trial and compared to results obtained from laboratory mixes. Field trial trenches in this phase were also excavated into Halton Till (Figure 3.16).This was considered when choosing optimum water content, as pouring any concrete mixtures into clay type soil can hinder the ability of the mix to drain at a fast rate. Trench sizes were similar to those of Phase II $\left(2.5 \mathrm{~m}^{3}\right)$.

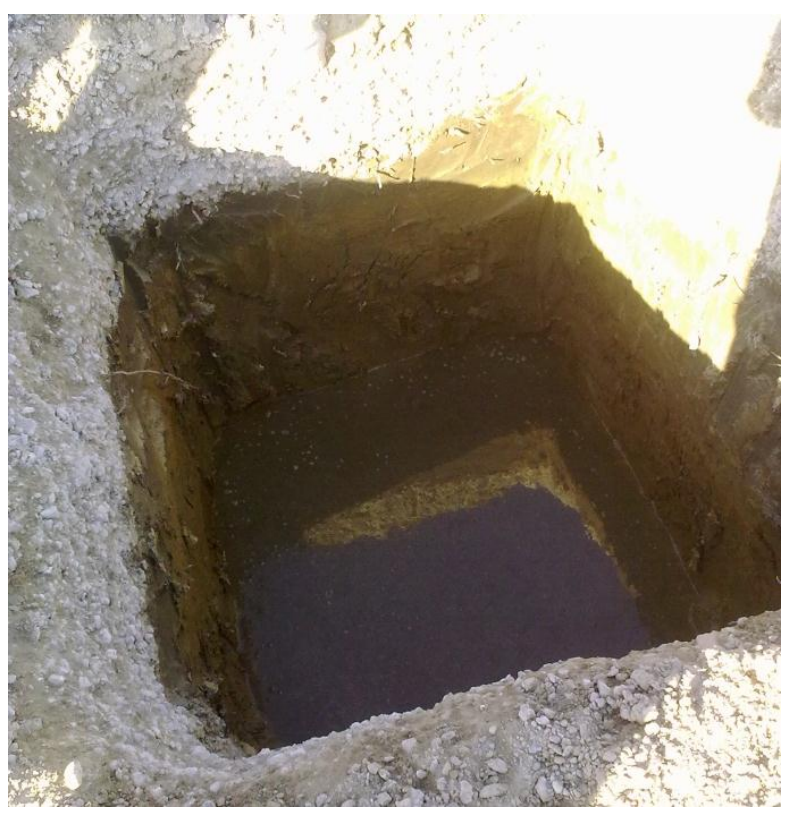

Figure 3.16: Trench excavated into clay-type soil 


\subsubsection{Phase IV: Mixes Containing Coarse RCA Aggregate of Low MDA Loss}

Based on observations from phase II and Phase III it was found that using RCA with low/marginal quality (not meeting OPSS 1002 requirements) will result in an extended hardening time. High amount of MDA loss and fines within the RCA used in phase II and III was proven to be problematic where low hardening time was desired. As a solution, it was decided to eliminate the use of RCA fines and only incorporate the coarse fraction into U-fill mixtures. By doing so, drainage reduction caused by highly absorbent RCA fines may be reduced. Furthermore, to reduce the total MDA loss, RCA of higher quality with low abrasion loss was used in this phase. The characteristics of the RCA aggregate incorporated within the U-fill mixes of this phase are summarized in Table 3.8. As it can be clearly seen, MDA loss of the RCA used in this phase is significantly lower than the RCA used in phase II and III (Table 3.6).To compensate for the absence of fines; concrete sand was used within the laboratory and field trial U-fill mixes. The compositions of phase IV laboratory mixes are summarized in Table 3.12.

Table 3.12: Phase IV laboratory mixes

\begin{tabular}{|c|c|c|c|c|}
\hline Mix \# & $\begin{array}{c}\text { \% Coarse aggregate } \\
\text { (RCA) }\end{array}$ & $\begin{array}{c}\text { \% Fine Aggregate } \\
\text { (Concrete sand) }\end{array}$ & $\begin{array}{c}\text { Water content } \\
\qquad\left(\mathrm{kg} / \mathrm{m}^{3}\right)\end{array}$ & $\begin{array}{c}\text { Cement content } \\
\qquad\left(\mathrm{kg} / \mathrm{m}^{3}\right)\end{array}$ \\
\hline Mix 1 & 80 & 20 & 190 & 25 \\
\hline Mix 2 & 70 & 30 & 190 & 25 \\
\hline Mix 3 & 60 & 40 & 190 & 25 \\
\hline Mix 4 & 55 & 45 & 190 & 25 \\
\hline
\end{tabular}

To test for hardening time and to be able to visually determine the amount of flowability, segregation and bleeding, laboratory mixes were poured into $62 \mathrm{~L}$ clear storage containers. Hardening time was measured in the same manner as described in section 3.2.1.3. No supplementary cementing material or admixtures were added to the mixes. Based on the 
results obtained from the laboratory mixes, the in-situ performance of two mixes were chosen to be investigated through a field trial. Trenches in this phase were excavated into a soil likely to be beach deposits (Figure 3.17). This soil was observed to be much more porous compared to that of phase II and III. It was speculated that drainage rate will be enhanced due to the faster water dissipation rate in these types of soils.

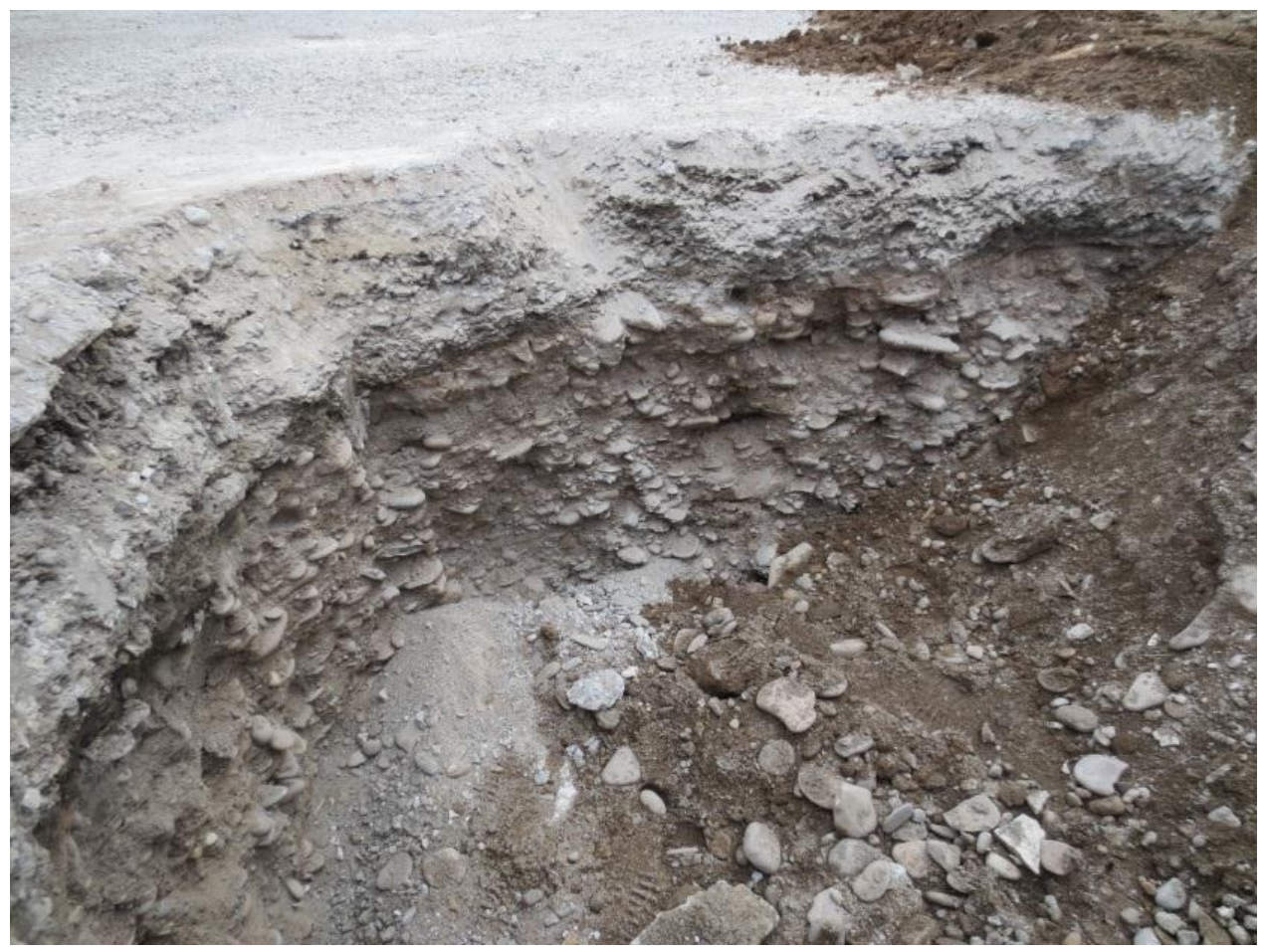

Figure 3.17: Phase IV trench excavated into porous soil 


\section{Chapter 4}

\section{Results and Discussion}

\subsection{Mortar bar expansion results}

\subsubsection{Phase I Results: Expansion of Mortar Bars Containing Aggregates of High Sulphate Content}

As stated in section 3.3.1.1, three sets of bars were produced in this phase, one containing concrete sand as a control batch, the second batch containing the fine as-sieved portion of the aggregate under study with a sulphate content of $3.23 \%$, and lastly a third batch containing the crushed coarse portion of the aggregate containing $0.94 \%$ SO4. The graph below shows the results obtained from expansion results of samples stored at $5{ }^{\circ} \mathrm{C}$ and $23^{\circ} \mathrm{C}$ (Figure $4.1 \&$ Figure 4.2).

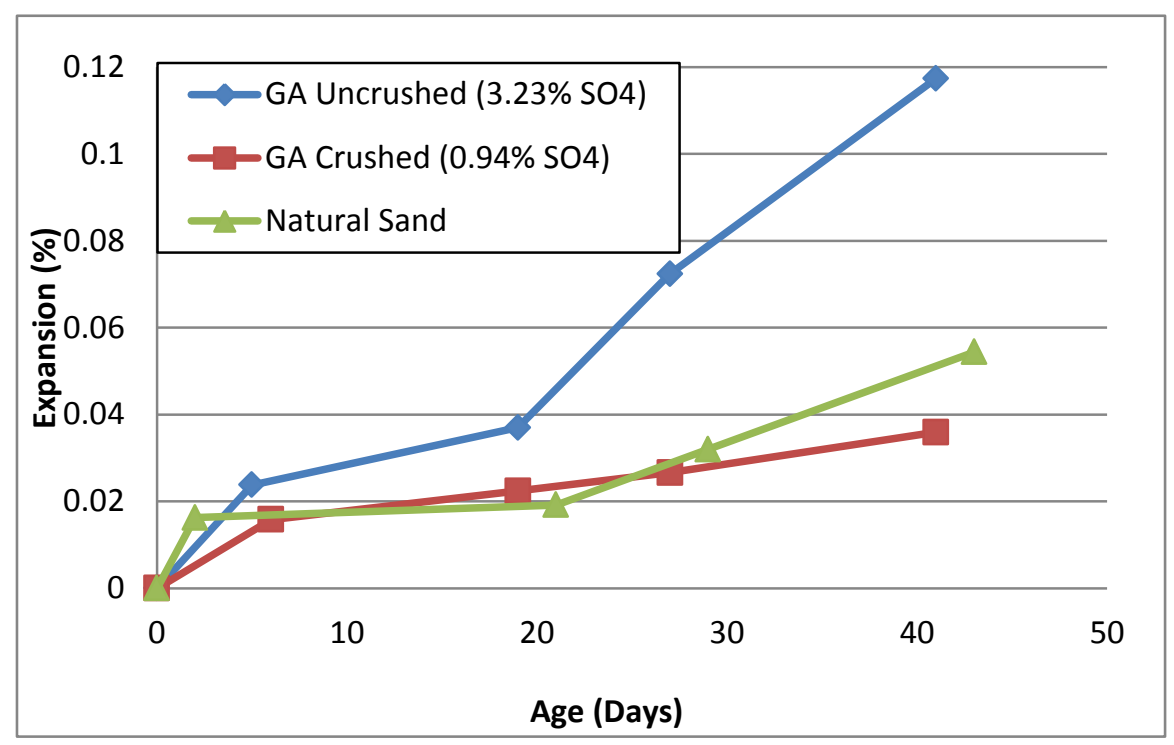

Figure 4.1: Expansion results of mortar bars stored at $5{ }^{\circ} \mathrm{C}$ 


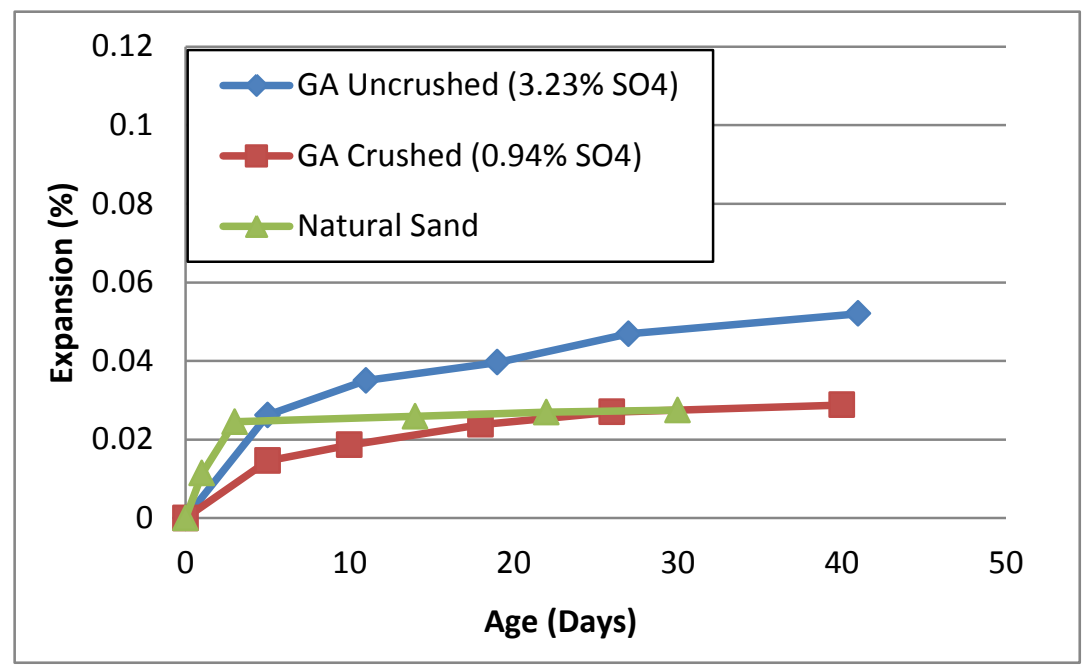

Figure 4.2: Expansion of mortar bars at $23 \mathrm{C}$

As it can be clearly seen from both graphs, bars containing the sand fraction with $3.23 \% \mathrm{SO}_{4}$ experienced the highest expansion, both at 23 and $5^{\circ} \mathrm{C}$ compared to bars containing crushed coarse aggregate $\left(0.94 \% \mathrm{SO}_{4}\right)$ and the control batch. Due to the low sulphate content in bars with $0.94 \% \mathrm{SO}_{4}$, expansion was insignificant and rather comparable to the control samples. Furthermore, overall expansion is clearly much higher at $5^{\circ} \mathrm{C}$. Maximum expansion of bars containing $3.23 \% \mathrm{SO}_{4}$ was found to be only $0.052 \%$ at $23^{\circ} \mathrm{C}$, whilst this amount increases to $0.117 \%$ at $5^{\circ} \mathrm{C}$, an increase of almost two folds (Figure 4.3 ).

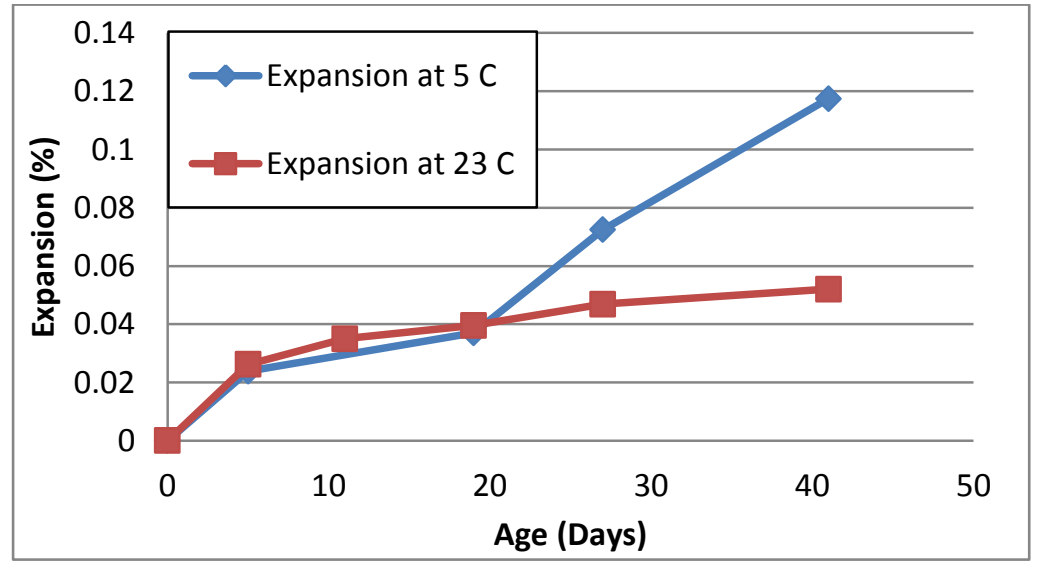

Figure 4.3: Comparison of expansion rate of mortar bars containing $3.23 \%$ SO4 at 23 and $5^{\circ} \mathrm{C}$ 
At only 41 days, bars made with uncrushed granular aggregate stored at $5^{\circ} \mathrm{C}$ were found to be completely deteriorated with no bond between aggregate and paste (Figure 4.4). However, due to the lower sulphate content, this deterioration was not observed in mortar bars containing the crushed coarse fraction of the Vinemount aggregate which had a total of $0.94 \%$ SO 4 .

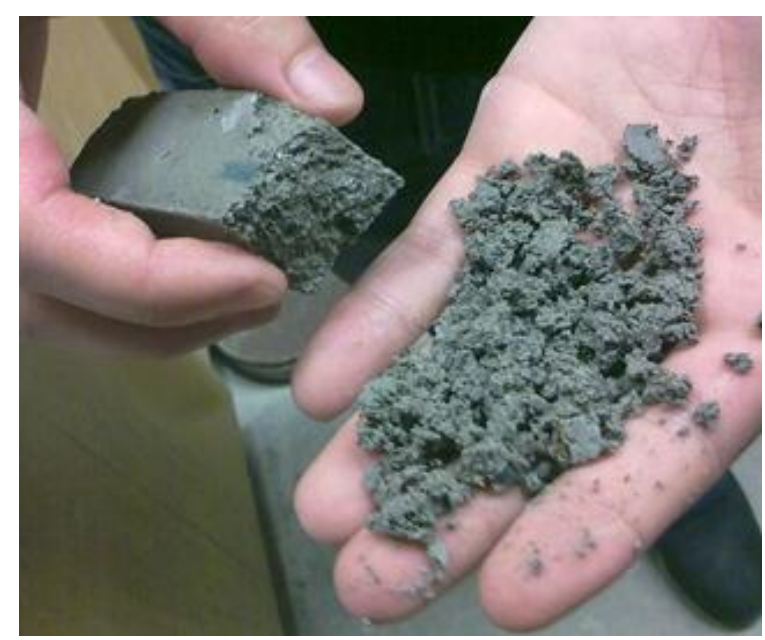

Figure 4.4: Loss of bond between aggregate \& paste due to internal sulphate attack

During this phase, it was assumed that the main mechanism behind the expansion of these bars is Thaumasite attack. At $23^{\circ} \mathrm{C}$ however expansion was presumed to be mainly due to the formation of Ettringite. Since Ettringite formation is highly dependent on the overall alumina content, using only a limited amount of cement resulted in less expansion, however, this was assumed to be not applicable to Thaumasite attack since only a limited level of alumina is needed for Thaumasite formation to occur.

To be able to examine samples and deterioration mechanism more closely, samples were casted in proctor moulds using aggregate containing $3.23 \% \mathrm{SO}_{4}$, cement content of $25 \mathrm{~kg} / \mathrm{m}^{3}$ and water content of $220 \mathrm{~kg} / \mathrm{m}^{3}$. After casting samples within the proctor moulds, they were saturated in limewater and kept at $5^{\circ} \mathrm{C}$. After only 30 days samples were found to be deteriorated and broken down into a mud-like paste (Figure 4.5 and Figure 4.6). Based on the observation retrieved from this experiment, it was confirmed that the main deterioration mechanism causing the failure is Thaumasite. 


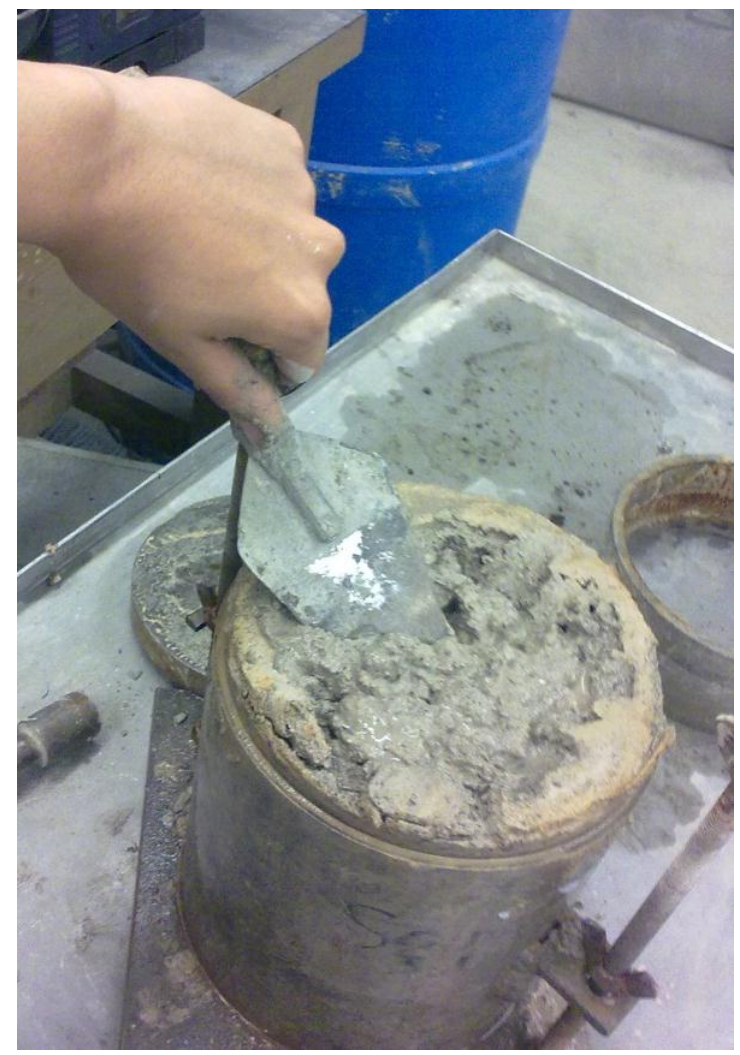

Figure 4.5: Sample deteriorated due to Thaumasite attack

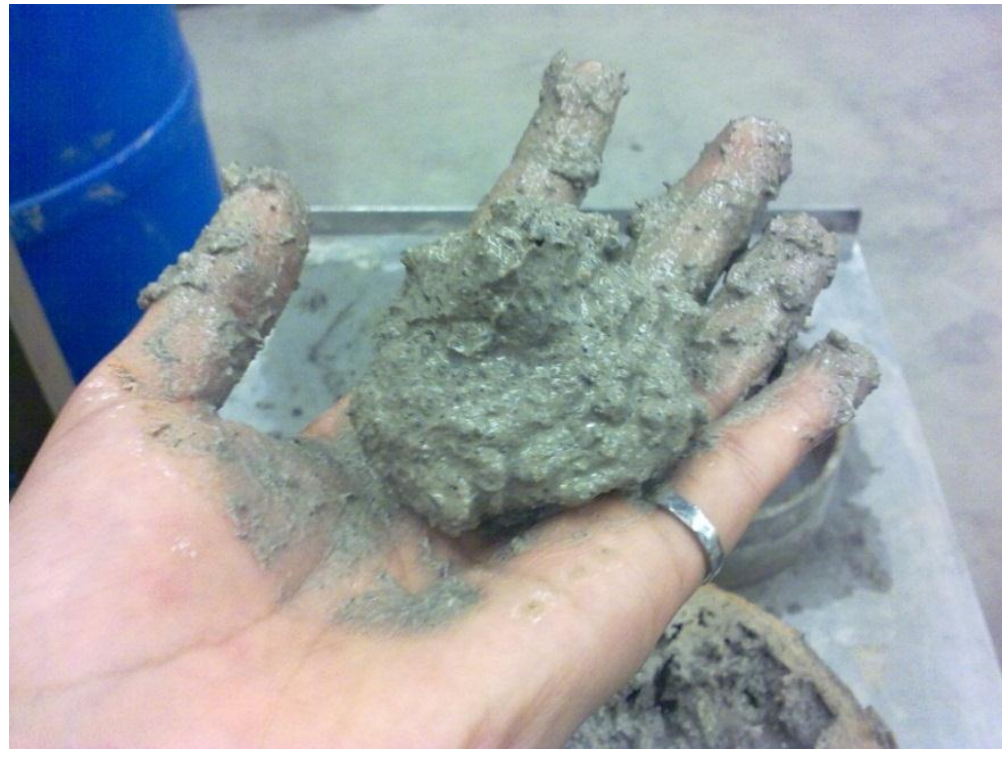

Figure 4.6: Sample deteriorated into a mud-like paste 


\subsubsection{Phase II Results: Determination of Expansion Rate at Various Percentages of Sulphate}

From expansion results obtained from phase I, it was concluded that in U-fill mixes where cement content is limited, the dominating form of internal sulphate attack would be Thaumasite. Moreover, it was seen that expansion is greater at higher percentages of sulphate at $5^{\circ} \mathrm{C}$ compared to bars containing lower amounts of sulphate $\left(0.94 \% \mathrm{SO}_{4}\right)$. To determine the maximum amount of sulphate where severe expansion would not occur, bars were produced with sulphate contents ranging from 0.5 to $3.5 \% \mathrm{SO}_{4}$, increasing in increments of 0.5 . Mortar bars were saturated in limewater solution and stored at $5^{\circ} \mathrm{C}$ and were measured periodically every week for up to nearly one year. Figure 4.7 shows the expansion results obtained from the mortar bars produced during this phase.

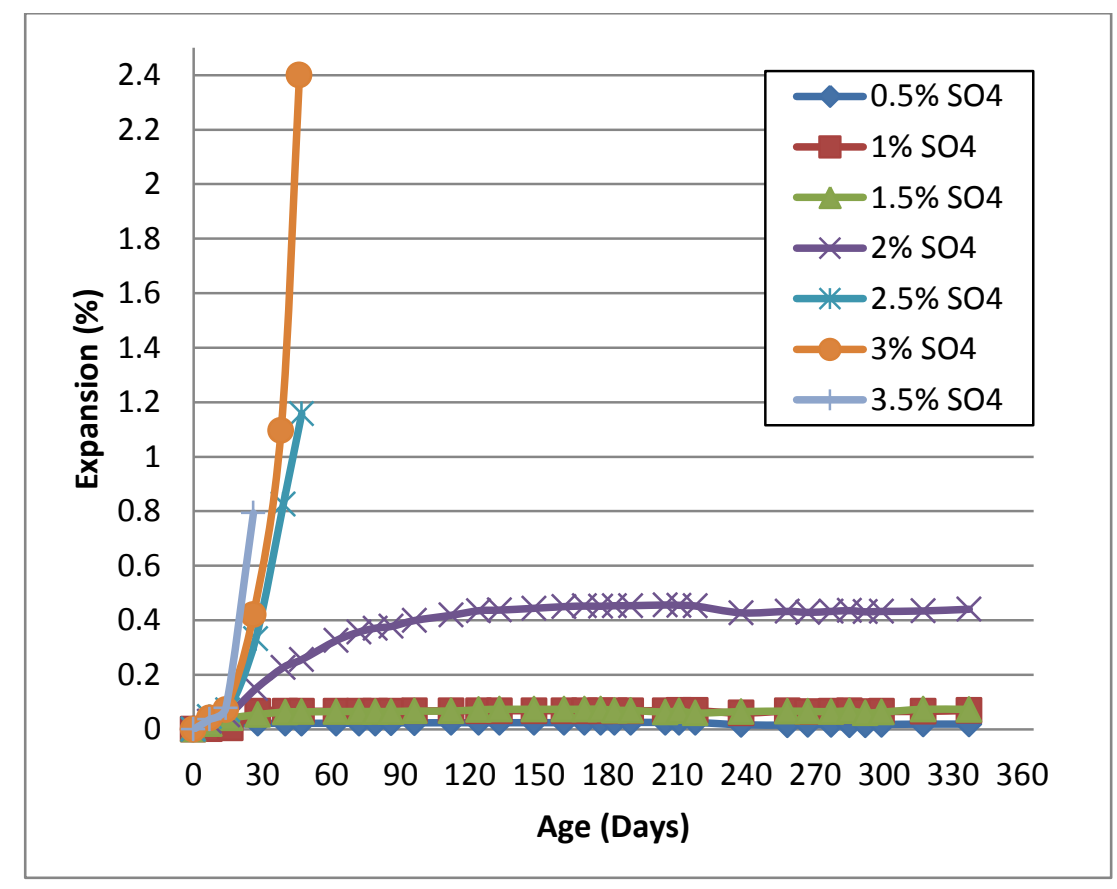

Figure 4.7: Expansion of mortar bars containing various percentages of $\mathrm{SO}_{4}$ stored in limewater solution at $5^{\circ} \mathrm{C}$ 
As seen in Figure 4.7, rate of expansion of bars containing $2.5,3$ and $3.5 \% \mathrm{SO}_{4}$ is significantly higher compared to those with sulphate contents of $2 \%$ or lower. At only 26 days, bars containing $3.5 \% \mathrm{SO}_{4}$, expanded up to $0.8 \%$ and were found to be severely deteriorated and did not have adequate strength to be held by hand (Figure 4.8). Prior to complete deterioration, bars containing higher percentages of sulphate $\left(2.5\right.$ to $\left.3.5 \% \mathrm{SO}_{4}\right)$ exhibited severe deformation which demonstrated the high rate of expansion in these bars (Figure 4.9).

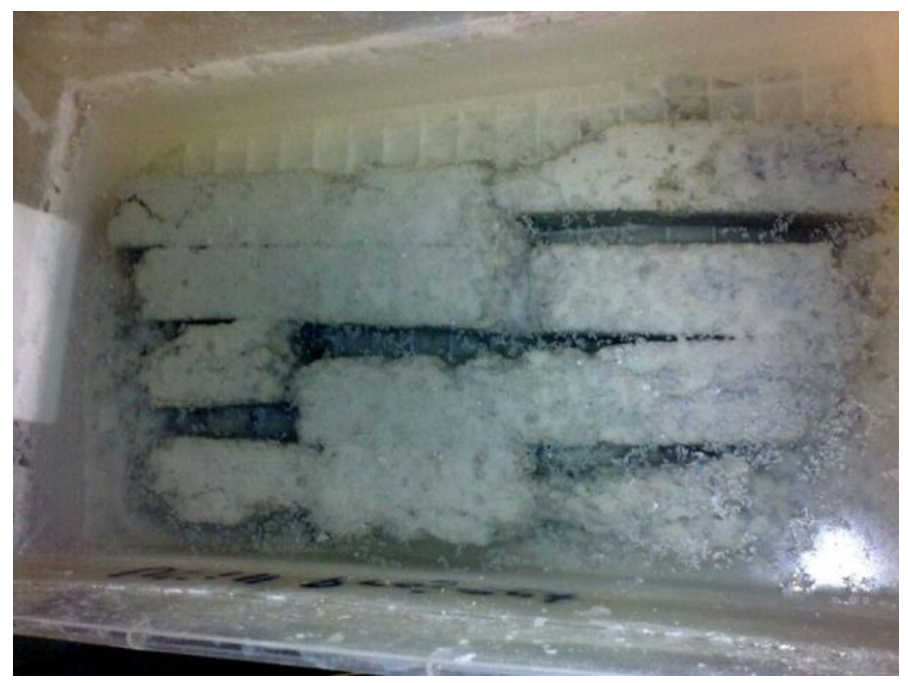

Figure 4.8: Deteriorated bars containing $3.5 \% \mathrm{SO}_{4}$ saturated in limewater solution

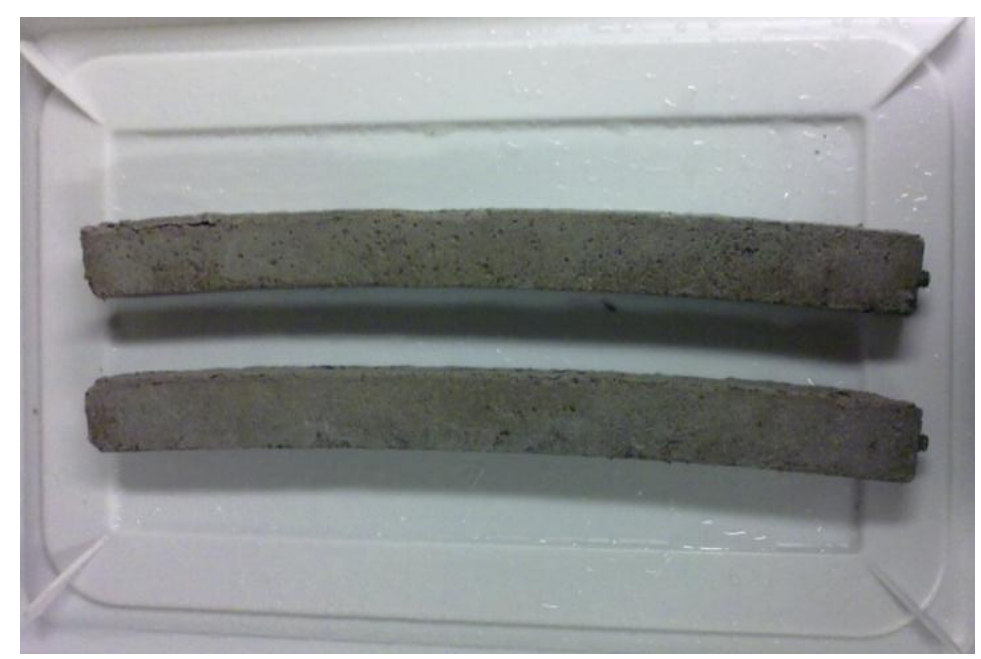

Figure 4.9: Bars bent due to severe expansion 
As seen in Figure 4.7, rate of expansion of bars with sulphate contents of $0.5,1$ and $1.5 \%$ are constant and do not exceed $0.07 \%$ expansion. However once sulphate content is increased to $2 \%$, expansion rate increases significantly, almost six times more than bars containing $1.5 \% \mathrm{SO}_{4}$ or lower. Based on the results observed from this experiment, a definite limit for total sulphate content where Thaumasite attack would not occur is suggested to be $1.5 \% \mathrm{SO}_{4}$.

\subsubsection{Phase III Results: Expansion of Mortar Bars Containing RCA}

In this phase, bars were produced using RCA aggregate in order to confirm results obtained from section 4.1.1 and 4.1.2. All bars produced in this phase were saturated in limewater solution and stored at $5^{\circ} \mathrm{C}$. While producing the mixes it was noticed that at the same water to cement ratio flowability of mixes were significantly lower, especially at higher percentages of gypsum. Both RCA and gypsum have a high amount of absorption; therefore in this phase it was necessary to increase the water-to-cement ratio in order to achieve a desired flowability similar to conventional U-fill mixtures. Results from periodical measurements of bars produced in this phase showed similar expansion as those obtained in phase II. Expansion of bars with sulphate contents of $1.5 \%$ or lower was significantly less than bars with $2,2.5,3$ and $3.5 \% \mathrm{SO}_{4}$ (Figure 4.10). As a result of expansion tests done both in phase II and III, it is safe to say that aggregates with sulphate contents as high as $1.5 \%$ will not cause severe expansion and can be used as an alternative aggregate in the production of $U$-fill mixtures. 


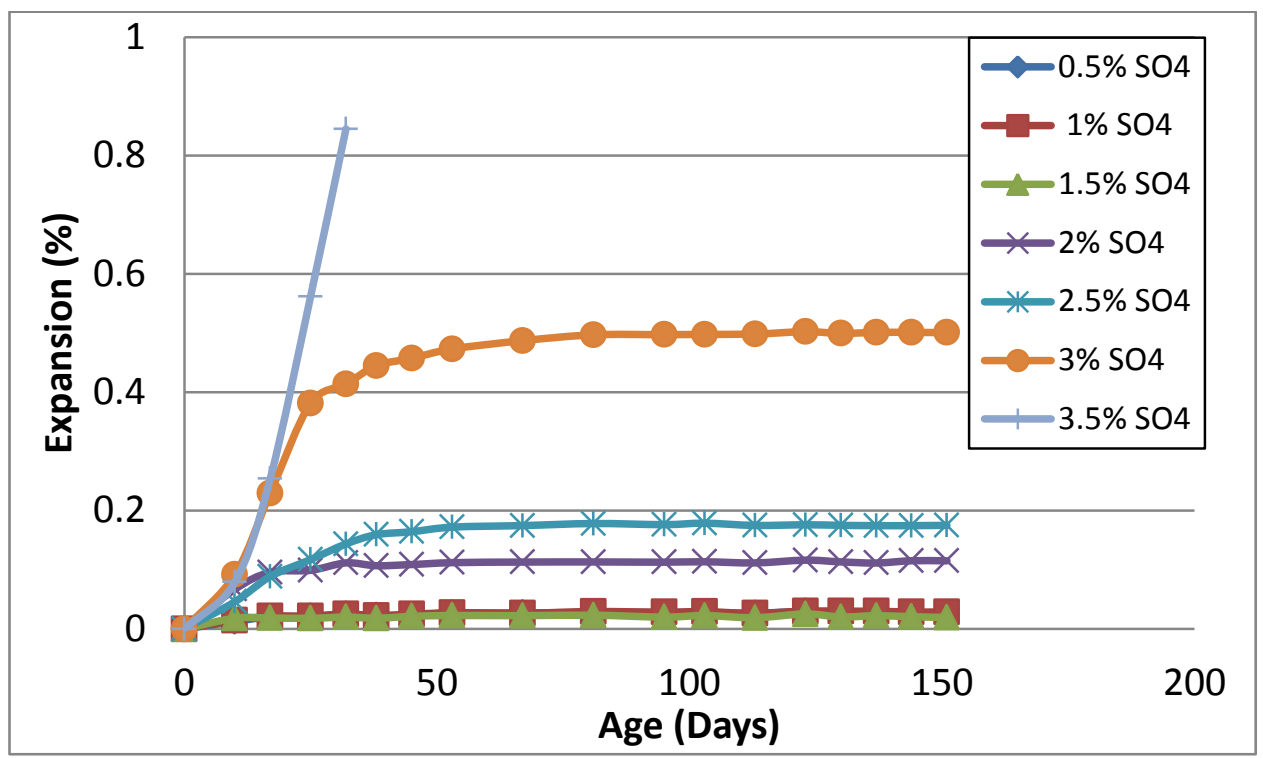

Figure 4.10: Expansion of bars containing RCA aggregate at various sulphate contents

The deterioration mechanism observed in this phase was similar to that of phase I and II. At early stages of expansion, bars containing sulphate contents of $2.5 \%$ or higher displayed cracks similar to what is shown in Figure 4.11. After crack formation was observed any further storing of these bars at $5^{\circ} \mathrm{C}$ resulted in a complete deterioration of the paste and depletion of any bonding to the point where bars would transformed into a soft paste.

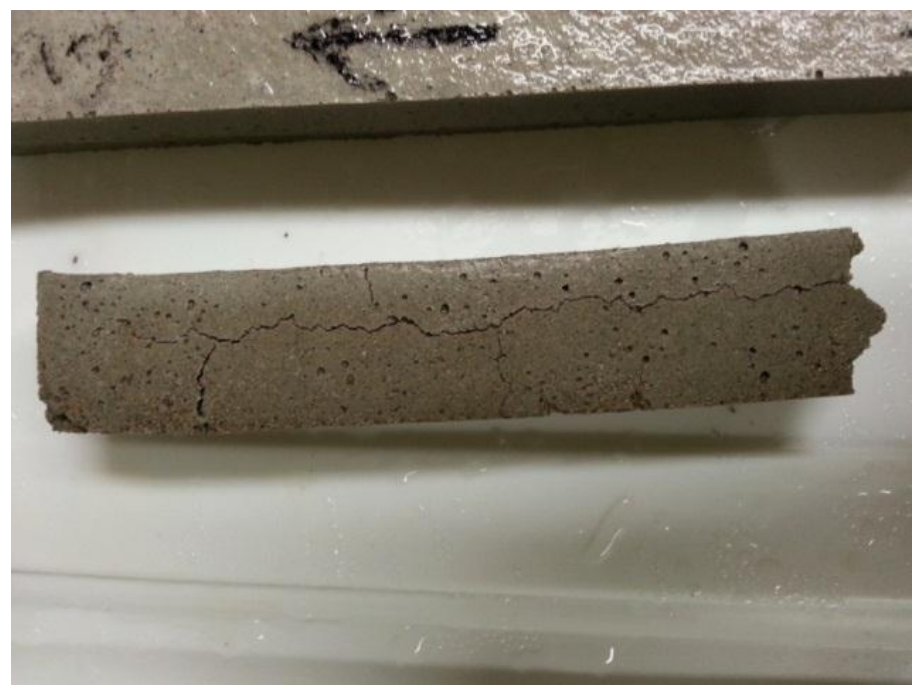

Figure 4.11: Cracks caused by severe expansion in bars containing $2.5 \% \mathrm{SO}_{4}$ 
It should be noted that mortar bar tested here were not of the same proportion as the U-fill. Indeed the ratio of cement to aggregate in $\mathrm{U}$-fill is much lower than that in the bars tested in this paper. The 11:1 ratio used in the bars was the lowest aggregate to cement ratio that could be used without breaking the bars during demoulding. Since Portland cement is the source of the main reactants to produce Ettringite $\left(\mathrm{Al}_{2} \mathrm{O}_{3}\right)$ and Thaumasite $\left(\mathrm{SiO}_{2}\right)$, one can argue that being of lower cement content, $U$-fill is less susceptible to internal sulphate attack than the bars used in this experimental program. On the other hand, the lower cement content of the U-fill could render it weaker than the bars; and hence, any level of sulphate attack can result in severe disintegration of the fill. While both arguments could be valid, the limit of $\mathrm{SO}_{4}$ recommended here still provides a reasonable guideline of the upper limit of $\mathrm{SO}_{4}$ content of aggregate intended to be used in U-fill.

To find out the cause of expansion in the tested bars, analysis was done using scanning electron microscopy and energy dispersive x-ray analysis on bars containing $3.5 \% \mathrm{SO}_{4}$. The analysis showed the presence of solid phases of Thaumasite and Ettringite as presented in Figure 4.12.
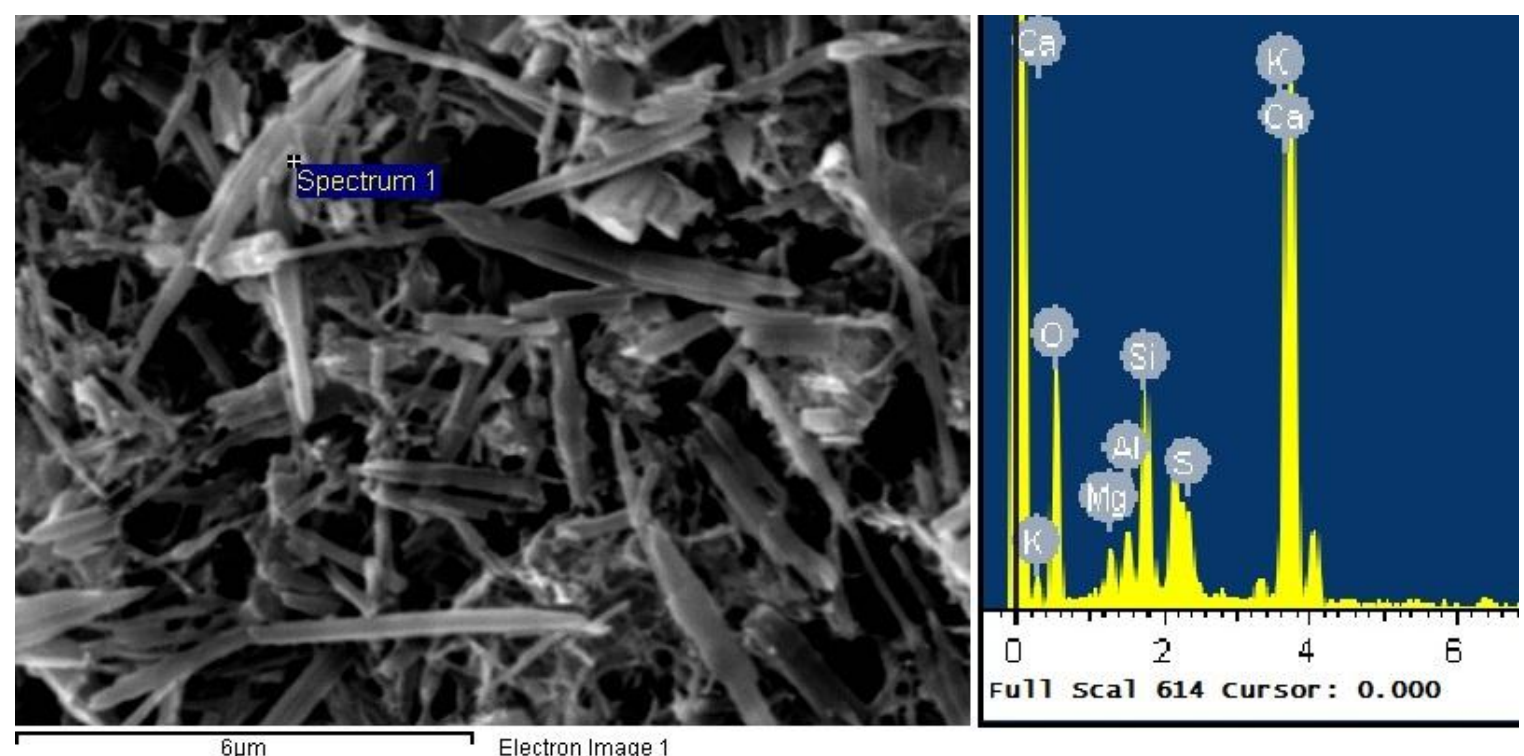

Figure 4.12: SEM results of mortar bars containing $3.5 \% \mathrm{SO}_{4}$ 


\subsubsection{Phase IV Results: Reduction of Expansion Due To Internal Sulphate Attack Using Supplementary Cementing Materials}

All results from the previous stages pointed towards the fact that severe deterioration will occur due to Thaumasite and Ettringite attack at higher percentages of sulphate. In order to reduce expansion, supplementary cementing material, namely Metakaolin and Ground Granulated Blast Furnace Slag (GGBFS) were incorporated into mortar bar mixes. As mentioned previously in section 3.3.1.4, the effects of adding 30\% GGBFS, 50\% GGBFS and 10\% Metakaolin were investigated.

All 3 batches were produced using a water-to-cement ratio of 2.9 and aggregate to cement ratio of 11:1. As a source of sulphate, gypsum was added to the all three batches. Since the results from previous phases indicated that expansion is more severe where sulphate contents are increased to above $1.5 \%$, bars in this phase were produced with sulphate contents of $2.5 \%$ to $3.5 \%$ in mixes containing $30 \%$ GGBFS and $10 \%$ metakaolin, and 2 to $3.5 \%$ for mixes containing 50\% GGBFS. Figure 4.13 through Figure 4.16 present the expansion results obtained from mixes containing 30 and 50\% slag and the corresponding reduction in expansion after 30 days.

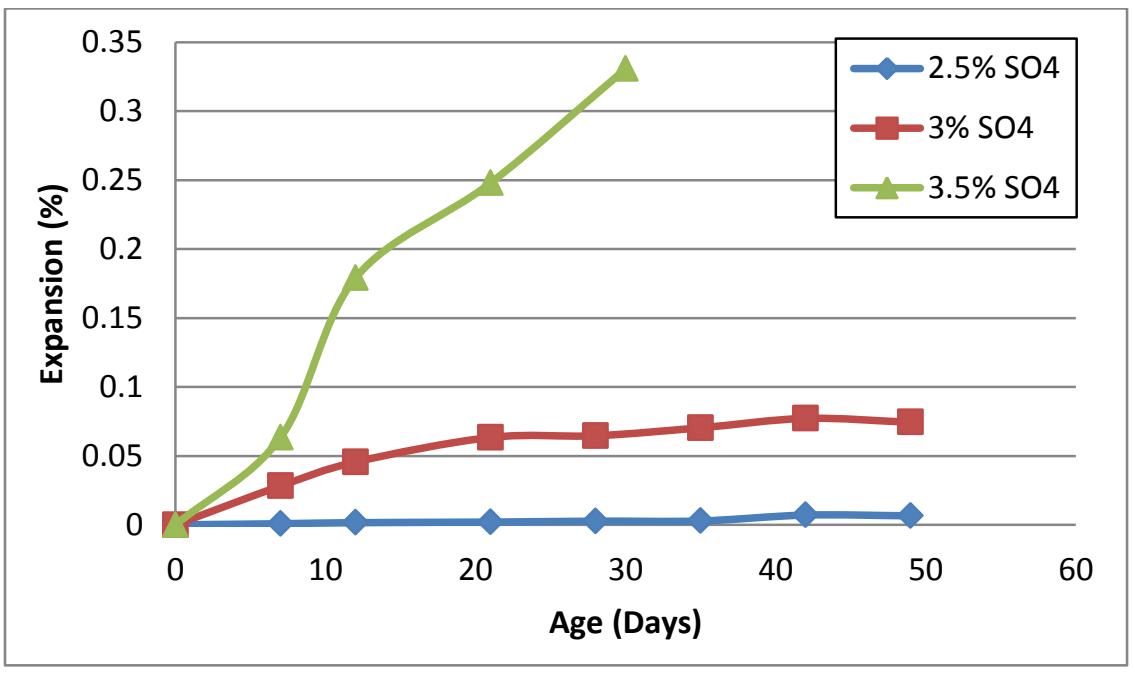

Figure 4.13: Expansion of mortar bars containing 30\% slag 


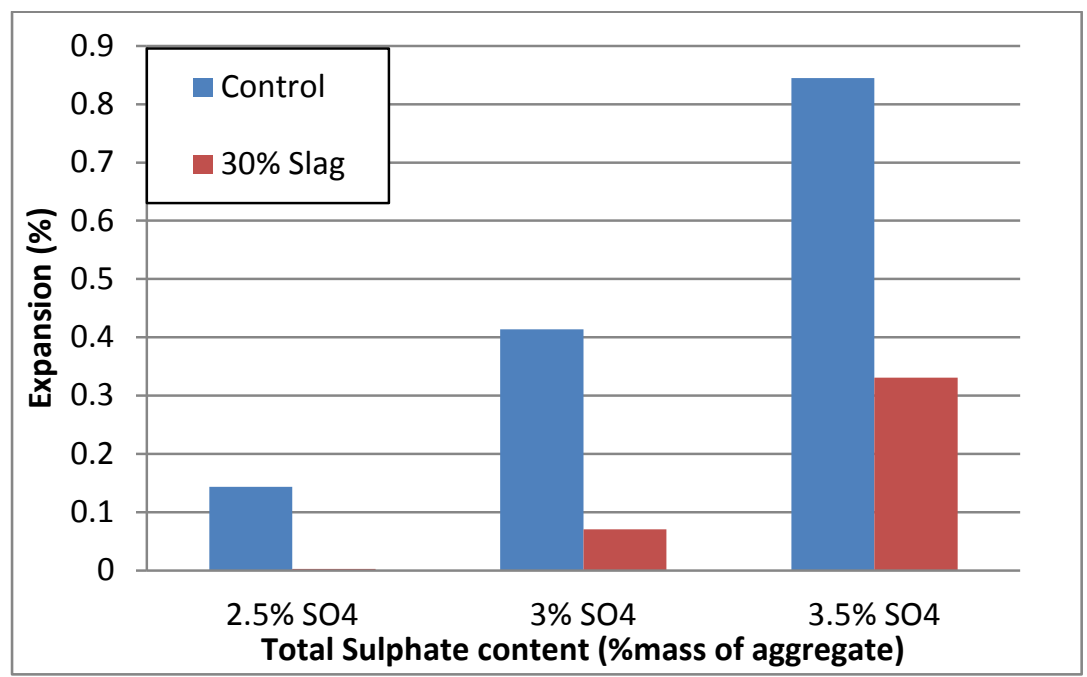

Figure 4.14: 30 day expansion reduction with $30 \%$ slag

Figure 4.14 demonstrates the amount of reduction in expansion of bars containing $30 \%$ slag as compared to bars containing no SCM's. A definite reduction in expansion is clearly noticeable. At $3.5 \% \mathrm{SO}_{4}$ however, the high rate of expansion caused the bars to fail at an early age.

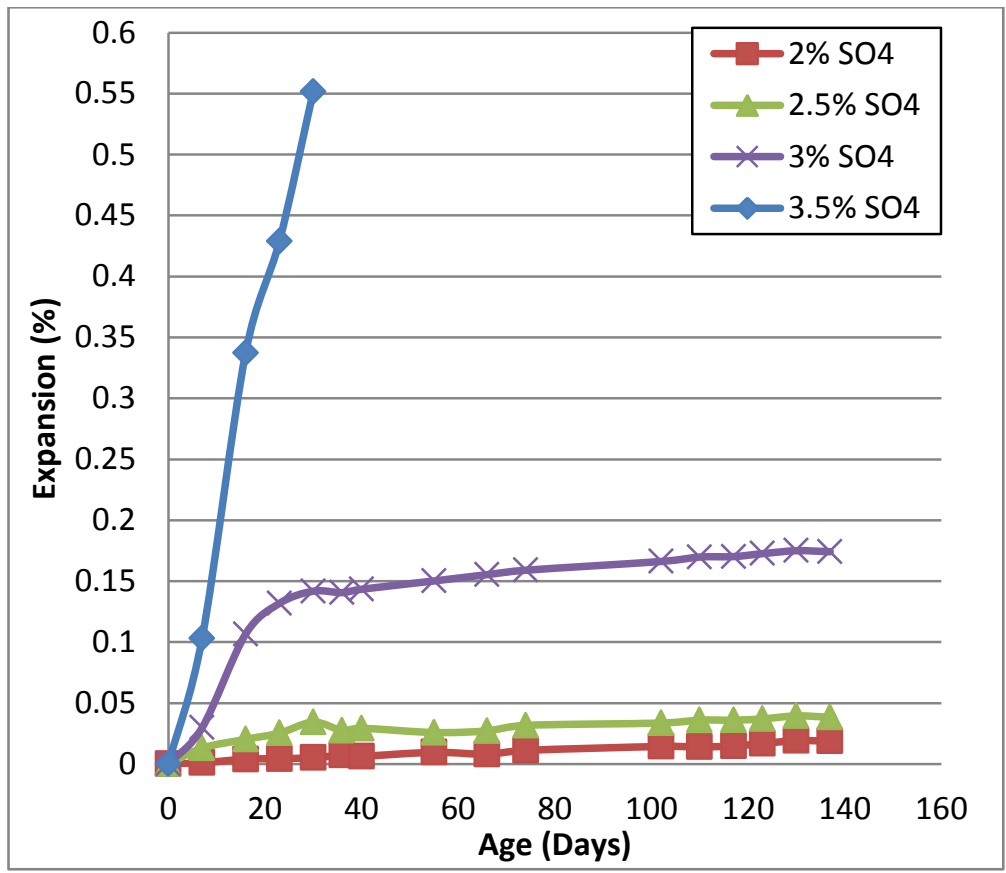

Figure 4.15: Expansion of mortar bars containing $50 \%$ slag 


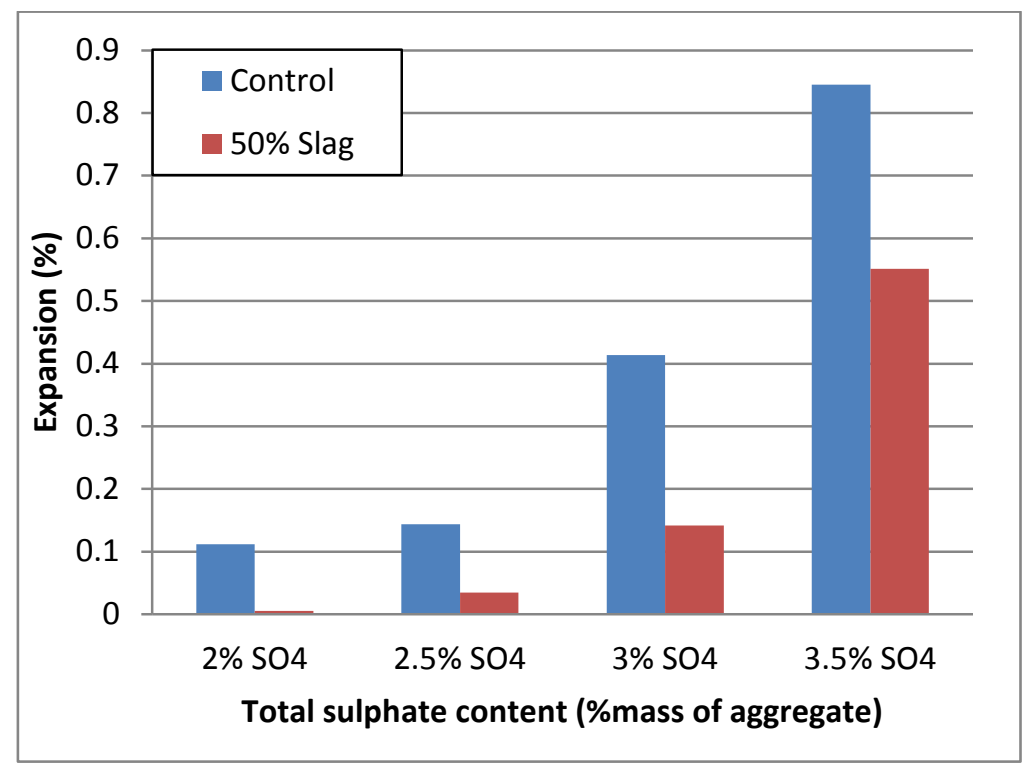

Figure 4.16: 30 day expansion reduction with $50 \%$ slag

Bars containing $50 \%$ slag had also a considerably lower rate of expansion. At a sulphate content of $3.5 \%$ however, similar to bars with $30 \%$ slag, expansion was not reduced significantly. At 30 days bars containing $3.5 \% \mathrm{SO}_{4}$ and $50 \%$ slag expanded up to $0.55 \%$ which resulted in the complete failure of these bars. Based on the mentioned expansion results, it is speculated that at $3.5 \%$, due to the larger amount of sulphates present within the system and perhaps the fast rate of reaction of gypsum with components of cement, deterioration cannot be prevented even where high percentages of slag is used.

Due to the pozzolanic reaction caused by the presence of slag, Thaumasite and Ettringite formation is hindered through the consumption of portlandite (calcium hydroxide) in producing calcium silicate hydrates. The reason for the slightly higher expansion in bars containing $50 \%$ slag compared to those containing $30 \%$ slag is not yet known. However, since there is a certain percentage of $C_{3} A$ within slag, perhaps by the addition of higher percentages of this material to the mortar mixes, expansion is rather promoted and conditions are favored towards the formation of Thaumasite. 


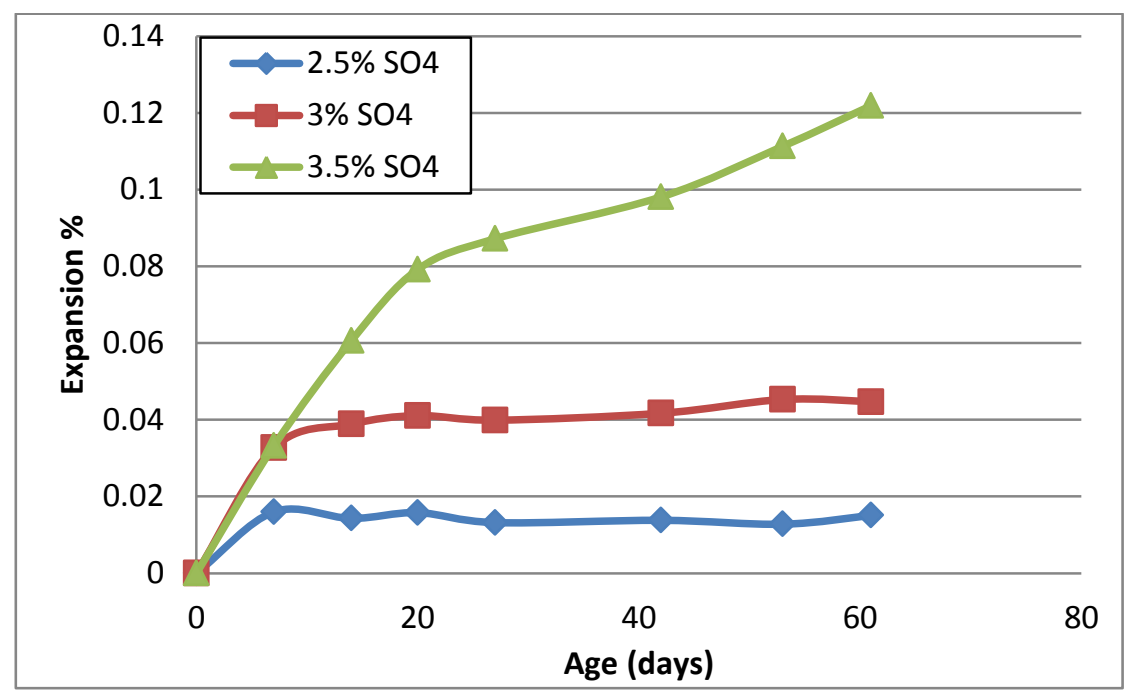

Figure 4.17: Expansion results of mortar bars containing 10\% Metakaolin

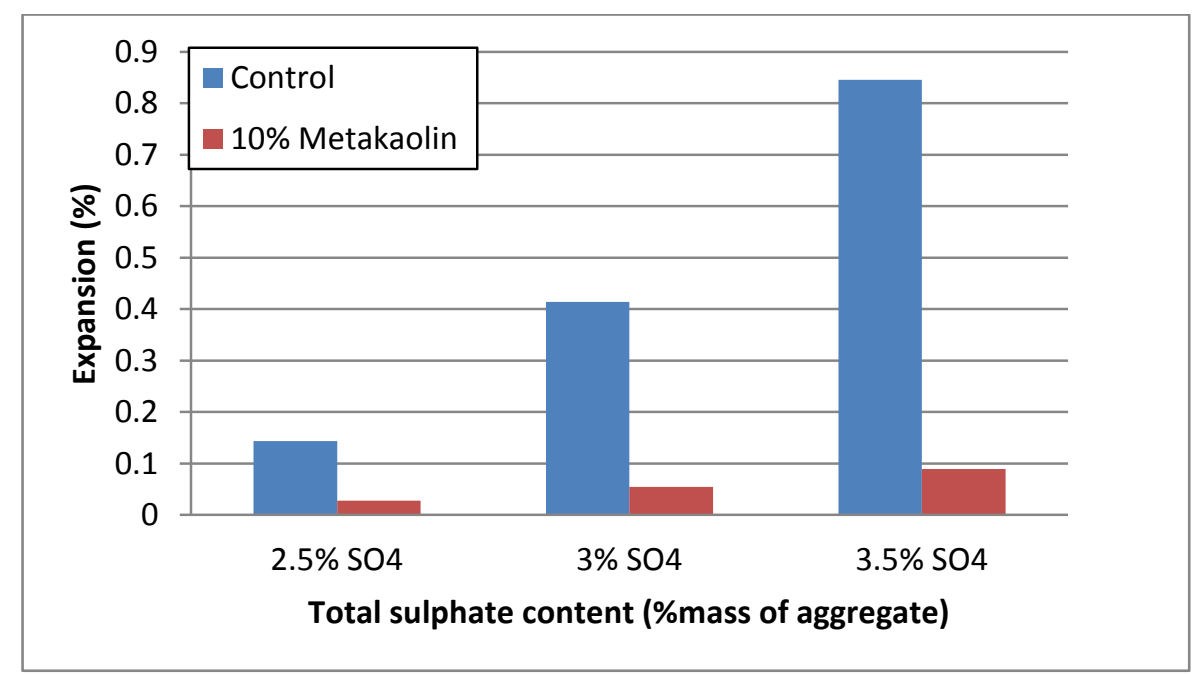

Figure 4.18: 30 day expansion reduction with $10 \%$ metakaolin

As it can be seen from figure 4.17 and 4.18, with the addition of only $10 \%$ Metakaolin, expansion is considerably reduced. An average reduction of about $85 \%$ can be seen amongst all three sets of bars containing 2.5,3 and $3.5 \% \mathrm{SO}_{4}$. The reason for the reduction in expansion can be explained by the following three mechanisms.

1) Since Metakaolin is partially replacing cement, the overall amount of tricalcium aluminate is reduced, thus causing a reduction in overall expansion caused by sulphate 
attack.

2) Calcium hydroxide reacts with metakaolin through pozzolanic reactions. Through this reaction calcium hydroxides are partially consumed and thus fewer amounts of expansive crystals are formed.

3) By the addition of metakaolin, the total effective pore size of the concrete paste is significantly reduced. Since Ettringite and Thaumasite tend to form within voids or pores, reducing pore size can inhibit the ability for crystal growth thus resulting in an overall reduction in expansion.

As seen previously with bars containing no SCM's and sulphate contents of $3.5 \%$, solid phases of Thaumasite and Ettringite were detected in bars containing $50 \%$ Slag and $3.5 \% \mathrm{SO}_{4}$ which explains the reason for expansion of these bars (Figure 4.19). It must be noted that even though the presence of Ettringite and Thaumasite has been detected, the effects on expansion would not be the same as where no SCM's are used. The crystal formations detected here are limited in size and quantity due to both a limited $\mathrm{C}_{3} \mathrm{~A}$ content and available void space for crystal formation. In contrast, bars containing 10\% Metakaolin did not indicate the presence of Thaumasite or Ettringite (Figure 4.20). The analysis indicated the presence of phases likely to be C-S-H with sulphur present as background or mixed with the C-S-H phase. It can be clearly observed that with a limited amount of Metakaolin, internal sulphate attack can be mitigated.

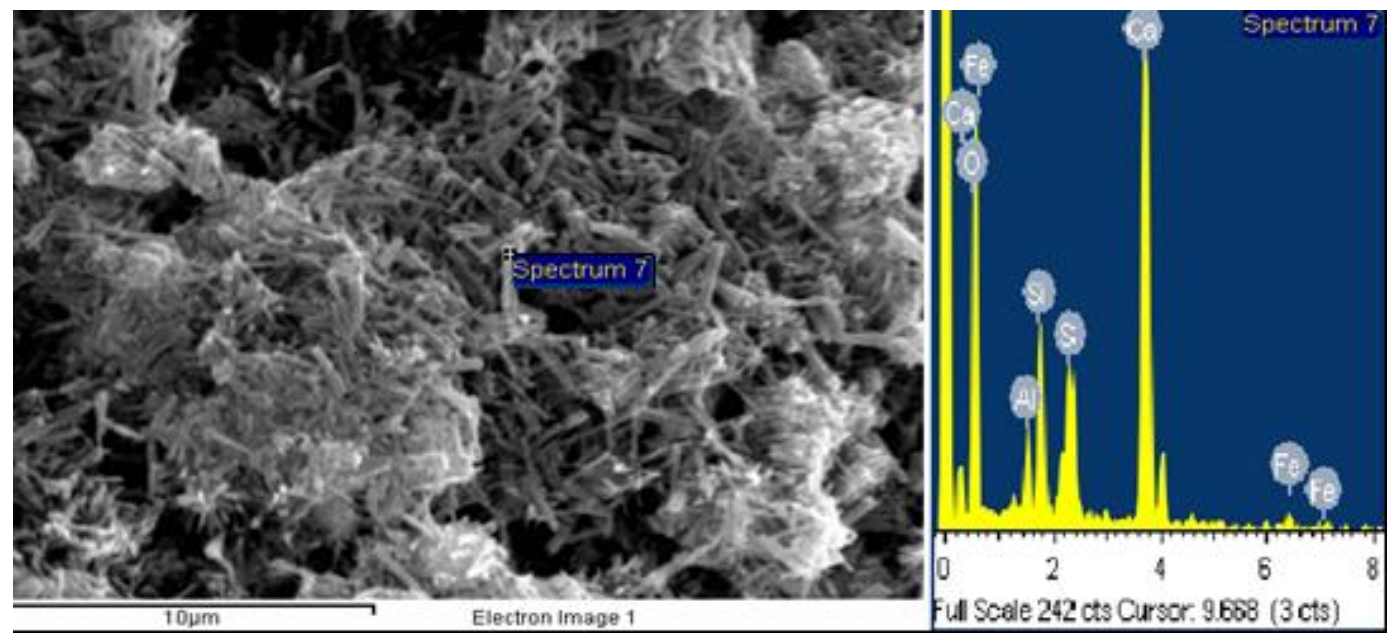

Figure 4.19: SEM results of mortar bars containing 3.5\% SO4 and 50\% slag 


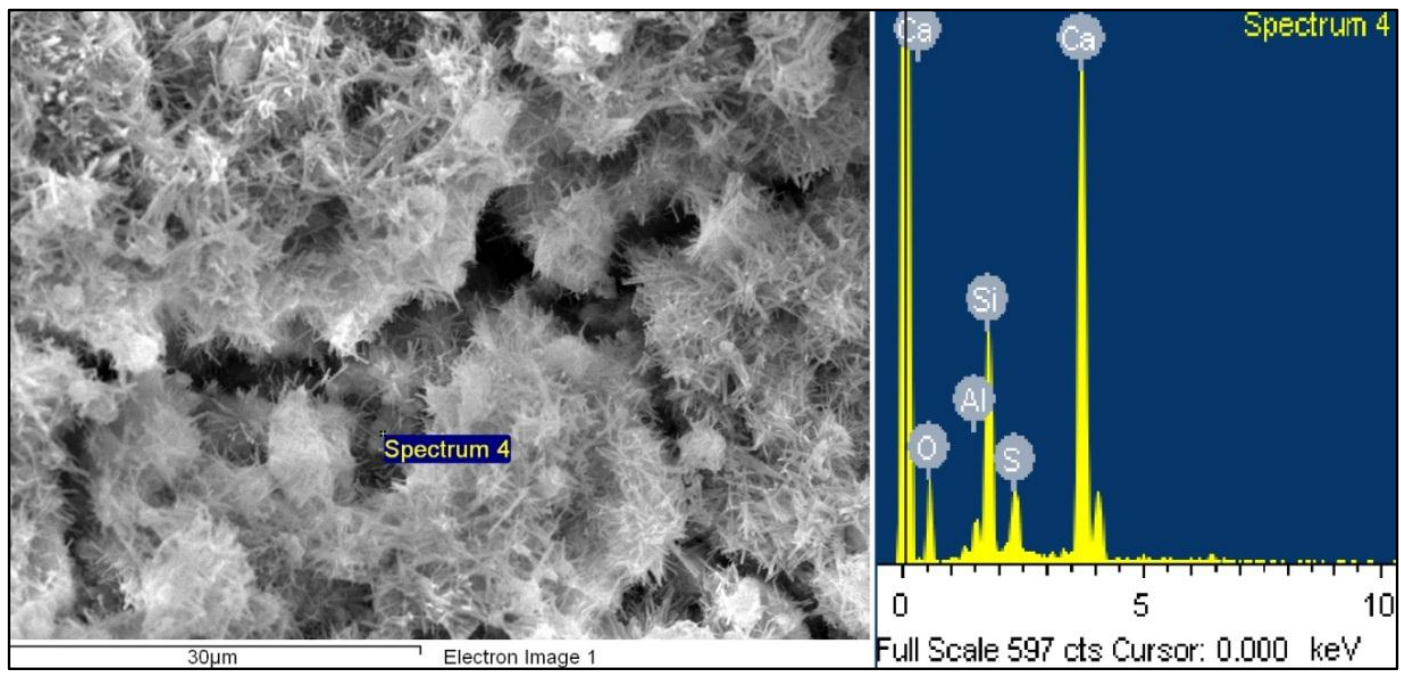

Figure 4.20: SEM results of mortar bars containing 3.5\% $\mathrm{SO}_{4}$ and $10 \%$ Metakaolin

\subsubsection{Phase V Results: Comparison of Expansion of Bars Containing $\mathrm{Na}_{2} \mathrm{SO}_{4}$ and Gypsum}

In this phase bars were produced using $\mathrm{Na}_{2} \mathrm{SO}_{4}$, rather than gypsum which was used in mortar bars discussed in the previous sections. This was done in order to investigate the variation in expansion due to lower overall calcium content within the chemical composition of bars made using $\mathrm{Na}_{2} \mathrm{SO}_{4}$ and also the higher solubility rate of $\mathrm{Na}_{2} \mathrm{SO}_{4}$ compared to gypsum. Figure 4.21 shows the expansion results obtained from bars containing 0.5 to $3.5 \% \mathrm{SO}_{4}$ (sulphate was added as $\mathrm{Na}_{2} \mathrm{SO}_{4}$ ). 


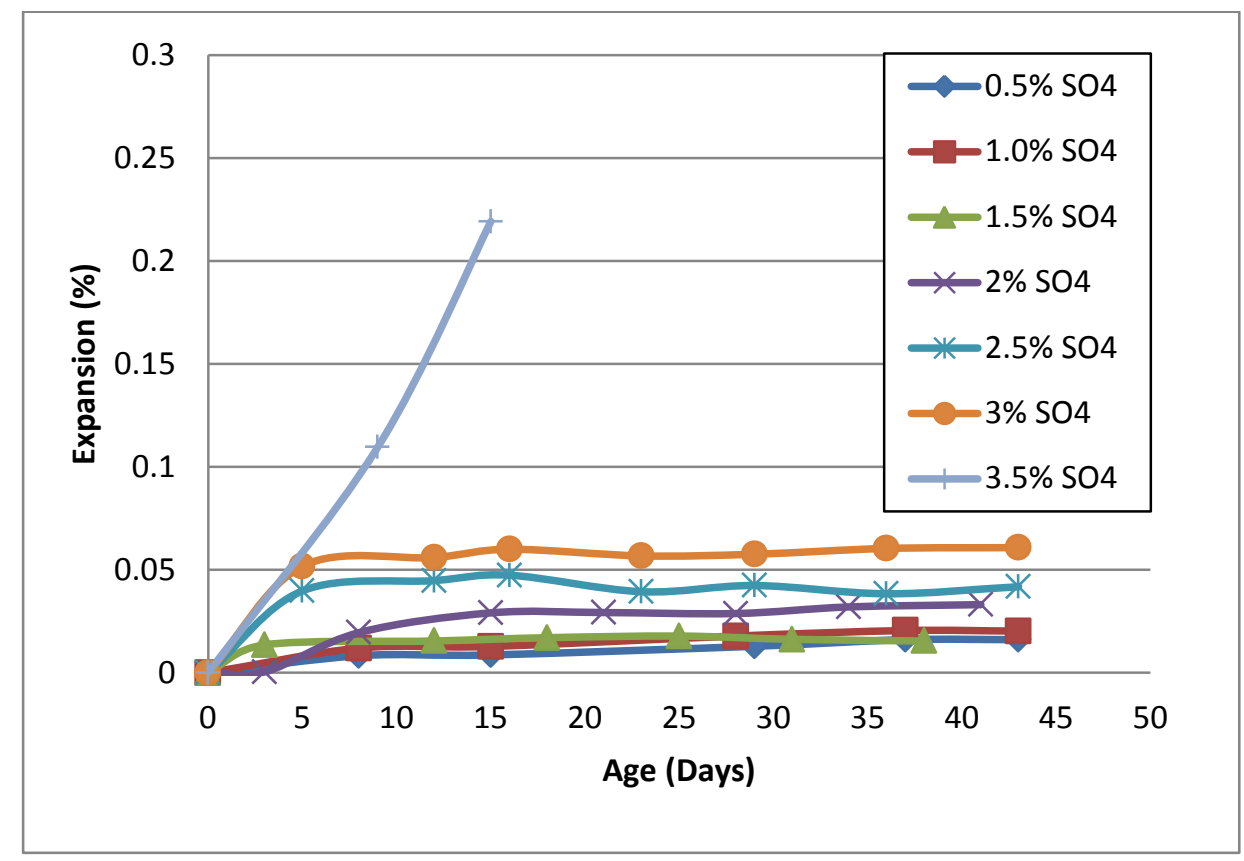

Figure 4.21: Expansion of mortar bars at various sulphate contents (Sulphate added as $\left.\mathrm{Na}_{2} \mathrm{SO}_{4}\right)$

Observations obtained from these bars verified that there is a definite reduction in expansion where sodium sulphate exists as the main source of sulphate compared to bars containing gypsum (Figure 4.10). As it can be seen in Figure 4.21, expansion rates for bars containing 0.5 to $3 \% \mathrm{SO}_{4}$, reach a rather constant rate. Unlike bars containing gypsum where a much higher expansion rate was observed in bars with sulphate contents of $2 \%$ or higher, bars with $\mathrm{Na}_{2} \mathrm{SO}_{4}$ did not show significant expansion with sulphate contents of up to $3 \%$. It is speculated that due to the lower overall amount of calcium within these bars, expansion rate is significantly lower, thus resulting in less formation of both Thaumasite and Ettringite.

Similar results were also obtained where slag was used within mortar bar containing $\mathrm{Na}_{2} \mathrm{SO}_{4}$. Figure 4.22 shows the expansion of bars containing $2.5 \%, 3 \%$ and $3.5 \% \mathrm{SO} 4\left(\mathrm{as} \mathrm{Na}_{2} \mathrm{SO}_{4}\right)$ and 30\% Ground Granulated Blast Furnace Slag (GGBFS). Comparing these expansion results to those obtained from bars containing gypsum as the source of sulphate, a clear difference can be observed, especially at $3.5 \% \mathrm{SO}_{4}$. Due to the lower overall calcium content existing within the mortar bars and limited cement content, the overall expansion rate due to Thaumasite 
attack and Ettringite is reduced significantly. The results from this phase are summarized and shown in Figure 4.22 and Table 4.1 below.

Table 4.1: Phase V expansion results for samples with $30 \%$ slag

\begin{tabular}{|c|c|c|c|c|c|c|}
\hline Percentage of sulphate & \multicolumn{2}{|c|}{$2.5 \% \mathrm{SO}_{4}$} & \multicolumn{2}{c|}{$3 \% \mathrm{SO}_{4}$} & \multicolumn{2}{c|}{$3.5 \% \mathrm{SO}_{4}$} \\
\hline Source of Sulphate & $\mathrm{Na}_{2} \mathrm{SO}_{4}$ & Gypsum & $\mathrm{Na}_{2} \mathrm{SO}_{4}$ & Gypsum & $\mathrm{Na}_{2} \mathrm{SO}_{4}$ & Gypsum \\
\hline Age (days) & \multicolumn{3}{|c|}{ Expansion (\%) } \\
\hline 0 & 0 & 0 & 0 & 0 & 0 & 0 \\
\hline 7 & 0 & 0 & 0.011 & 0.028 & 0.019 & 0.058 \\
\hline 14 & 0.012 & 0.001 & 0.019 & 0.05 & 0.0252 & 0.15 \\
\hline 21 & 0.012 & 0.002 & 0.02 & 0.063 & 0.028 & 0.221 \\
\hline 28 & 0.014 & 0.003 & 0.022 & 0.064 & 0.029 & broke \\
\hline 35 & 0.016 & 0.003 & 0.025 & 0.07 & 0.0328 & broke \\
\hline 42 & 0.016 & 0.007 & 0.026 & 0.075 & 0.035 & broke \\
\hline 49 & 0.021 & 0.022 & 0.031 & 0.074 & 0.035 & broke \\
\hline
\end{tabular}

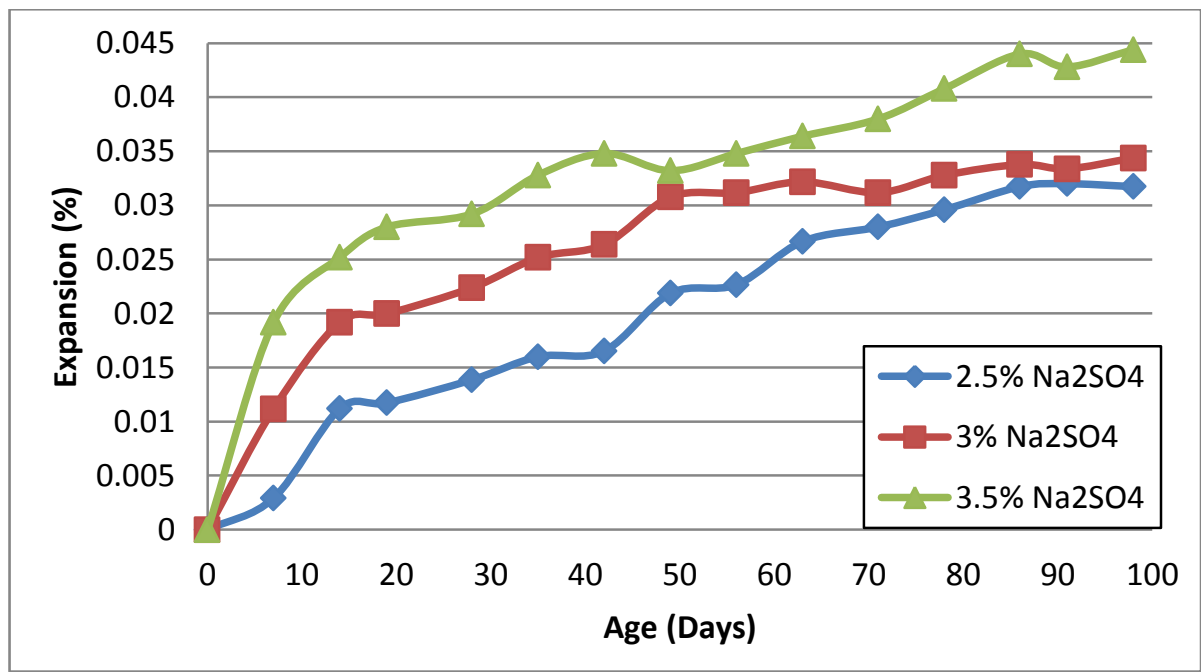

Figure 4.22: Expansion of bars containing $30 \%$ slag and $\mathrm{Na}_{2} \mathrm{SO}_{4}$ as source of sulphate 
For ease of comparison, expansion results of bars containing $\mathrm{Na}_{2} \mathrm{SO}_{4}$ have been plotted alongside bars containing gypsum in figures 4.23 through 4.25 . In each figure both sets of mortar bars contain the same overall amount of sulphate $\left(2.5,3\right.$ or $\left.3.5 \% \mathrm{SO}_{4}\right)$.

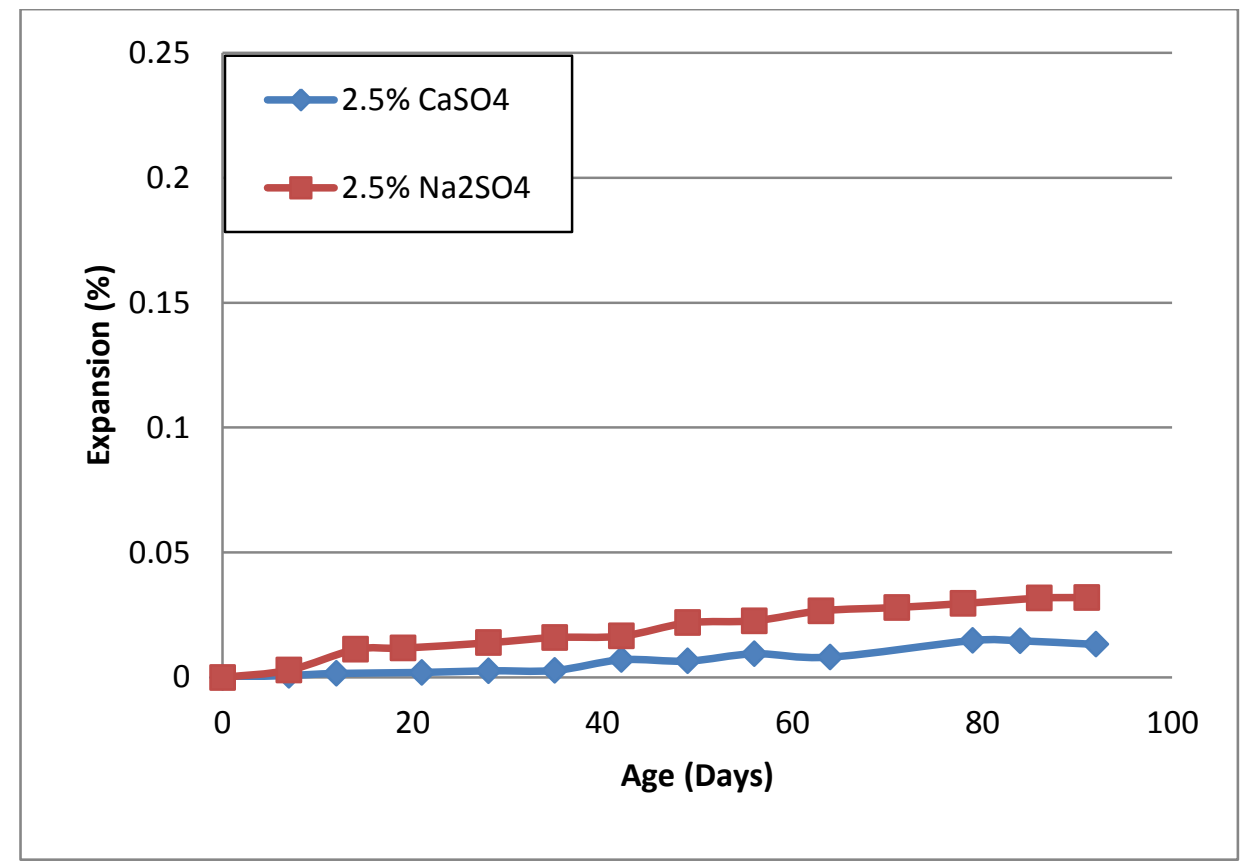

Figure 4.23: Comparison of expansion in bars containing $30 \%$ slag and $2.5 \% \mathrm{SO}_{4}$

As it can be seen from Figure 4.23, the expansion rate of bars containing both gypsum and $\mathrm{Na}_{2} \mathrm{SO}_{4}$ follow a relatively similar rate. It should be noted that the lower rate of expansion of bars produced in this stage as compared those produced in phase I, II and III is due to the addition of GGBFS. The slightly greater expansion in the bars containing $\mathrm{Na}_{2} \mathrm{SO}_{4}$ as the main source of sulphate could be related to the higher rate of solubility of $\mathrm{Na}_{2} \mathrm{SO}_{4}$ thus causes a faster rate of reaction in producing Ettringite and Thaumasite crystals. 


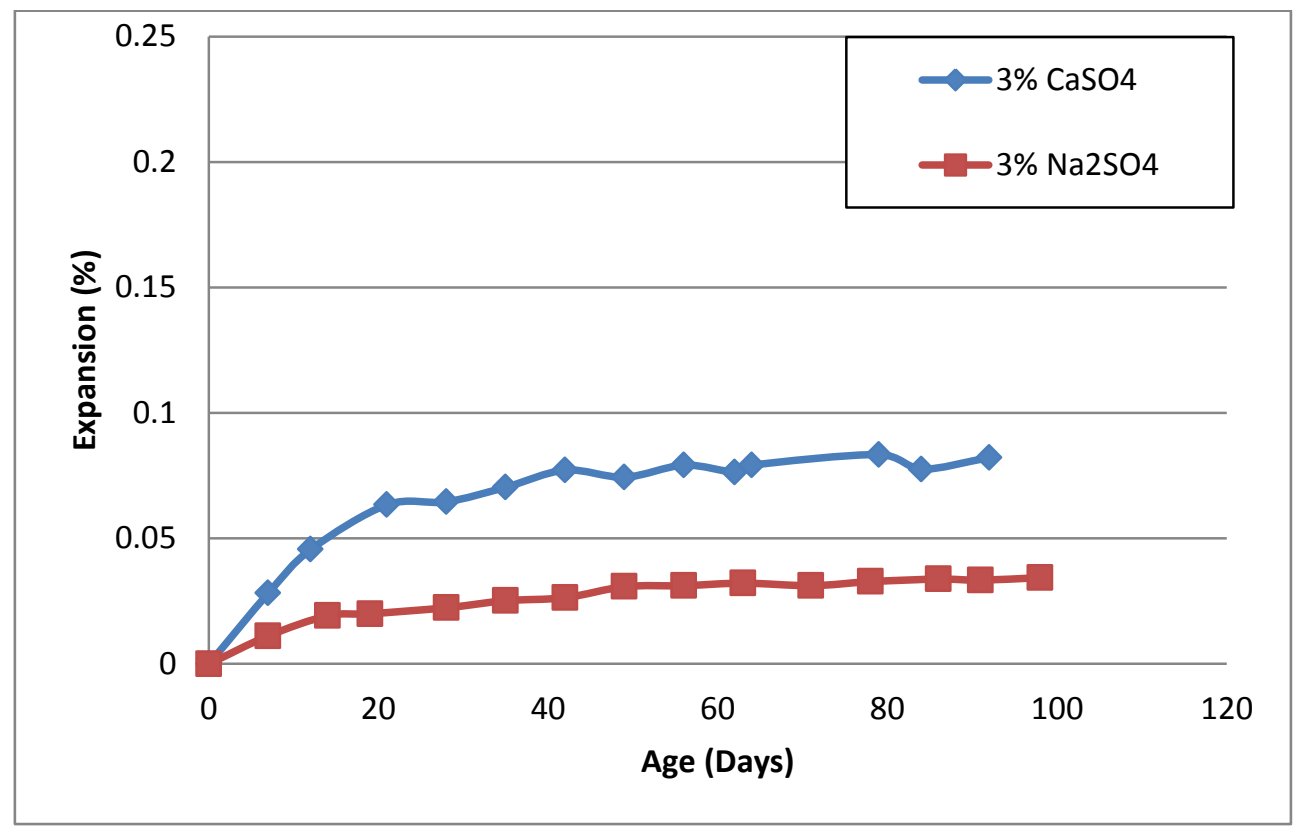

Figure 4.24: Comparison of expansion in bars containing $30 \%$ slag and $3 \% \mathrm{SO}_{4}$

When sulphate contents are increased to $3 \%$ (Figure 4.24) a more definite difference in the rate of expansion can be observed in bars containing $\mathrm{Na}_{2} \mathrm{SO}_{4}$ compared to those produced using gypsum. The higher overall calcium content within the chemical system where gypsum is used as the main source of sulphate may cause a higher and more severe rate of expansion due to the existence of more readily available reaction products to form Thaumasite and Ettringite. At 49 days the amount of expansion of bars with $2.5 \% \mathrm{SO}_{4}$ (added as $\mathrm{Na}_{2} \mathrm{SO}_{4}$ ) is 0.022 percent while at $3 \% \mathrm{SO}_{4}$ this value only increases to $0.03 \%$. In bars containing gypsum however, at 49 days the expansion is $0.006 \%$ while at $3 \% \mathrm{SO}_{4}$, the amount of expansion increases to $0.074 \%$, about 12 times higher. The higher amount of calcium content within the chemical system may cause a larger volume of Ettringite and Thaumasite formation while in mixes containing $\mathrm{Na}_{2} \mathrm{SO}_{4}$, due to the fact that the source of calcium is limited to what is derived from the aggregate or cement, and the reduction of calcium hydroxides through the pozzolanic reaction of slag, the overall expansion does not increase significantly and stays within a constant boundary. 


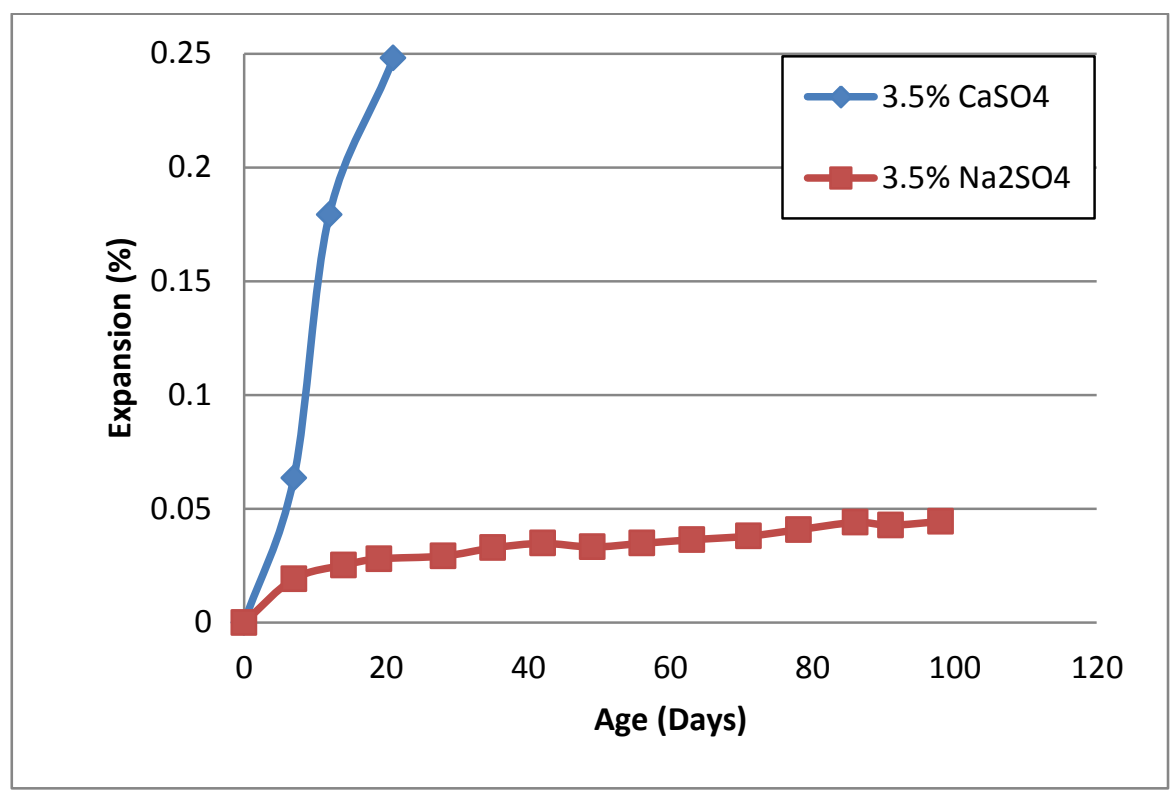

Figure 4.25: Comparison of expansion in bars containing 30\% slag and 3.5\% SO4

Once total sulphate content in the mortar bars were increases to 3.5\% (Figure 4.25), severe expansion was observed in bars containing gypsum. At only 21 days these bars displayed signs of deterioration, which based on observations obtained from previous steps, was found to be mainly due to Thaumasite formation. Similar to bars containing 2.5 and $3 \% \mathrm{SO}_{4}$, at $3.5 \%$ bars containing $\mathrm{Na}_{2} \mathrm{SO}_{4}$ still did not show much signs of expansion and at 49 days the expansion increased to only $0.033 \%$. As it can be understood from the above results, limiting total calcium content can significantly reduce expansion. Where sulphate is present in aggregate as gypsum, deterioration caused by Thaumasite attack should be expected to be much more severe than where sulphates are present as $\mathrm{Na}_{2} \mathrm{SO}_{4}$. The effects of supplementary cementing material should also be noted. Where Slag is not added to the mortar bar mixtures, expansion should be expected to be higher. 


\subsection{Expansion of U-fill Mixtures Containing Aggregate of High Sulphate Content}

In order to investigate the induced forces on surface layers caused by expansion of U-fill mixtures containing aggregates of high sulphate content, an alternative mould was produced as discussed in section 4.3. A U-fill mixture was made using aggregate with a sulphate content of $3.23 \%, 25 \mathrm{~kg} / \mathrm{m}^{3}$ of cement and $190 \mathrm{~kg} / \mathrm{m}^{3}$ of water. Once poured into the moulds, mixes were left to cure at room temperature for a period of 24 hours; sufficient space was left on top to allow for the placement of an annular surcharge (Figure 4.26).

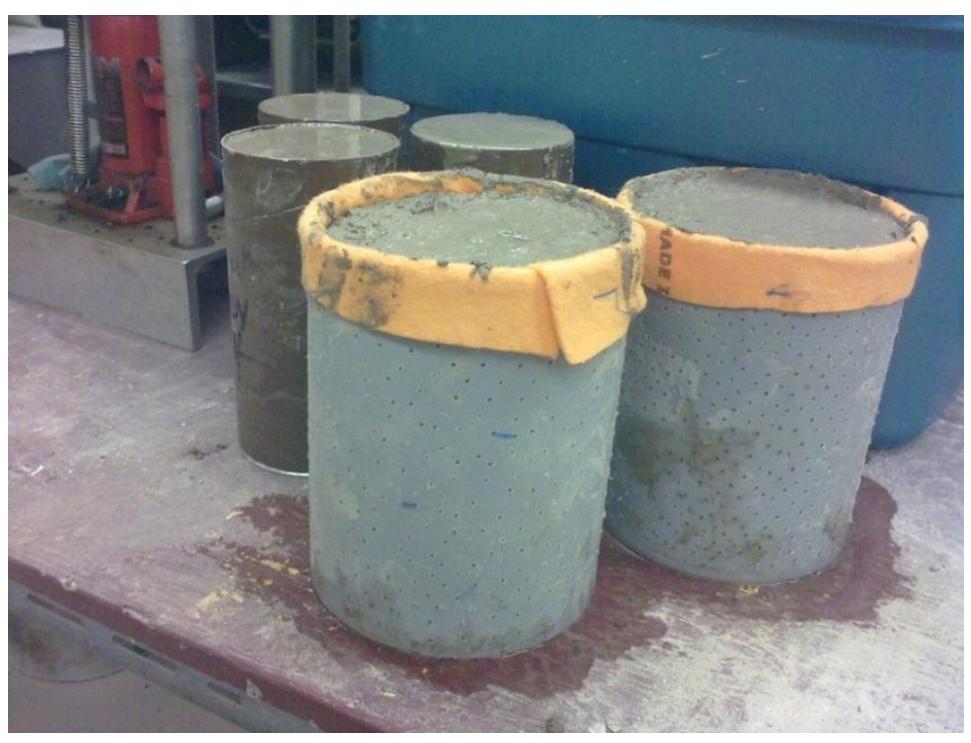

Figure 4.26: Samples containing aggregate of high sulphate content prior to saturation in limewater solution

Once adequate strength was achieved, moulds were saturated in a limewater solution at $5^{\circ} \mathrm{C}$ and expansion was measured weekly. After a month of measurements, due to the saturation of the surcharge and dial gauges within limewater, severe rusting occurred which altered the dial gauge readings significantly. Also, since samples were stored at $5^{\circ} \mathrm{C}$, dial gauges would tare or turn off automatically which resulted in losing track of the total amount of expansion caused 
during the period since the last measurements. Although expansion results could not be retrieved from this experiment, severe deterioration was observed within these samples. As the moulds were further stored in limewater, deterioration increased to the point where no bond strength was found between the aggregates (Figure 4.27).

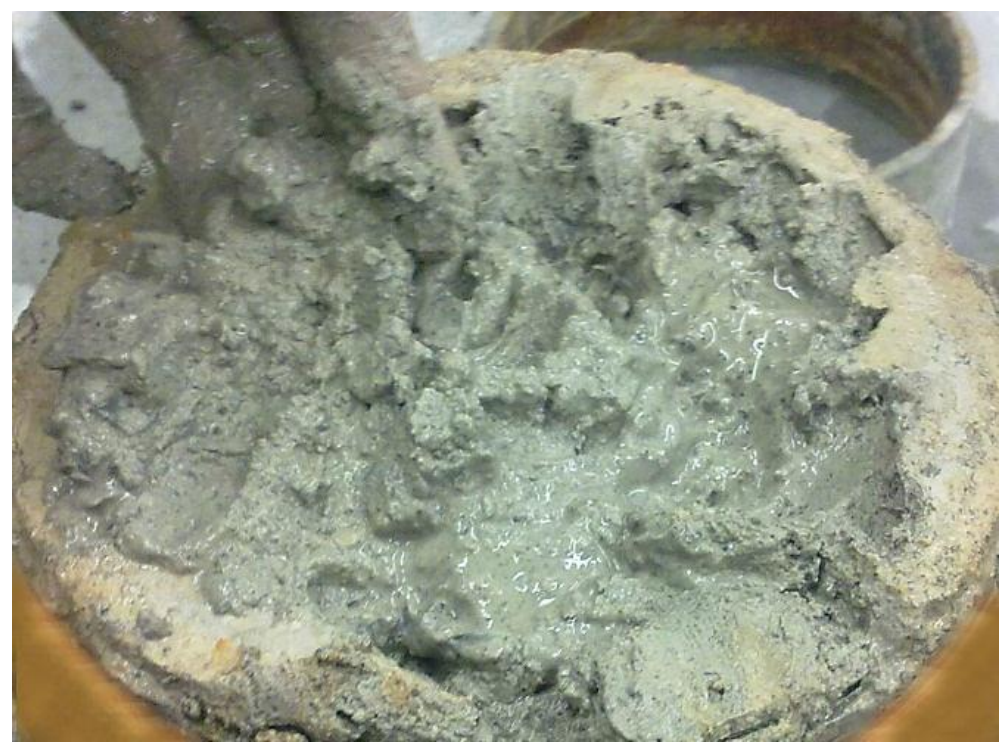

Figure 4.27: Deterioration of U-fill mixtures stored at $5{ }^{\circ} \mathrm{C}$ 


\subsection{Laboratory and Field Trial Results}

\subsubsection{Phase I Results: Mixes Containing Out-of-Specification Granular Aggregate}

In this phase, mixes were produced using solely aggregate from the Bayview quarry (Figure 3.1). Mixes were produced with increasing water contents and $25 \mathrm{~kg} / \mathrm{m}^{3}$ cement. By observation of the coarse-to-fine ratio, it was assumed that using $100 \%$ Granular ' $A$ ' would result in an acceptable mix, and at the same time allow most efficient aggregate use. Despite the variation in water content, samples containing $100 \%$ Granular ' $\mathrm{A}$ ' exhibited higher segregation at higher amounts of water. Figure 4.28 below shows the segregation in samples with decreasing water contents $\left(205 \mathrm{~kg} / \mathrm{m}^{3}, 185 \mathrm{~kg} / \mathrm{m}^{3}, 165 \mathrm{~kg} / \mathrm{m}^{3}\right)$, from left to right respectively.

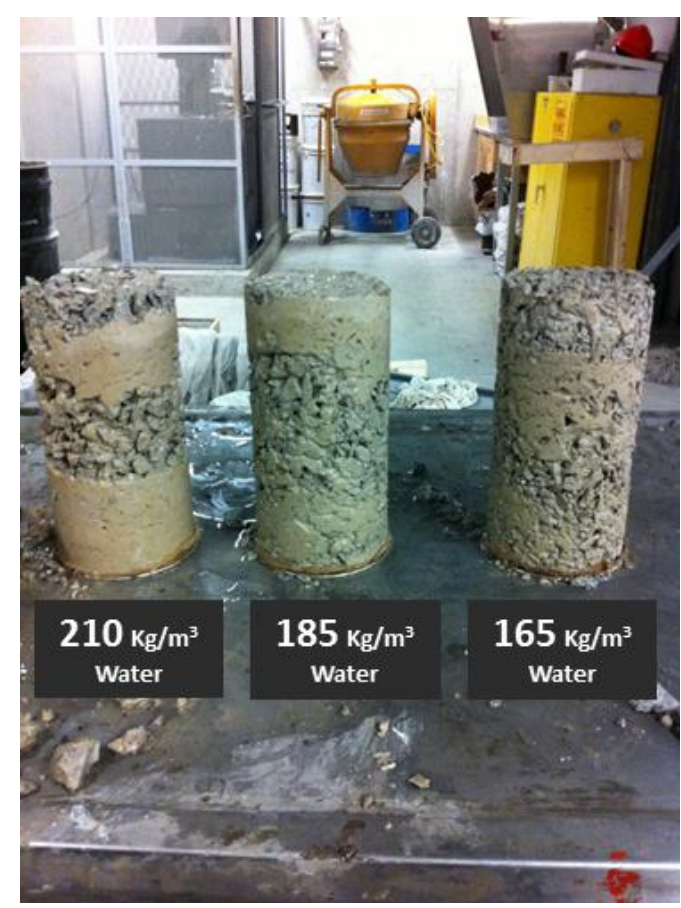

Figure 4.28: Segregation of $100 \%$ Granular ' $A$ ' at different water content

In the absence of a filler the mix had no cohesiveness and showed segregation. To mitigate this issue, Granular ' $A$ ' was mixed with sand. Different compositions were tested in order to achieve optimum flowability with minimal use of sand. It was observed that using $15 \%$ sand and $85 \%$ 
Granular ' $A$ ' produces an optimized mix with much more cohesion and no seggregation (Figure 4.29).

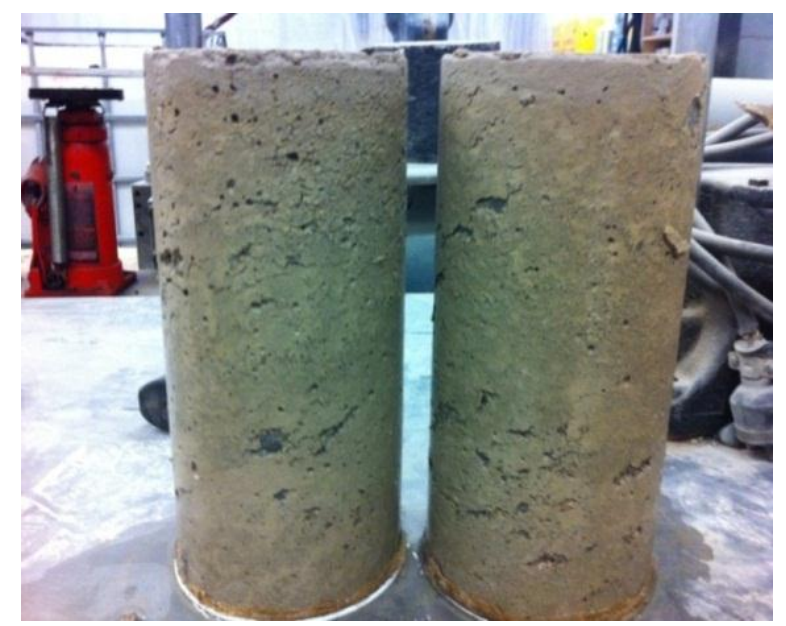

Figure 4.29: Samples composed of $15 \%$ sand and $85 \%$ Granular ' $A$ '

Several mixes were made using Granular ' $A$ ' and water contents ranging from $165 \mathrm{~kg} / \mathrm{m}^{3}$ to 220 $\mathrm{kg} / \mathrm{m}^{3}$. The cement was kept constant at $25 \mathrm{~kg} / \mathrm{m}^{3}$ for all the mixes. Through the slump test it was observed that most mixes were susceptible to segregation. This was also observed when demoulding the cylinder samples as can be seen in Figure 4.30.
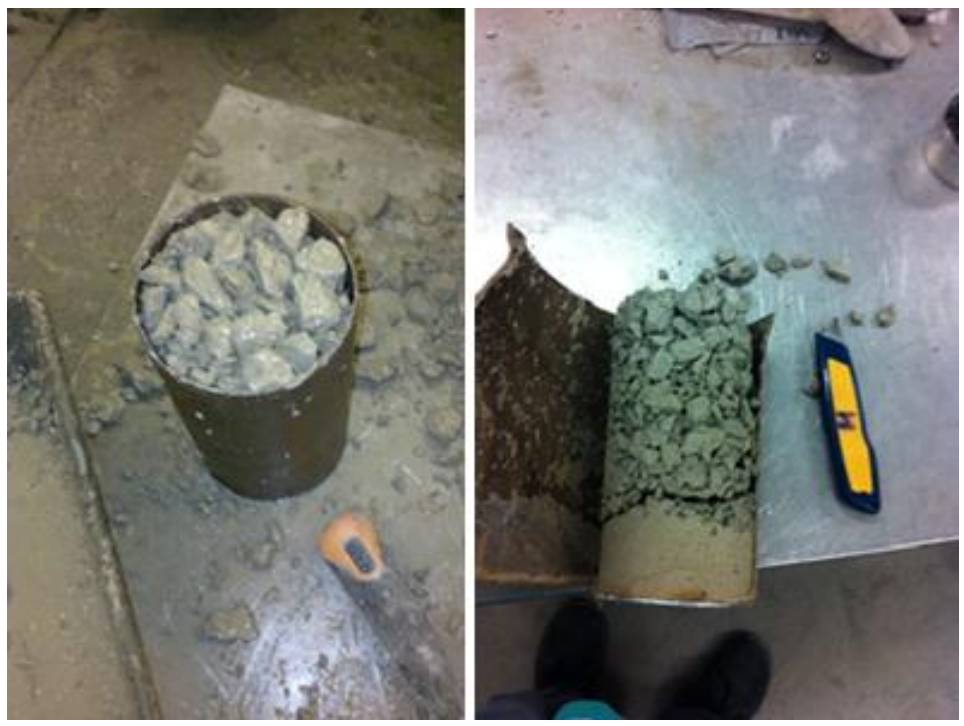

Figure 4.30: Segregation of fines within samples containing granular aggregate 
Due to the high amount of coarse material, most of the water and paste had migrated into the bottom of the sample cylinders. Without a proper mix design, this could occur on site and remain unnoticed. Furthermore, the samples were tested at 7 , and 28 days for compressive strength. Most cylinders broke while demoulding as shown in Figure 4.30. The cured samples were very porous and weak, and only a small amount of the particles' surface areas were in contact. It was determined that this was caused by the lack of fines. In order to obtain stronger and more cohesive mixes, the addition of concrete sand proved to be necessary.

Table 4.2: Mixes containing out-of-specification granular aggregate combined with various percentages of sand

\begin{tabular}{|c|c|c|c|}
\hline & 0\% Sand & 15\% Sand & 25\% Sand \\
\hline Hardening Time (hours) & 28 & 36 & 40 \\
\hline Water $\left(\mathbf{k g} / \mathbf{m}^{\mathbf{3}}\right)$ & 228 & 245 & 255 \\
\hline Slump (mm) & 160 & 165 & 171 \\
\hline Comp. Strength 7 days (MPa) & 0.150 & 0.183 & 0.169 \\
\hline Comp. Strength 28 days (MPa) & 0.257 & 0.364 & 0.360 \\
\hline
\end{tabular}

The addition of sand to Granular ' $A$ ' resulted in a more cohesive mix. By adding only $15 \%$ sand segregation was significantly reduced. The cement was kept constant at $25 \mathrm{~kg} / \mathrm{m}^{3}$ and the water was adjusted to achieve a slump between $160 \mathrm{~mm}$ and $170 \mathrm{~mm}$. The specific water content for each mix is shown in Table 4.2. The compressive strength obtained at 28 for mixes containing 15 and $25 \%$ sand were below the maximum limit of $0.7 \mathrm{MPa}$. By using $85 \%$ Granular ' $A$ ' and $15 \%$ sand the cohesiveness of the mix was improved. Figure 4.31 shows the relationship between hardening time and water content and also hardening versus percent sand. 


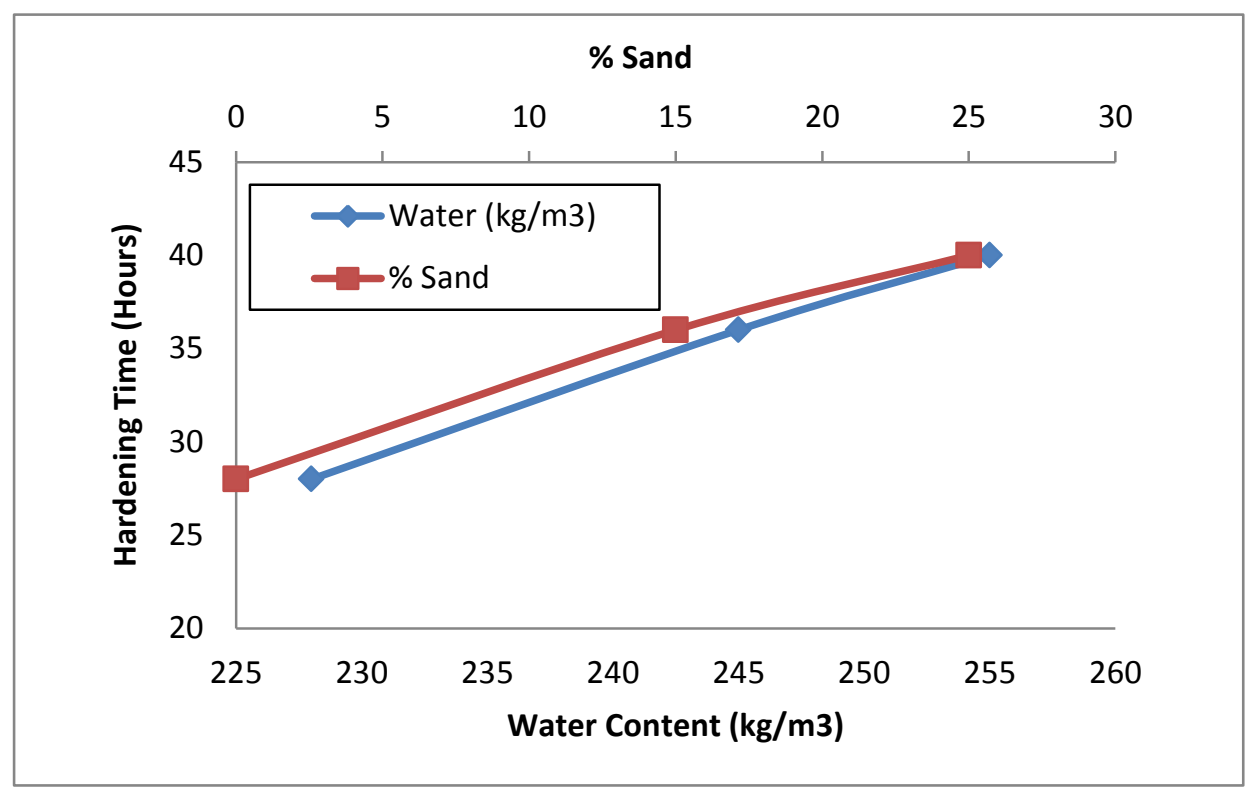

Figure 4.31: Water content vs. hardening time

The graphs above demonstrate that the hardening time increases with a higher sand content. In other words, as more sand is mixed with Granular ' $A$ ', the higher the hardening time will be. Also, hardening time increases with a higher water content. It should be noted that these graphs show the hardening time for Granular ' $A$ ' at different water content and different ratios of Granular ' $A$ ' to fines, and should not be used to predict hardening time for any other U-fill mixes.

\subsubsection{Phase II Results: U-fill Containing RCA of Low Quality}

As mentioned in section 3.3.2.2, two trial mixes were prepared in this stage using only RCA aggregate. One set of mixes were prepared using Portland cement and the other with GGBFS. Results obtained from mixes made with Portland cement were all in compliance with standards specified by OPSS 1359. As it can be seen from Table 4.3, strength of test samples decreases with an increase in water content, less segregation and a more uniform dispersion of fines were seen in samples containing $220 \mathrm{~kg} / \mathrm{m}^{3}$. 
Table 4.3: Phase II-Cement mix results

\begin{tabular}{|c|c|c|c|c|c|}
\hline Mix \# & $\begin{array}{c}\text { Cement } \\
\text { Content } \\
\left(\mathbf{k g} / \mathbf{m}^{\mathbf{3}}\right)\end{array}$ & $\begin{array}{c}\text { Water } \\
\text { Content } \\
\left(\mathbf{k g} / \mathbf{m}^{3}\right)\end{array}$ & $\begin{array}{c}\text { Slump } \\
\mathbf{( m m )}\end{array}$ & $\begin{array}{c}\text { 7 Day } \\
\text { Strength } \\
(\mathbf{M P a})\end{array}$ & $\begin{array}{c}\text { 28 Day } \\
\text { Strength } \\
(\mathbf{M P a})\end{array}$ \\
\hline 1 & 25 & 160 & 155 & 0.035 & 0.116 \\
\hline 2 & 25 & 185 & 162 & 0.030 & 0.096 \\
\hline 3 & 25 & 220 & 175 & 0.015 & 0.087 \\
\hline
\end{tabular}

Proportions of the mixes made with slag were equivalent to mixes containing cement. Similar results were seen with these mixes as well (Table 4.4). Strength results at 7 and 28 days were slightly higher than the mixes containing cement; however the difference is negligible considering the variables associated with measuring such low strength levels.

Table 4.4: Phase II- Slag mix results

\begin{tabular}{|c|c|c|c|c|c|}
\hline Mix \# & $\begin{array}{c}\text { Slag } \\
\text { Content } \\
\left(\mathbf{k g} / \mathbf{m}^{3}\right)\end{array}$ & $\begin{array}{c}\text { Water } \\
\text { Content } \\
\left(\mathbf{k g} / \mathbf{m}^{\mathbf{3}}\right)\end{array}$ & $\begin{array}{c}\text { Slump } \\
(\mathbf{m m})\end{array}$ & $\begin{array}{c}\text { 7 Day } \\
\text { Strength } \\
(\mathbf{M P a})\end{array}$ & $\begin{array}{c}\mathbf{2 8} \text { Day } \\
\text { Strength } \\
(\mathbf{M P a})\end{array}$ \\
\hline 4 & 25 & 160 & 150 & 0.092 & 0.254 \\
\hline 5 & 25 & 185 & 165 & 0.084 & 0.192 \\
\hline 6 & 25 & 220 & 180 & 0.077 & 0.119 \\
\hline
\end{tabular}

A field trial was carried out using mix number 2 from table 4.3 with $185 \mathrm{~kg} / \mathrm{m}^{3}$ water and mix number 6 from table 4.4 with $220 \mathrm{~kg} / \mathrm{m}^{3}$. Water contents for each mix were selected based on the amount of water existing within the trench prior to pouring. From the trial, it was observed that both mixes showed a longer than expected hardening time. When compared to a control mix produced using gravel and sand (Figure 4.33) it was noticed that there is a significant amount of increase in fines due to abrasion while mixing, in mixes containing RCA. This was 
determined from the bleed water settled on top of the mixtures during pouring which was grey in color. Due to the pre-exiting water within the trench and the high amount of water in mix 6 from table 4.4, a significant amount of segregation was observed. Mix 2 table 4.3 did not display this characteristic, however it was noticed that water dissipation is rather slow. It is hypothesized that RCA, due to its hygroscopic properties and high absorption, hinders water from draining outwards. Results from the field trial are summarized in table 4.5. As expected both 7 day and 28 day strengths are below the $0.7 \mathrm{MPa}$ limit.

Table 4.5: Results from first field trial

\begin{tabular}{|c|c|c|c|c|}
\hline Mix \# & Type & 7 Day Strength & 28 Day Strength & $\begin{array}{c}\text { Hardening } \\
\text { Time }\end{array}$ \\
\hline $\mathbf{2}$ (from Table 4.3) & Cement \& RCA & $0.22 \mathrm{MPa}$ & $0.33 \mathrm{MPa}$ & $\approx 44$ hours \\
\hline $\mathbf{6}$ (from Table 4.4) & Slag \& RCA & $0.19 \mathrm{MPa}$ & $0.26 \mathrm{MPa}$ & $\approx 21$ hours \\
\hline
\end{tabular}
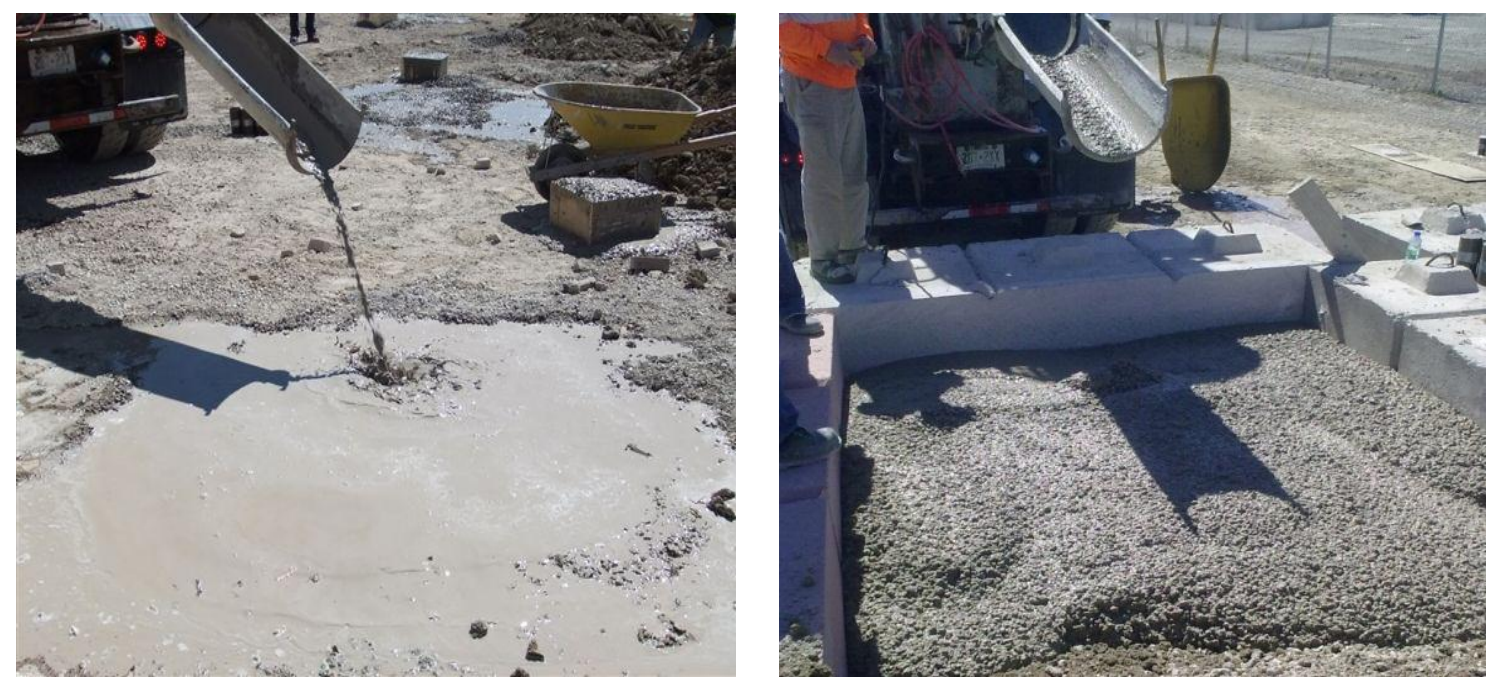

Figure 4.32: Slag and RCA mix (left) cement \&RCA mix (right). Note that the excessive water in the slag mix is attributable to the presence of water in the trench prior to placement of the $U$ fill mix 


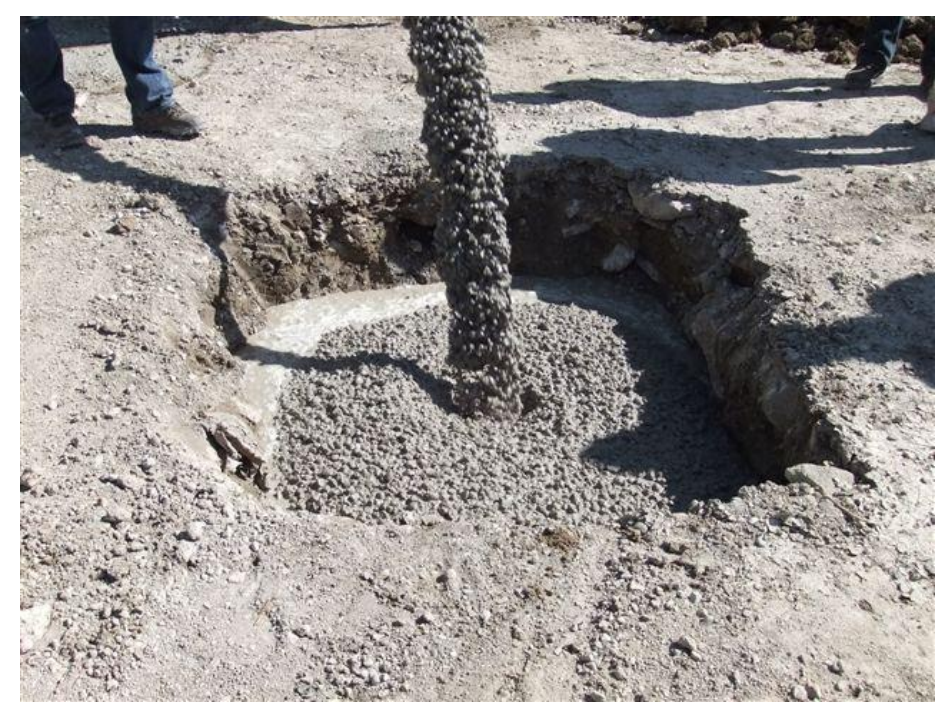

Figure 4.33: Control mixtures produced using gravel and sand

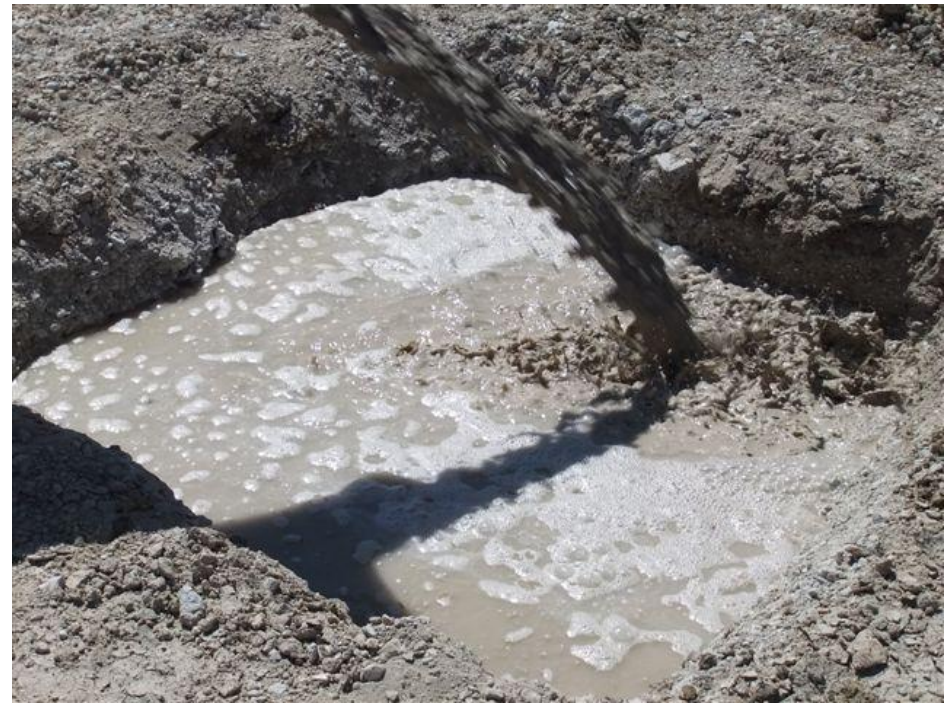

Figure 4.34: Sample containing RCA and slag as the main cementing material

\subsubsection{Phase III Results: Mixes Containing Gravel, Sand and RCA}

In order to reduce hardening time and enable fast draining of water, new mixes were produced by incorporating gravel to the mixes (Table 4.6). Due to their low strength, these mixes could not be demoulded for strength measurement. They also showed high segregation due to the increased percentage of coarse aggregate however the performance of mixes with lower gravel 
content was better in terms of reduced segregation and flowability (Figure 4.35). It had been assumed that due to low abrasion resistance of the RCA aggregate (Table 3.6) there is a significant increase in fines during mixing which would further alter the overall fresh properties of the mix and limit the ability to achieve a desirable hardening time.

Table 4.6: Phase III laboratory mix results

\begin{tabular}{|c|c|c|c|c|}
\hline Mix \# & Aggregate combination & $\begin{array}{c}\text { Water content } \\
\left(\mathbf{k g} / \mathbf{m}^{\mathbf{3}}\right)\end{array}$ & $\begin{array}{c}\text { Cement content } \\
\left(\mathbf{k g} / \mathbf{m}^{\mathbf{3}}\right)\end{array}$ & $\begin{array}{c}\text { Slump } \\
\left(\mathbf{m m}^{\mathbf{2}}\right)\end{array}$ \\
\hline 7 & $70 \%$ RCA \& 30\% Gravel & 180 & 25 & 190 \\
\hline 8 & $70 \%$ RCA \& 30\% Gravel & 220 & 25 & 190 \\
\hline 9 & $50 \%$ RCA \& 50\% Gravel & 220 & 25 & 220 \\
\hline 10 & $80 \%$ RCA \& 20\% Gravel & 185 & 25 & 180 \\
\hline 11 & $80 \%$ RCA \& 20\% Gravel & 220 & 25 & 195 \\
\hline
\end{tabular}

* Hardening time for the above mixes were not measured as segregation was observed in all except for mixes containing 70\%RCA \& 30\%Gravel.The hardening time for this mix with 220 $\mathrm{kg} / \mathrm{m}^{3}$ was tested in stage II (table 4.7).
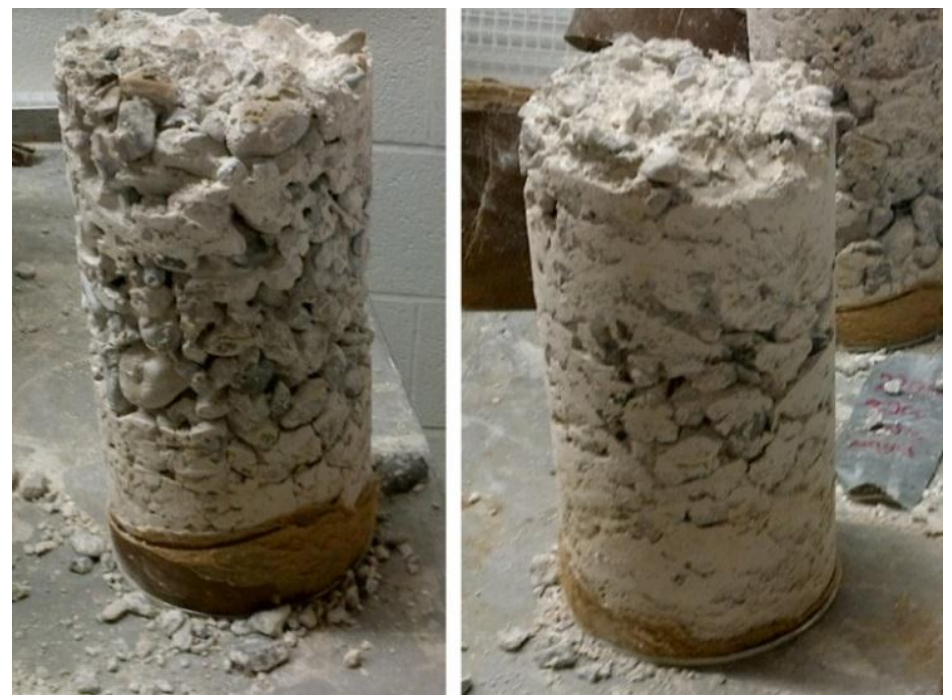

Figure 4.35: Unshrinkable fill mix containing 50\% Gravel and 50\% RCA (left)-80\%Gravel and $20 \%$ RCA (right) 
Due to the lack of performance of mixes containing gravel and sand it was decided that sand must be included into the mixtures in order to provide for a more dense graded mixture (Figure 4.36) which would resulted in mixtures with better performance in terms of segregation and hardening (Table 4.7). A significant difference was noticed within these mixes mainly due to the lower overall absorption of the combined aggregate. Water dissipation rate was significantly higher compared to those mixes made with RCA alone or RCA and gravel combined. It can be clearly seen in Figure 4.37 that hardening time increases with higher RCA contents.

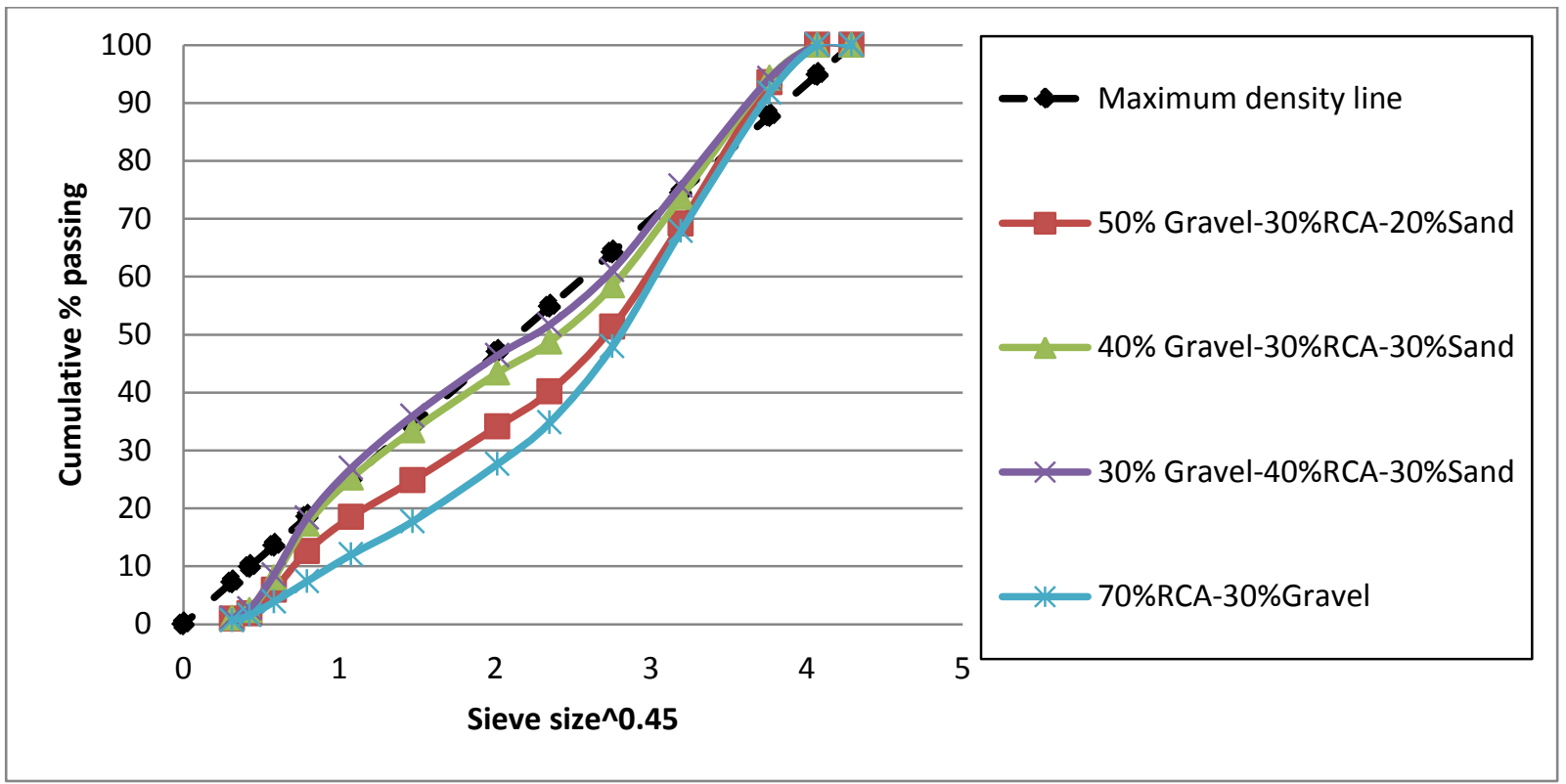

Figure 4.36: 0.45 power gradation curve of phase III mixes

Table 4.7: Stage II of Phase III mixes (lab results)

\begin{tabular}{|c|c|c|c|c|c|c|}
\hline Mix \# & Gravel & RCA & Sand & $\begin{array}{c}\text { Cement } \\
\left(\mathbf{k g} / \mathbf{m}^{3}\right)\end{array}$ & $\begin{array}{c}\text { Water } \\
\left(\mathbf{k g} / \mathbf{m}^{3}\right)\end{array}$ & $\begin{array}{c}\text { Hardening } \\
\text { time (min) }\end{array}$ \\
\hline 12 & $50 \%$ & $30 \%$ & $20 \%$ & 25 & 220 & 20 \\
\hline 13 & $40 \%$ & $30 \%$ & $30 \%$ & 25 & 220 & 35 \\
\hline 14 & $30 \%$ & $40 \%$ & $30 \%$ & 25 & 220 & 40 \\
\hline 15 & $30 \%$ & $70 \%$ & -- & 25 & 220 & 50 \\
\hline
\end{tabular}




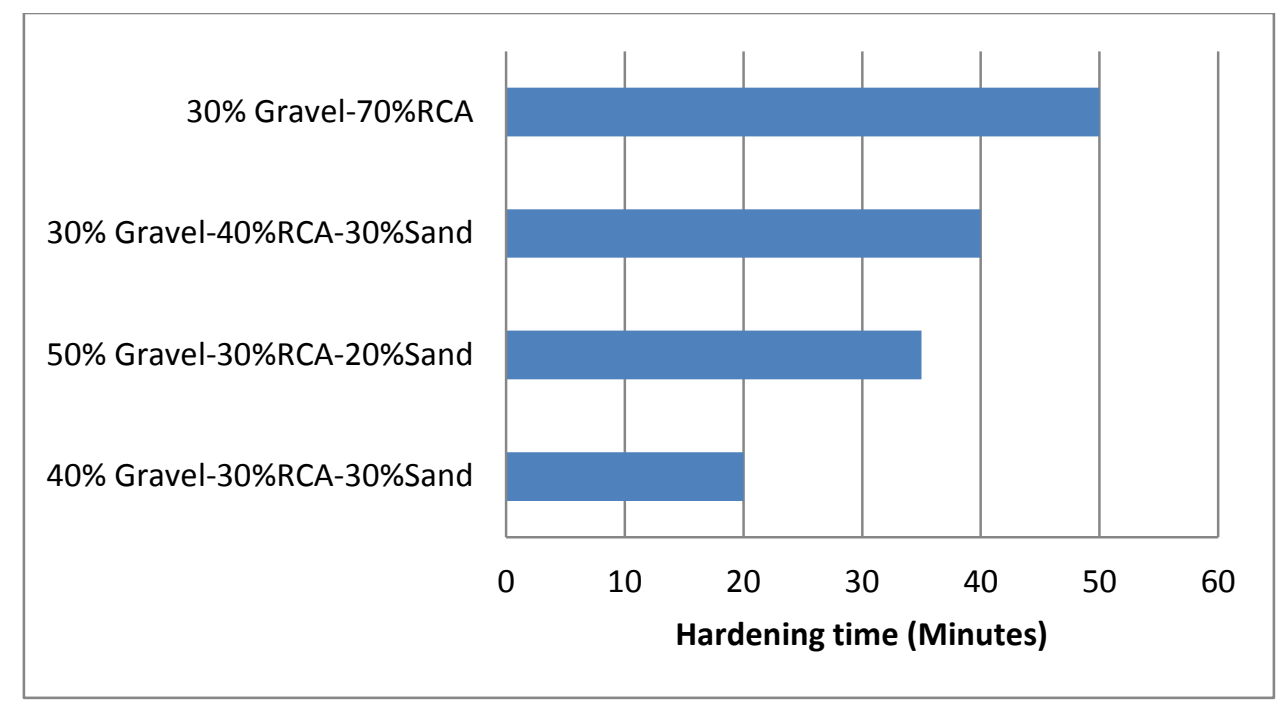

Figure 4.37: Hardening time of phase III laboratory mixes

The reasons behind the effect of RCA on hardening time are not yet fully understood. It appears that factors other than the high absorption of RCA affect the rate of water drainage from the fresh mix. Increased fines may have been generated during the mixing process at the batch plant or in the transport vehicle due to the low abrasion resistance of RCA. The high ability of such fines to retain water through increased absorption and adsorption capacity could be a contributing factor as well.

The three mixes selected for the second field trial are summarized in Table 4.8. Due to the poor drainage properties of the surrounding Halton Till, water dissipated at a much lower rate than the lab mixes which were tested in wooden boxes (Table 4.7). Therefore, to further reduce the hardening time, the third mix was batched using $70 \%$ gravel, $20 \%$ RCA and $10 \%$ sand (mix 16 ). However, the hardening time for this mix was higher than the mix containing $50 \%$ gravel, $30 \%$ RCA and $20 \%$ sand (mix 12 from table 4.7 ).

The reason behind this increase in hardening time could be attributed to the fact that during mixing, abrasion of the RCA causes an increase in fines and thus an increase in hardening time. As seen in Table 3.6, the MDA losses of the RCA used in these experiments were relatively high. 
This could have increased the total fines in the mixtures resulting in lower water dissipation from the fresh fill. Therefore it is necessary to find the correct proportions of fine and coarse aggregate and examine various trial mixes prior to finalizing them in order to be able to accurately predict the performance of U-fill produced with RCA.

Table 4.8: Results from second field trial

\begin{tabular}{|c|c|c|c|c|c|}
\hline Mix \# & Gravel & RCA & Sand & Water $\left(\mathrm{kg} / \mathrm{m}^{\mathbf{3}}\right)$ & Hardening time \\
\hline $\mathbf{1 5}$ (from table 4.7) & $30 \%$ & $70 \%$ & $0 \%$ & 220 & $\approx 5$ hours \\
\hline $\mathbf{1 2}$ (from table 4.7) & $50 \%$ & $30 \%$ & $20 \%$ & 220 & $\approx 1$ Hour \\
\hline 16 & $70 \%$ & $20 \%$ & $10 \%$ & 200 & $\approx 3$ Hours \\
\hline
\end{tabular}
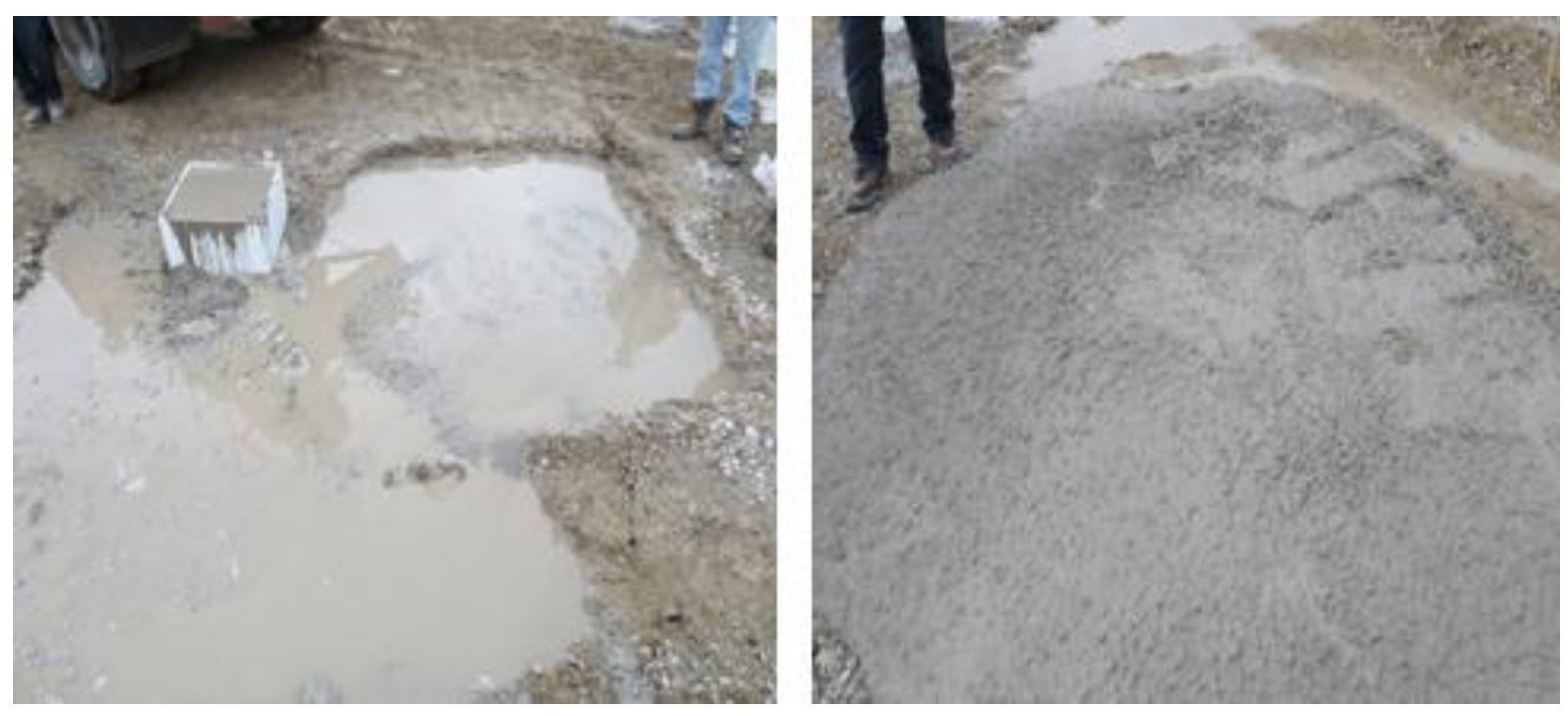

Figure 4.38: Field trial mix containing 50\% Gravel, 30\% RCA \& $20 \%$ Sand (Left) \& Field trial mix containing $70 \%$ Gravel, 30\% RCA \& $20 \%$ Sand (Right) 


\subsubsection{Phase IV Results: U-fill Mixtures Containing RCA of Low MDA Loss}

As seen in Table 3.8, aggregates used in this phase had lower overall MDA loss as compared to those summarized Table 3.6. It was assumed that due to the higher durability of the RCA used in this phase, fresh properties of the $U$-fill mixes (such as flowability and hardening time) would be significantly enhanced. It must be also noted that the RCA used in this phase contained only aggregate sizes of $4.75 \mathrm{~mm}$ and above. Using only coarse RCA would decrease the overall absorption, therefore enhancing the water dissipation rate. As previously discussed in section 3.3.2.4, concrete sand was added to the mixes in this phase along with RCA to enhance flowability. Results of laboratory mixes produced in this phase are shown in table 4.9.

Table 4.9: Phase IV laboratory mix results

\begin{tabular}{|c|c|c|c|c|c|}
\hline Mix \# & $\begin{array}{c}\text { \%Coarse aggregate } \\
\text { (RCA) }\end{array}$ & $\begin{array}{c}\text { \%Fine aggregate } \\
\text { (Concrete sand) }\end{array}$ & $\begin{array}{c}\text { Water } \\
\text { content } \\
\left(\mathbf{k g} / \mathbf{m}^{\mathbf{3}}\right)\end{array}$ & $\begin{array}{c}\text { Cement } \\
\text { content } \\
\left(\mathbf{k g} / \mathbf{m}^{\mathbf{3}}\right)\end{array}$ & $\begin{array}{c}\text { Hardening } \\
\text { time } \\
\text { (Minutes) }\end{array}$ \\
\hline Mix 1 & 80 & 20 & 190 & 25 & 12 \\
\hline Mix 2 & 70 & 30 & 190 & 25 & 12 \\
\hline Mix 3 & 60 & 40 & 190 & 25 & 10 \\
\hline Mix 4 & 55 & 45 & 190 & 25 & 6 \\
\hline
\end{tabular}

As expected, mixes produced in this phase had a significantly lower hardening time compared to laboratory mixes produced in phase I, II and III. Using concrete sand and lower overall MDA loss of coarse RCA aggregate proved to have a significant effect in terms of water dissipation. Higher amount of segregation and bleeding was observed in mixes 1 and 2 which contained the largest \% of coarse aggregate (mix 1 and 2). Also In terms of flowability, mixes 3 and 4 were superior compared to mixes 1 and 2 .

In order to investigate the in-situ performance of the mixes produced in this phase, two mixes 
with slightly higher water contents were selected from Table 4.9 to be tested at a field trial. A control mix containing gravel and sand were also batched for comparison purposes. The coarse and fine proportions of these mixes were as follows:

- Mix 1: $52 \%$ Gravel and 48\% concrete sand (Control batch- Note that this mix does not contain RCA)

- Mix 2: 70\% RCA (Coarse) and 30\% concrete sand

- Mix 3: 55\% RCA (Coarse) and 45\% concrete sand

Once poured, Mix 1 (Control mix) showed great flowability characteristics with minimum amount of segregation (Figure 4.39). Unlike mixes from phase II and III where drainage of water was found to be slow, this mix showed exceptional drainage characteristics. As predicted, this mix was able to take load within a relatively short period of time from being poured. As seen in the figure below, the darker contour around the mix displays the absorbent characteristic of the soil surrounding the mix, causing an enhancement in water dissipation rate.

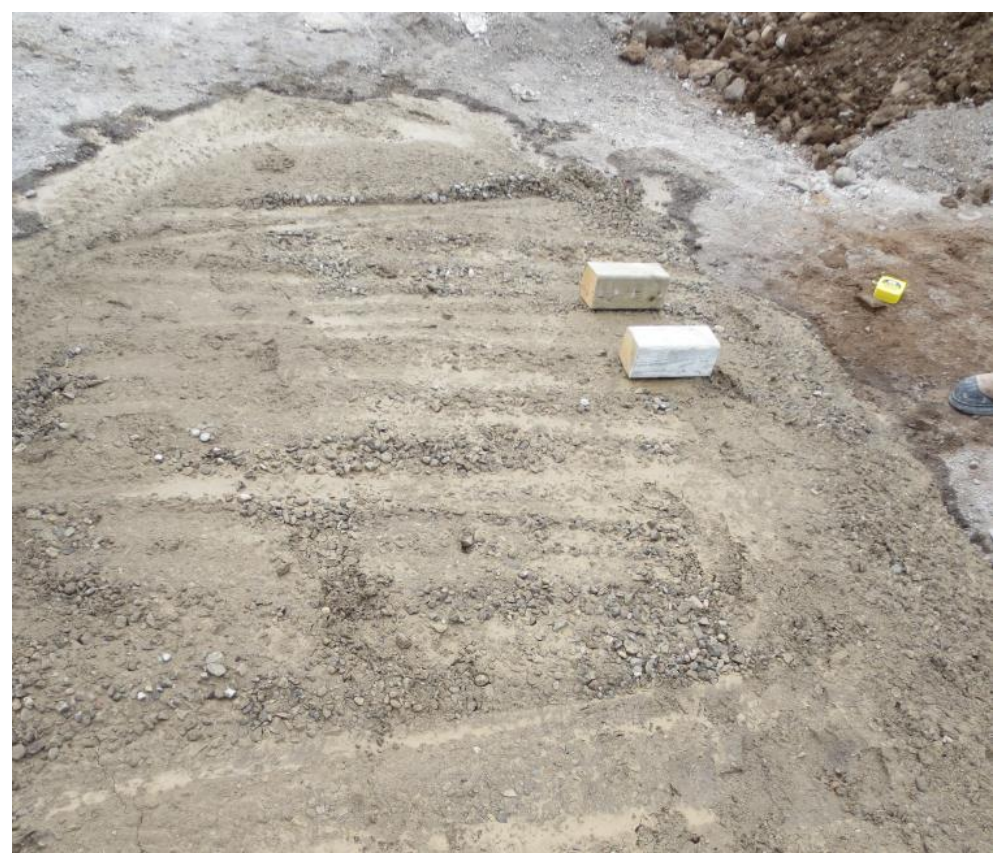

Figure 4.39: Control mix containing gravel and concrete sand 
Mix 2 containing 70\% RCA and 30\% concrete sand was selected in order to investigate the feasibility of using high percentages of RCA while achieving desirable properties. Unlike the control mix, signs of segregation were observed with this mix due to the lack of fines. While being poured, coarse aggregates were pushed to one side of the trench by the force exerted from the mix being poured out of the mixer chute while water along with much of the fines were gathered on the opposite side (Figure 4.40). At a closer glance at the coarser area, the lack of fines was completely noticeable (Figure 4.41).

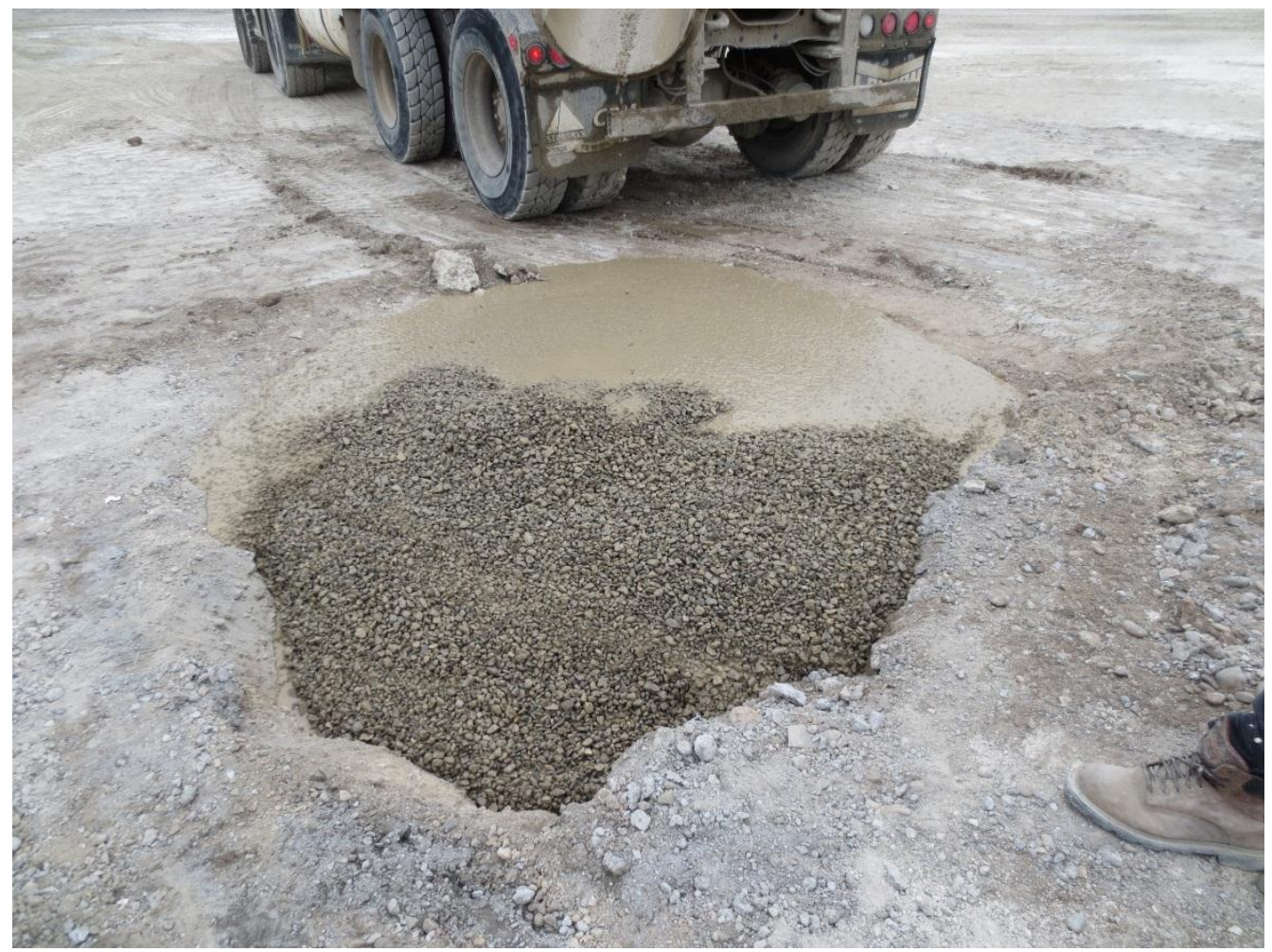

Figure 4.40: Mix 2 from phase IV containing 70\% RCA and 30\% sand 


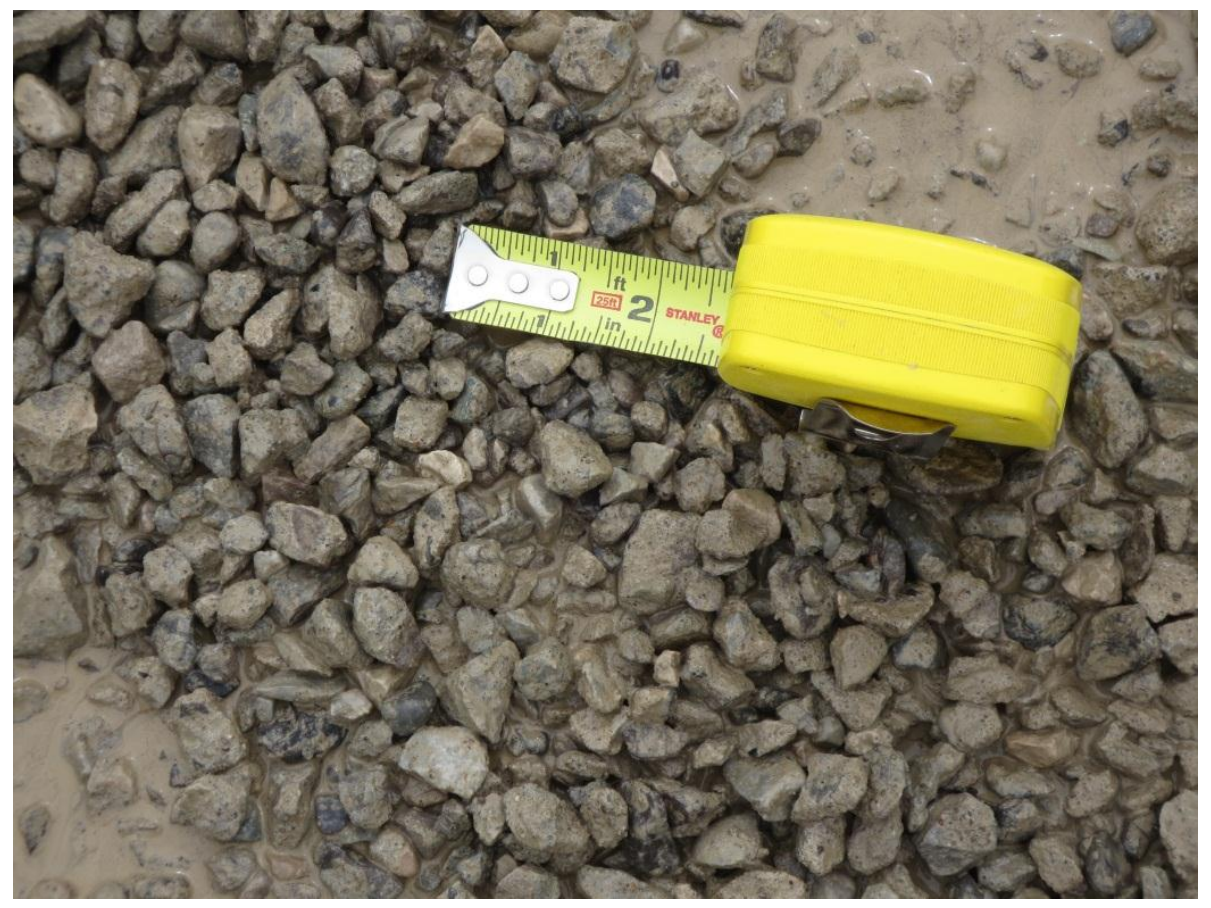

Figure 4.41: Separation of coarse and fine aggregate in mix 2 containing 70\% RCA (Coarse) and $30 \%$ concrete sand

Contrary to field trial mixes produced in phase II and III, the mix shown in Figure 4.40 did not show an affinity to water retention. It can be argued that since RCA used in phase II and III had a higher percentage of abrasion loss, an increase in highly absorbent micro fines during mixing had resulted in a reduction in drainage capabilities while in this phase, due to the lower overall abrasion loss of RCA, water dissipation rate was much faster.

Based on results observed from Mix 1 and 2, it was decided to reduce the RCA content to 55\% in order to mitigate segregation and separation of fines. As expected, this mix displayed much better characteristics compared to Mix 2 containing 70\% RCA. While being poured, this mixture showed great flowability and lower segregation compared to Mix 2 (Figure 4.42). 


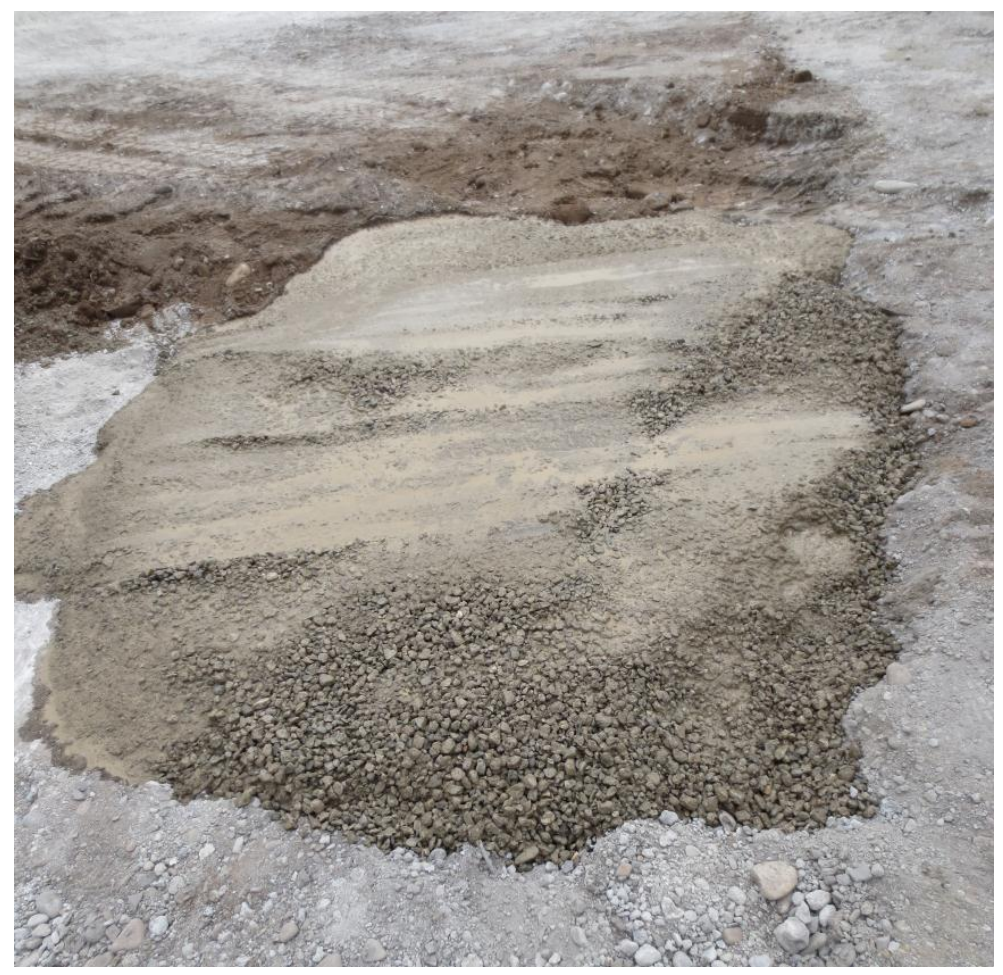

Figure 4.42: Mix 3 from phase IV containing 55\% RCA and 45\% concrete sand

Fresh properties of Mix 3 were very similar to that of the control mix (Mix 1). This U-fill mixture was capable of taking load within a very short amount of time. In fact, hardening time was found to be lower than the control mix. The results from all three mixes are summarized in table 4.10.

Table 4.10: Phase IV field trial results

\begin{tabular}{|c|c|c|c|c|c|}
\hline Mix \# & \% Coarse & $\begin{array}{c}\text { \%Fines } \\
\text { (Concrete sand) }\end{array}$ & $\begin{array}{c}\text { Water content } \\
\left(\mathbf{k g} / \mathbf{m}^{\mathbf{3}}\right)\end{array}$ & $\begin{array}{c}\text { Slump } \\
(\mathbf{m m})\end{array}$ & $\begin{array}{c}\text { Hardening } \\
\text { time } \\
\text { (Minutes) }\end{array}$ \\
\hline Mix 1 & 52 (added as gravel) & 48 & 228 & 205 & 46 \\
\hline Mix 2 & 70 (added as RCA) & 30 & 230 & 230 & 65 \\
\hline Mix 3 & 55 (added as RCA) & 45 & 220 & 220 & 20 \\
\hline
\end{tabular}


It should be noted that all three mixes were more or less capable of taking load soon after pouring. However, based on the Kelly ball apparatus used to measure hardening time, the indentation left by the ball on the surface of the mixes at various time increments differed. Since Mix 2 displayed signs of segregation, hardening time was measured in two areas, one being the separated coarser area and the other being the area composed mostly of fine aggregate (area one and two in Figure 4.43 respectively).

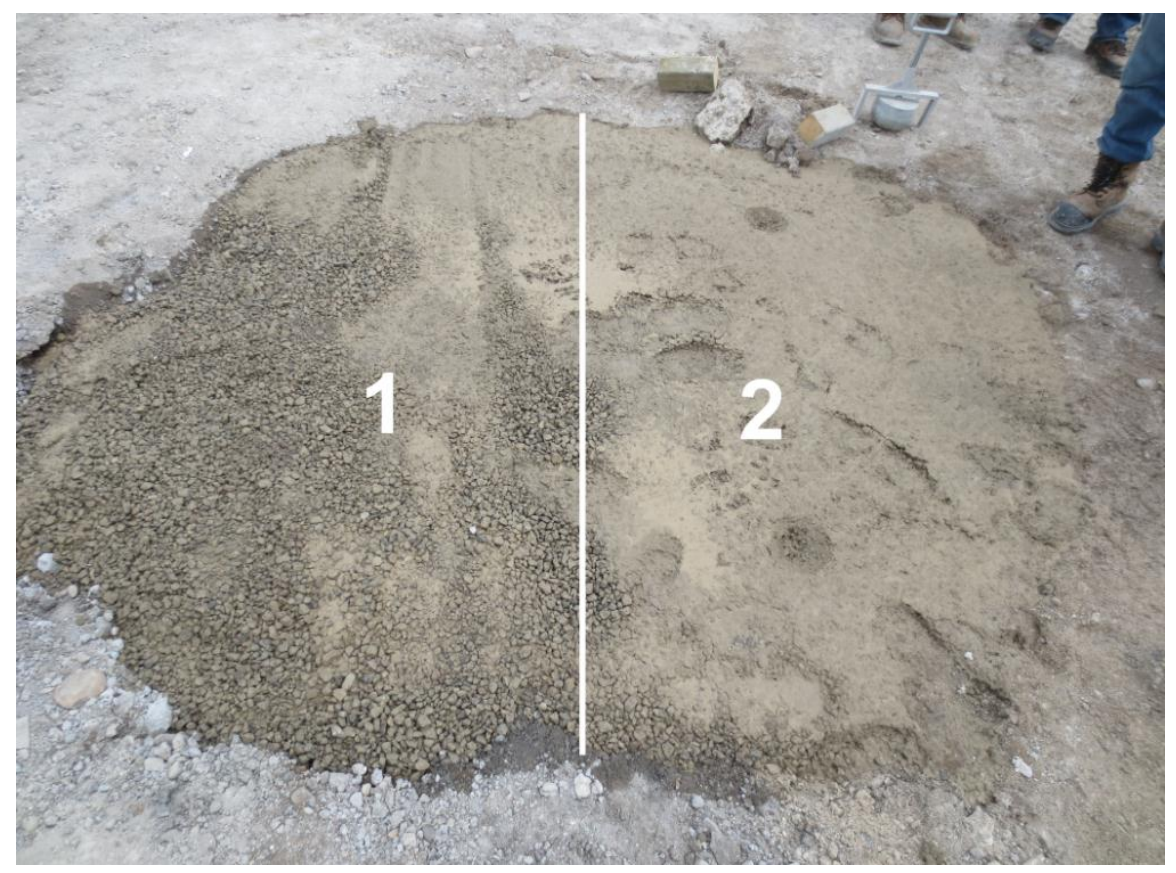

Figure 4.43: Locations for hardening time measurements on segregated mixes

Due to the higher amount of fines in area two, hardening time measurements at this location was slightly higher compared to area one. The hardening times shown in Table 4.10 corresponds to the maximum hardening time obtained from each mix. However, if the hardening times were to be expressed as the time measured from the location on the surface having the most amount of coarse aggregate, these results would be even lower. This matter is displayed in Table 4.11. As it can be seen, due to the higher amount of segregation in the mix containing $70 \%$ RCA (coarse) and $30 \%$ sand, there is a larger difference in hardening time between the two locations. 
A slight amount of separation of fines was also observed in mix 3 . This perhaps could be due to reasons other than the coarse aggregate content of the mix (such as time of mixing and pouring method). To ensure that proper hardening time was obtained, similar to mix 2 the ball drop apparatus was used in two locations. Overall, in mix 3 containing 55\% RCA (coarse) and 45\% sand, due to minimum amount of segregation and more cohesiveness, difference in hardening time between the two areas was found to be much lower.

Table 4.11: Hardening time measurements of area 1 and 2

\begin{tabular}{|c|c|c|}
\hline Mix \# & $\begin{array}{c}\text { Hardening time (Minutes) } \\
\text { Area 1 }\end{array}$ & $\begin{array}{c}\text { Hardening time (Minutes) } \\
\text { Area 2 }\end{array}$ \\
\hline $\begin{array}{c}\text { Mix 2: 70\% RCA (Coarse) } \\
\text { and 30\% concrete sand }\end{array}$ & 20 & 65 \\
\hline $\begin{array}{c}\text { Mix 3: 55\% RCA (Coarse) } \\
\text { and 45\% concrete sand }\end{array}$ & 15 & 20 \\
\hline
\end{tabular}

Based on observation from laboratory and U-fill mixes of phase I through IV, and industrial standards and requirements for U-fill mixtures, it can be said that mix 3 displays all characteristics of a desirable U-fill mix. 


\subsubsection{Effects of Unhydrated Cement Paste of RCA}

Throughout the investigation of RCA it has been noticed that where returned to plant RCA is used, some binding is observed between aggregate particles in the absence of any cementing materials. Throughout the mixing procedures, an agglomeration of RCA was seen whilst being mixed with only water. This characteristic was also seen in RCA stockpiles where aggregates were perhaps moistened through precipitation causing fine particles to bind together, forming large masses (Figure 4.44).

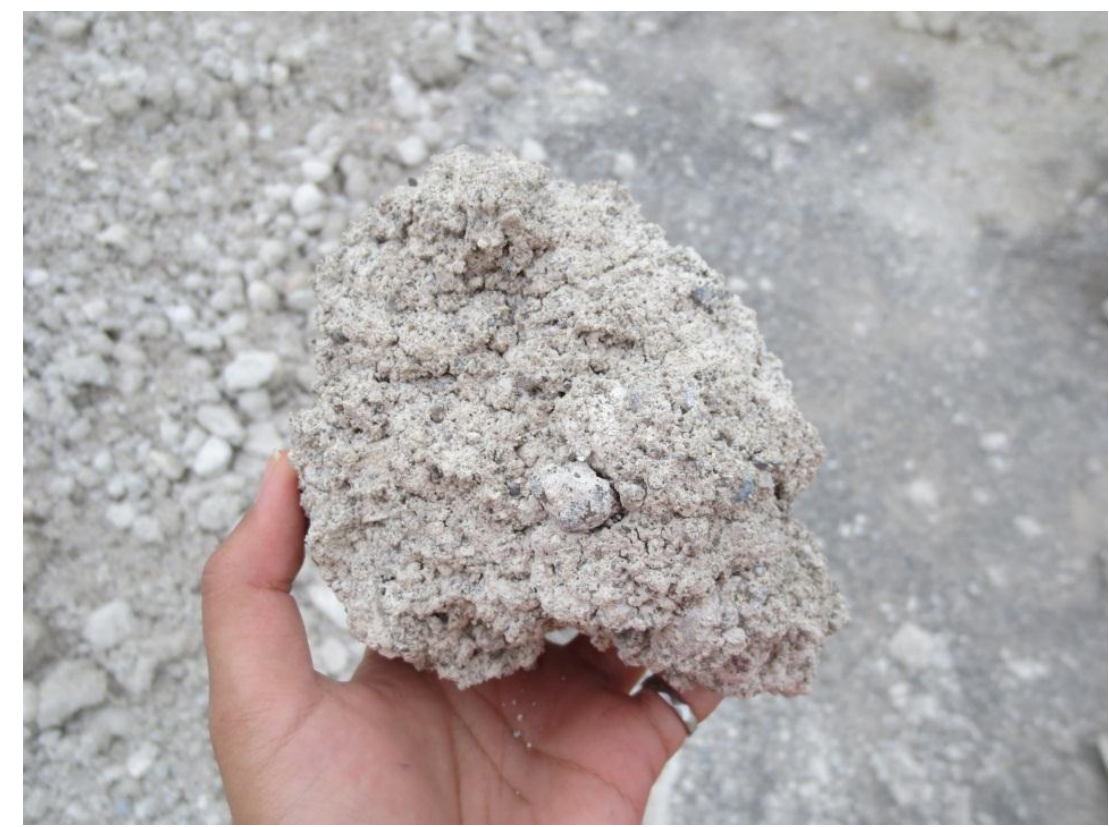

Figure 4.44: Agglomeration of RCA fines from a stockpile showing considerable bonding due to presence of unhydrated cement paste

To further investigate this property, RCA with high MDA loss was mixed with a water content of $185 \mathrm{~kg} / \mathrm{m}^{3}$ and tested for 28day strength. Based on results obtained from 6 sample cylinders, compressive strength was found to be $0.31 \mathrm{MPa}$. Visually however, the samples also displayed good signs of bonding. 
Figure 4.45 below shows a sample cylinder containing only RCA and $185 \mathrm{~kg} / \mathrm{m}^{3}$ of water (right) in comparison to a sample produced using $55 \%$ gravel, $45 \%$ concrete sand, $25 \mathrm{~kg} / \mathrm{m}^{3}$ of cement and $185 \mathrm{~kg} / \mathrm{m}^{3}$ of water (left). As it can be seen, no signs of segregation can be seen in either sample. The sample cylinder shown on the left also displayed a similar strength. The reason for the high amount of binding in the sample containing of RCA is perhaps due to the existence of unhydrated cement paste within the aggregate.

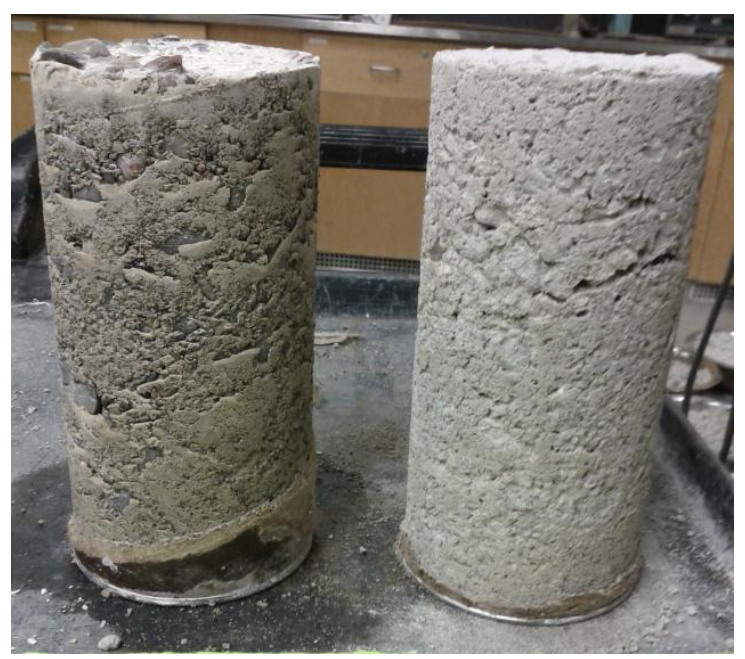

Figure 4.45: Sample containing 55\% Gravel, $45 \%$ sand, $25 \mathrm{~kg} / \mathrm{m}^{3}$ cement and $185 \mathrm{~kg} / \mathrm{m}^{3}$ of water (left) \& sample containing RCA of high MDA loss and $185 \mathrm{~kg} / \mathrm{m}^{3}$ of water (right)

Once exposed to water, the unhydrated paste will provide a weak bond between the aggregates. This amount of bond is enough to produce sufficient strength for U-fill applications. As mentioned previously in section 2.2.3 and as discussed by Abbas et al. (2009), the effects of mortar associated with RCA should not be overlooked in concrete mix designs as it does influence the mix properties and the performance of hardened concrete. RCA can be retrieved from a wide range of demolished or returned to plant concrete. Based on this variation, amount of binding caused by the unhydrated cement paste might differ from one source of RCA to another. Therefore, a detailed investigation must be carried out in order to determine the effects of unhydrated paste could have on various characteristics of concrete mixes. 


\section{Chapter 5}

\section{Conclusions and Recommendations for Further Studies}

Based on the results of this research program, it can be concluded that:

- Using $100 \%$ RCA aggregate with high Micro-Deval loss to produce Unshrinkable fill mixes will not fully satisfy all fresh requirements of U-fill mainly because this will result in an extended hardening time due to slow dissipation of mixing water.

- The increase in fines due to mixing and abrasion of the RCA can further increase the water dissipation time. This however is not applicable where the MDA loss of the aggregate is low, meeting requirements for concrete aggregate.

- Where aggregates with low MDA loss and absorption are used, U-fill mixes will have characteristics very similar to mixes produced using natural stones such as gravel and sand. This is particularly correct, if such RCA is used with natural sand.

- An optimum mix containing $55 \%$ coarse recycled concrete aggregate and $45 \%$ concrete sand was found to display characteristics of a desirable U-fill mix. Based on the physical properties such as absorption and MDA loss of RCA's under study, these proportions could differ.

- Where U-fill mixes are produced using RCA of low or marginal quality (high MDA loss) it is recommended that a mixture of RCA, natural coarse aggregate and concrete sand be used to achieve desirable fresh U-fill mix properties. The amount of coarse aggregate and sand content of each mix should be adjusted based on the gradation of the RCA under study and the percent increase in fines due to abrasion. 
- It should be borne in mind since the physical properties of RCA aggregates vary depending on the source from which they are produced from, analyzing the aggregate durability and physical properties are of significant importance as it can considerably increase or reduce flowability and hardening time which are very important characteristics when choosing optimum U-fill mixes.

- As a result of the chemical analysis done in this research program on mortar bars tested at an aggregate to cement ratio of $11: 1$, and a water to cement ratio of 1.9 , and soaked in a saturated solution of lime water, it was found that sulphate contents as high as $1.5 \% \mathrm{SO}_{4}$ by mass of aggregate do not produce expansion due to internal sulphate attack (Ettringite, Thaumasite formation).

- Since U-fill mixes contain only $25 \mathrm{~kg} / \mathrm{m}^{3}$ of cement, the effects of Thaumasite formation could be different than the bars investigated here; however, this requires further investigation.

- The aggregate to cement ratio used in the bars investigated here was higher than what a u-fill mix should be but lower than a conventional mortar bar mix with 2.75:1 aggregate to cement ratio and 0.485 water to cement ratio. The higher cement content used in these bars was solely for demoulding and testing purposes. However it can be understood that in a conventional u-fill mixes the effects of sulphate bearing aggregate on expansion will be much less predominant and noticeable since Thaumasite is dependent on the components of Portland cement.

- It has been found that using only $10 \%$ Metakaolin mixes with sulphate contents of $2.5 \%$ (by mass of aggregate) or higher can considerably reduce expansion caused by Ettringite and Thaumasite formation. Alternatively, the use of GGBFS also proves to be a viable method in mitigating expansion. 
- Expansion due to internal sulphate attack can be expected to be much lower where sulphates in aggregate are present as $\mathrm{Na}_{2} \mathrm{SO}_{4}$ rather than gypsum. Due to the lower calcium content in mortar bars produced using $\mathrm{Na}_{2} \mathrm{SO}_{4}$, a significantly lower expansion was observed.

- Based on the observations mentioned above, it can be concluded that aggregates not meeting the requirements of OPSS 1002 can be successfully used in U-fill. An acceptable U-fill mix can be produced with aggregates with sulphate contents of $1.5 \%$ $\mathrm{SO}_{4}$ or lower; however, with the addition of SCM's such as slag or metakaolin, a durable mixture may be achieved.

- While metakaolin could be an expensive material to use in U-Fill, slag is a more economic and feasible option as many ready mix plants have slag readily available in their silos. 


\section{Recommendations for future study}

U-fill mixtures are commonly used as a fill for cuts in pavements; therefore the extent of the effects that severe expansion caused by sulphate bearing aggregate could induce onto surface layers (concrete or asphalt) must be investigated. This is especially important since severe expansion of $U$-fill can cause heaving and induce cracks in the surface layers; this may promote the ingress of other deleterious chemicals into the surface and subsurface layers causing even further damage. The in-situ performance of U-fill containing aggregates of high sulphate content was not investigated in this research program. However it is speculated that due to the overall lower amount of cement in U-fill mixtures compared to mortar bars produced in this study, expansion caused by sulphate contents of up to $2.5 \%$ would be rather insignificant and not cause much damage to the superimposed structures.

Furthermore, mortar bars produced in this research program were designed to simulate conventional U-fill mixtures and thus cement contents were rather low. However, to further investigate the causes and effects of Ettringite and Thaumasite attack on concrete structures, it is recommended that a detailed research is carried out on bars produced based on the outlines indicated in ASTM C452 and the addition of various percentages of sulphate. A detailed study on the microstructure and deterioration mechanism may then be done in order to determine and confirm the limits of sulphate where expansion is not severe. The effects of total $C_{3} A$ content have not been studied in this research program; however it is suggested that as a second step to the studies done in this paper the effects of various amounts of $C_{3} A$ on expansion caused by Ettringite and Thaumasite formation must be determined at various sulphate contents. 


\section{References}

Abbas , A., Fathifazl, G., Isgor, B., Ghani Razaqpur, A., Fournier, B., \& Foo, S. (2009). Durability of recycled aggregate concrete designed with equivalent mortar volume method. Cement and Concrete Composites, 31(8), 555-563.

ASTM Standard C452, (2010), "Standard Test Method for Potential Expansion of PortlandCement Mortars Exposed to Sulphate", ASTM International, West Conshohocken, PA, 2003, DOI: 10.1520/C0452_C0452M-10, www.astm.org.

ASTM Standard C157, (2008), "Standard Test Method for Length Change of Hardened HydraulicCement Mortar and Concrete", ASTM International, West Conshohocken, PA, 2003, DOI: 10.1520/C0157_C0157M-08, www.astm.org.

ASTM Standard D6024, (2007), "Standard Test Method for Ball Drop on Controlled Low Strength Material (CLSM) to Determine Suitability for Load Application", ASTM International, West Conshohocken, PA, 2003, DOI: 10.1520/D6024-07, www.astm.org.

BETON Innovative services. (2013). Concrete reclaimers. Retrieved June $3^{\text {rd }}, 2013$ from: http://www.betoninnovativeservices.com/concrete reclaimers.php

Bensted, J. (2003). Thaumasite-direct, woodfordite and other possible formation routs. Cement and Concrete Composites, 25(8), 873-877.

Bellmann, F., \& Stark, J. (2007). Prevention of Thaumasite formation in concrete exposed to sulphate attack. Cement and Concrete Research, 37(8), 1215-1222.

Blanco-Varela, M. T., Aguilera, J., \& Martinez-Ramirez, S. (2006). Effect of cement c 3 a content, temperature and storage medium on Thaumasite formation in carbonated mortars. 
Cement and Concrete Composites, 36(4), 707-716.

Buck, A. D. (1977). Recycled concrete as a source of aggregate. ACl Journal, 74 (5), 212-219.

Brueckner, R., Williamson, S. J., \& Clark, L. A. (2002). Rate of the Thaumasite form of sulphate attack under laboratory conditions. Cement and Concrete Composites, 34(3), 365-369.

California Department of Resources Recycling and Recovery (CalRecycle). (2013). Tirederived product (tdp) descriptions and case studies. Retrieved May $15^{\text {th }}, 2013$,from: http://www.calrecycle.ca.gov/Tires/BizAssist/TireFeed.htm

Clark, L. A., \& Fattuhi, N. I. (1996). Cement based materials containing shredded scrap truck tire rubber. Construction and building materials,10(4), 229-236.

Collepardi, M. (1999). Thaumasite formation and deterioration in historic buildings. Cement and Concrete Composites, 21(2), 147-154.

Crammond, N. J. (2003). The Thaumasite form of sulphate attack in the UK. Cement and Concrete Composites, 25(8), 809-818.

De Brito, J., (2010). Abrasion resistance of concrete made with recycled aggregates. International Journal of Sustainable Engineering, 3(1), 58-64.

Du, L., Folliard, K. J., Trejo, D., (2002). Effects of constituent materials and quantities on water demand and compressive strength of controlled low strength material. Journals of Materials in Civil Engineering, 4(6), 485-495.

Fumei, L., Mingyu, H., \& Mingshu, T. (2006). The Thaumasite form of sulfate attack in concrete of Yongan dam. Cement and Concrete Research, 36(10), 2006-2008. 
Folliard, K. J., Du, L., Trejo, D., Halmen, C., Sabol, S., \& Leshchinsky, D. National Cooperative Highway Research Program, (2008).Development of a recommended practice for use of controlled low strength material in highway construction (Report No.597). Washington: Transportation Research Board.

Gassman, S. L., Pierce, C. E., \& Schroeder, A. J. (2001). Effects of prolonged mixing and retempering on properties of controlled low strength material (CLSM). ACl Materials Journal, 98(2), 194-199.

Gaze, M. E., \& Crammond, N. J. (2000). The formation of Thaumasite in a cement:lime:sand mortar exposed to cold magnesium and potassium sulfate solutions. Cement and Concrete Composites, 22(3), 209-222.

Gorst, N. J. S., \& Clark, L. A. (2003). Effects of Thaumasite on bond strength of reinforcement in concrete. Cement and Concrete Composites, 25(8), 1084-1094.

Heinz, D., and Ludwig, U. (1996), "Mechanism of subsequent Ettringite formation in mortars and concretes after heat treatment," Proceedings, 8th International Congress on Chemistry of Cement, Rio de Janeiro, Brazil Vol. 5, 189-194.

Jennings, H., \& Thomas, J. (2008). The science of concrete. Retrieved June $12^{\text {th }}, 2013$, from: http://iti.northwestern.edu/cement/monograph/Monograph3 8.html

Johansen, V. Thaulow, J. Skalny, J. (1993).Simultaneous presence of alkali silica gel and Ettringite in concrete, Advances in cement research, 5(17), 23-29

Katz, A., Kovler, K., (2004). Utilization of Industrial By-Products for the Production of Controlled Low-Strength Materials, Journal of Waste Management, 24(5), 501-512. 
Kohler, S., Heinz, D., \& Urbonas, L. (2005). Effects of Ettringite on Thaumasite formation. Cement and Concrete Composites, 36(4), 697-706.

Lachemi, M., Hossain, K. M. A., Shehata, M., \& Thaha, W. (2008). Controlled low strength materials incorporating cement kiln dust from various sources. Cement and Concrete Composites, 30(5), 381-392.

Lachemi, M., Sahmaran, M., Hossain, K. M. A., Lotfy, A., \& Shehata, M. (2010). Properties of controlled low-strength materials incorporating cement kiln dust and slag. Cement and Concrete Composites, 32(8), 623-629.

Ma, B., Gao, X., Byars, E., \& Zhou, Q. (2006). Thaumasite formation in a tunnel of Bapanxia dam in western china. Cement and Concrete Research, 36(4), 716-722.

Mulenga, D. M., Stark , J., \& Nobst, P. (2003). Thaumasite formation in concrete and mortars containing fly ash. Cement and Concrete Composites, 25(8), 907-912.

Naganathan, S., Mustapha, K. N., \& Omar, H. (2012). Use of recycled concrete aggregate in controlled low strength material (CLSM). Civil Engineering Dimension, 14(1), 13-18.

Nagaraj, T. S., Udayshankar, B. C. \& Shashishankar, A. (2006). Flow behavior of CLSM slurries analysis and assessment. Bulletin of ACCE (I), 39-44.

NRMCA (National Ready Mix Concrete Association) (2009).Flowable fill materials. Retrieved May $8^{\text {th }}$ 2013, from: http://www.nrmca.org/aboutconcrete/cips/17p.pdf

Ontario Provincial Standard Specification OPSS 1359. (November 2006). Material specifications for unshrinkable backfill. Ontario Provincial Standards for Roads \& Public Works 
Ontario Provincial Standard Specification OPSS 1010. (April 2004). Material Specification for Aggregates - Base, Subbase, Select Subgrade and Backfill Material, Ontario Provincial Standards for Roads \& Public Works

Ontario Ministry of Natural Resources. (2009). State of the aggregate resource in Ontario study (SAROS). Kingston: Queens's printer for Ontario. Retrieved May $28^{\text {th }}, 2013$, from: http://www.mnr.gov.on.ca/stdprodconsume/groups//r/@mnr/@aggregates/documents/ document/stdprod 067712.pdf

Padmini, A. K., Ramamurthy, K., \& Mathew, M. S. (2009). Influence of parent concrete on the properties of recycled aggregate concrete. Construction and building materials, 23(2), 829-836.

Pierce, C. E., \& Blackwell, M. C. (2003). Potential of scrap tire rubber as lightweight aggregate in flowable fill. Science Direct, 23(3), 197-208.

Portland Cement Association (PCA). (2009).Controlled low strength material (CLSM). Retrieved

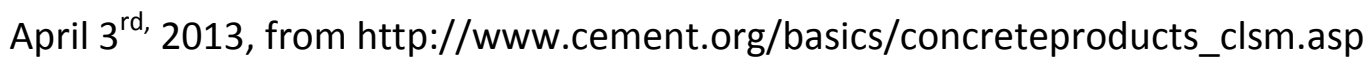

Rahal, K. (2007) Mechanical properties of concrete with recycled coarse aggregate. Building and Environment, 42(1), 407-415

Recycling Council of Ontario. (2005). Let's climb another Molehill, Natural Resource Canada. Retrieved May $10^{\text {th }}, 2013$, from: http://www.nrcan.gc.ca/sites/www.nrcan.gc.ca.minerals-metals/files/pdf/mms$\underline{\mathrm{smm} / \mathrm{busi} \text {-indu/rad-rad/pdf/f-molehill-r-eng.pdf }}$

Sahu, S., Exline, D. L., \& Nelson, M. P. (2002). Identification of Thaumasite in concrete by raman chemical imaging. Cement and Concrete Composites, 24(3), 347-350. 
Sibbick, R. G., Crammond, N. J., \& Metcalf, D. (2003). The microscopical characterization of Thaumasite. Cement \& Concrete Composites, 25(8), 831-837.

Sibbick, R. G., \& Crammon, N. J. (2001). Proceedings of the 8th Euroseminar on microscopy applied to building materials, 261-269.

Shi, C., Wang, D., \& Behnood, A. (2012). Review of Thaumasite sulphate attack on cement mortar and concrete. Journal of materials in civil engineering , 24(12), 1450-1460.

Sahu, S., Exline, D. L., \& Nelson, M. P. (2002). Identification of Thaumasite in concrete by Raman chemical imaging. Cement and Concrete Composites, 24(3), 347-350.

Sims, I., \& Huntley, A. (2004). The Thaumasite form of sulphate attack-breaking the rules. Cement and Concrete Composites, 26(7), 837-844.

Siddique, R. (2009). Utilization of waste materials and by-products in producing controlled low strength material. Resources, conservation and recycling, 54(1), 1-8.

Swapp, S. (2012). Geochemical instrumentation and analysis. Retrieved February $24^{\text {th }}, 2013$, from: http://serc.carleton.edu/research_education/geochemsheets/techniques/SEM.html

Taylor, P. C. (2007). Cement hydration: The basics. IMPC manual, 4, 69-104. Retrieved July $20^{\text {th }}$, 2013, from: http://www.cptechcenter.org/publications/imcp/tech_summaries/4a Hydration Basics.pdf

Thomas, M. D. A., Rogers, C. A., \& Bleszynski, R. F. (2003). Occurrences of Thaumasite in laboratory and field concrete. Cement and Concrete Composites, 25(8), 1045-1050. 
Tsivilis, S., Kakali, G., Skarpoulou, A., Sharp, J. H., \& Swamy, R. N. (2013). Use of mineral admixtures to prevent Thaumasite formation in limestone cement mortar. Cement and Concrete Composites, 25(8), 968-976.

Torres, S. M., Kirk, C. A., Lynsdale, C. J., Swamy, R. N., \& Sharp, J. H. (2004). ThaumasiteEttringite solid solutions in degraded mortars. Cement \& Concrete Research, 34(8), 12971305.

van Hees, R. P. J., Wijffels, T. J., \& Van der Klugt, L. J. A. R. (2003). Thaumasite swelling in historic mortars: field observations and laboratory research. Cement and Concrete Composites, 25(8), 1165-1171.

Yang, K.H.; Chung, H.S.; Ashour, A. (2008) Influence of type and replacement level of recycled aggregates on concrete properties. ACI Mater, 105(3), 289-296.

24tons Inc. (2013). Tire buffings. OTR \& commercial truck tire dust or chips. Retrieved July $19^{\text {th }}$, 2013, from: http://24tons.com/tire-buffings-otr-commercial-truck-tire-dust-or-chips/ 